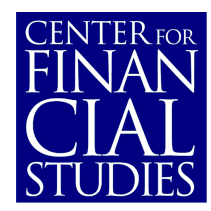

No. $2003 / 42$

The Role of Expectations in Economic Fluctuations and the Efficacy of Monetary Policy

Mordecai Kurz, Hehui Jin and Maurizio Motolese

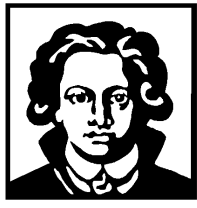

Center for Financial Studies 


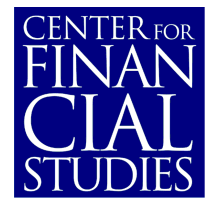

\section{Center for Financial Studies}

The Center for Financial Studies is a nonprofit research organization, supported by an association of more than 120 banks, insurance companies, industrial corporations and public institutions. Established in 1968 and closely affiliated with the University of Frankfurt, it provides a strong link between the financial community and academia.

The CFS Working Paper Series presents the result of scientific research on selected topics in the field of money, banking and finance. The authors were either participants in the Center's Research Fellow Program or members of one of the Center's Research Projects.

If you would like to know more about the Center for Financial Studies, please let us know of your interest.

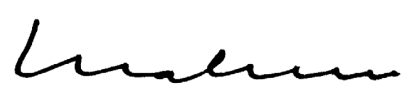

Prof. Dr. Jan Pieter Krahnen

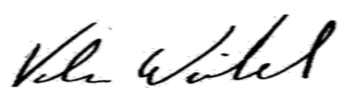

Prof. Volker Wieland, Ph.D.

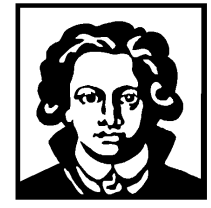




\title{
Imperfect Knowledge, Inflation Expectations, and Monetary Policy
}

\author{
Athanasios Orphanides*, John C. Williams**
}

July 2003

\begin{abstract}
:
This paper investigates the role that imperfect knowledge about the structure of the economy plays in the formation of expectations, macroeconomic dynamics, and the efficient formulation of monetary policy. Economic agents rely on an adaptive learning technology to form expectations and to update continuously their beliefs regarding the dynamic structure of the economy based on incoming data. The process of perpetual learning introduces an additional layer of dynamic interaction between monetary policy and economic outcomes. We find that policies that would be efficient under rational expectations can perform poorly when knowledge is imperfect. In particular, policies that fail to maintain tight control over inflation are prone to episodes in which the public's expectations of inflation become uncoupled from the policy objective and stagflation results, in a pattern similar to that experienced in the United States during the 1970s. Our results highlight the value of effective communication of a central bank's inflation objective and of continued vigilance against inflation in anchoring inflation expectations and fostering macroeconomic stability.
\end{abstract}

\section{JEL Classification: E52}

Keywords: Imperfect Knowledge, Inflation Expectations, Monetary Policy

Presented at the research conference "Expectations, Learning and Monetary Policy " August 2003 sponsored by the Deutsche Bundesbank, the Journal of Economic Dynamics and Control (JEDC) and the Center for Financial Studies (CFS).

*Athanasios Orphanides, Federal Reserve Board, Washington, DC, E-mail: athanasios.orphanides@frb.gov

**John C. Williams., Federal Reserve Bank of San Francisco, E-mail: john.c.Williams@sf.frb.org

All rights reserved. Short sections of text, not to exceed two paragraphs, may be quoted without explicit permission provided that full credit, including (C) notice, is given to the source. 


\section{The Role of Expectations in Economic Fluctuations and the Efficacy of Monetary Policy ${ }^{1}$ \\ by Mordecai Kurz ${ }^{2}$, Hehui Jin $^{3}$ and Maurizio Motolese ${ }^{4}$ \\ November 12, 2003}

\section{Introduction}

What explains the observed real effect of money on the economy and is money not neutral? This is perhaps the most debated question of our time. Empirical evidence has demonstrated that monetary policy, unanticipated and anticipated (e.g. Mishkin (1982)), has real effects and virtually all countries established economic stabilization as the main goal of central bank policy. However, if we seek a scientific justification for this policy, we find sharp differences in models, assumptions and methods used to arrive at this conclusion.

On one side is the standard rational expectations (in short, RE) based real business cycle theory which holds that all real fluctuations are caused by exogenous real technological shocks, money is neutral and only relative prices matter for economic allocation. Under this theory, anticipated monetary policy cannot have real effect and hence stabilizing monetary policy cannot provide any long term and consistent social benefits (e.g. see Lucas (1972), Sargent and Wallace (1978)).

An opposing view holds that money is not neutral, that economic fluctuations impose a policy tradeoff between inflation and unemployment and such a "Phillips curve" is at the foundation of economic stabilization policy. In recent years this Keynesian perspective has been developed by the Dynamic New Keynesian (in short DNK) Theory which erected the Keynesian view on three pillars: (1) the market consists of price setting monopolistically competitive firms, (2) prices are "sticky" due to restrictions on firms' ability to adjust prices (e.g. Taylor (1980) (1993) (1999), Calvo (1983), Yun

\footnotetext{
${ }^{1}$ This research was supported by a grant of the Smith Richardson Foundation to the Stanford Institute for Economic Policy Research (SIEPR). We thank Kenneth Judd for constant advice which was crucial at several points in the development of this work. We also thank Ho-Mou Wu for constructive suggestions.

${ }^{2}$ Department of Economics, Stanford University, Stanford, CA. 94305-6072.

${ }^{3}$ Department of Economics, Stanford University, Stanford, CA. 94305-6072.

${ }^{4}$ Istituto di Politica Economica, Universitá Cattolica di Milano, Via Necchi 5, 20123, Milano, Italy
} 
(1996), Goodfriend and King (1997), Bernanke, Gertler and Gilchrist (1999), Clarida, Gali, and Gertler (1999), Levin Wieland and Williams (1999), Mankiw and Reis (2002), McCallum and Nelson (1999), Rotemberg and Woodford (1999), Woodford (2001a), (2001b), (2002)), and (3) markets are complete, agents are identical and hold RE within a Rational Expectations Equilibrium (in short, REE). Most work with Calvo's (1983) idealization where at any date only a fraction of firms are "allowed" to change prices while others cannot. In such an economy output fluctuations are caused by exogenous shocks and amplified by incorrect firms' price setting. This monopolistic competitive equilibrium is not Pareto efficient. Changes in nominal rates have real effects because they impact expected future prices by firms. An exogenous shock causes some firms to change prices but others cannot adjust them and must produce output given prices set earlier, based on expectations held at that date and are thus the "wrong" prices today. Monetary policy aims to restore efficiency by countering the negative effect of price rigidity. Depending upon the model of price stickiness, this objective implies that central bank aims to set nominal rates at each date so the resulting equilibrium private sector expected inflation equals the rate anticipated by agents forced to fix prices in the previous date.

We share the DNK theory's view that monetary policy is a very useful stabilization tool. However, this paper shows an important cause for the efficacy of monetary policy is the heterogeneity of market expectations rather than price inflexibility and monopolistic competition in price setting. An argument in support of the efficacy of monetary policy would consist of three parts:

(A) In a market economy agents make socially undesirable allocation decisions resulting in excess fluctuations of inflation and real variables hence a component of business cycle fluctuations is man made, endogenously propagated by the actions of agents.

(B) Money is not neutral: changes in the nominal rate impact aggregate excess demand.

(C) Monetary policy can help stabilize the endogenous component of fluctuations.

In what economies do conclusions (A)-(C) hold? Under the standard assumptions of (i) frictionless perfect competition, (ii) flexible prices and (iii) REE allocations, conclusions (A)-(C) cannot be reached: money is neutral and monetary policy has no social function. To deduce (A)-(C), some of these assumptions must be modified. The DNK theory is based on rejecting the first two, postulating instead a monopolistic price setting and price inflexibility. We preserve the assumptions of perfect competition and price flexibility hence our model economy is entirely standard. However, we remove 
the homogeneous belief assumption and deduce our results from the assumption that agents hold heterogenous beliefs about state variables. In fact, even if a monetary policy rule is transparent and there are no differences of opinion about what the rule is, agents still make different forecasts since they make different forecasts of the state variables. Our equilibrium is a Radner Equilibrium (Radner (1972)) but we restrict beliefs by requiring them to satisfy the rationality principle of Rational Belief (in short RB or RBE for "Rational Belief Equilibrium") developed by Kurz (1994) and others in Kurz (1996), (1997). We explain later the restrictions on beliefs imposed by the RB principle. Since belief heterogeneity is the driving force of our theory, we provide a short review of the RB perspective.

\subsection{The Rational Belief Principle}

"Rational Belief" is not a theory which demonstrates rational agents should adopt any specific

belief. In fact, since the RB theory explains the observed heterogeneity of beliefs, it would be a contradiction to propose that any particular belief is the "correct" belief which rational agents must adopt. The RB theory starts by observing that the true stochastic law of motion of the economy is a non-stationary process with structural breaks and complex dynamics and the probability law of this process is not known by anyone. Agents have a long history of data generated by the process in the past which they use to compute relative frequencies of finite dimensional events and correlation among observed variables. With this knowledge they compute the empirical distribution of observed variables and use it to construct an empirical probability measure over sequences. Since all these measures are based on the law of large numbers, it is a theorem that this estimated probability model must be stationary. In the RB theory it is called the "empirical measure" or the "stationary measure."

In contrast with REE where the true law of motion is common knowledge, agents in an RBE form beliefs based only on the available data. Hence, any principle on the basis of which agents can be judged as rational must be based on the data rather than on the true but unknown law of motion. Since a "belief" is a model of the economy together with a probability measure over sequences of variables, such a model can be simulated to generate artificial data. With simulated data the agent can compute the empirical distribution of observed variables and hence the empirical probability measure the model implies. Based on these facts, the RB theory proposes a simple Principle of Rationality. It says that if the agent's model generates an empirical distribution which is not the same as the one known for the 
economy at large, then the agent's model (i.e. "belief") should be declared irrational. The converse is also required to hold: for a belief to be rational its simulated data must reproduce the known empirical distribution of the observed variables. The RB rationality principle means a belief is viewed as rational if it is a subjective model which cannot be disproved with the empirical evidence. Since diverse theories are compatible with the same evidence, this rationality principle permits diversity of beliefs among equally informed rational agents. Agents who hold rational beliefs may make "incorrect" forecasts at any date $\mathrm{t}$ but must be correct, on average. Also, date $\mathrm{t}$ forecasts may deviate from the forecast implied by the long run empirical distribution. However, since the RB rationality principle requires the long term average of an agent's forecasts to agree with the forecast based on the empirical frequencies, it follows as a theorem that agents who hold rational beliefs must have forecast functions which vary over time. The key tool we use to describe the distribution of beliefs in an economy is the "market state of belief." This is a state variable which uniquely identifies the vector of conditional probability functions held by all agents in the economy at each date $t^{5}$.

The $\mathrm{RB}$ rationality principle is compatible with several known theories. An REE is a special case of an RBE and so are the associated REE with sunspots or with bubbles. Also, several models of Bayesian Learning and Behavioral Economics are special cases of an RBE and satisfy the RB rationality principle for some parameter choices.

A short explanation of how an RBE leads to implications (A)-(C) above may be helpful. In a typical RBE endogenous variables depend upon the state of belief which exhibit fluctuations over time. Such fluctuations induce fluctuations of economic variables making them more volatile than explained by exogenous shocks. Excess volatility, called "Endogenous Uncertainty," is amplified by correlation among individual beliefs. Belief heterogeneity takes two forms: (i) diverse interpretation

5 We note examples of prior work which used the RBE perspective. Earlier papers have argued that most volatility in financial markets is caused by the beliefs of agents (e.g. Kurz (1996), (1997a), Kurz and Schneider (1996), Kurz and Beltratti (1997), Kurz and Motolese (2001) and Nielsen (1996)). These papers introduced a unified model which explains, simultaneously, a list of financial phenomena regarded as "anomalies" centered around the Equity Premium Puzzle. The model's key feature is the heterogeneity of agent's beliefs where the distribution of market beliefs (i.e. market "state of belief") fluctuates over time. Phenomena such as the Equity Premium Puzzle are then explained by the fact that pessimistic "bears" who aim to avoid capital losses drive interest rates low and the equity premium high (for a unified treatment see Kurz and Motolese (2001)). The RBE theory was used by Kurz (1997b) and Nielsen (2003) to explain the volatility of foreign exchange markets and by Wu and Guo (2003) to study speculation and trading volume in asset markets. 
of information, and (ii) diverse forecasts of future prices due to diverse individual forecasts of future state of belief of others. When states of belief are "optimistic," agents increase the level of economic activity above normal and when they are "pessimistic" they cut back on consumption, investment and production plans below normal levels. Fluctuations in market states of belief act as an externality, causing private sector plans to be excessively volatile and socially undesirable.

Implication (B) showing that money is not neutral in an RBE is not new. It has been reported in Motolese (2001), (2003) and in Kurz, Jin and Motolese (2003) who study monetary policy with the model of random growth of money. The present paper builds on Kurz, Jin and Motolese (2003) whose aim was only to demonstrate that diversity of beliefs can reproduce all the empirical regularities observed in monetary economies, under competitive conditions and with fully flexible prices. To see why money is not neutral in an RBE one can simply refer to Lucas (1972). In this seminal contribution Lucas showed the problem of money neutrality is fundamentally an expectational problem and the Quantity Theory of money is an inappropriate tool to study it. To exhibit money neutrality Lucas (1972) used an equilibrium context and showed one must assume agents hold the same beliefs, all expecting money to be neutral. If common belief in money neutrality does not hold money is not neutral. But once we deviate from REE, agents hold different beliefs about all future events including the effect of monetary shocks even if they have the same information. Money non neutrality is the natural outcome.

As for implication (C), central bank policy cannot affect fluctuations due to technology. Since money is not neutral, the excess endogenous volatility of a market economy suggests the bank can stabilize the endogenous component of fluctuations by countering the effect of private beliefs.

Rigidities and imperfections such as inflexible wages, costly input adjustments, asymmetric information or insufficient hedging opportunities certainly play some role in the efficacy of monetary policy. Such factors complement our theory. The diversity of market beliefs is a demand driven mechanism which generates economic volatility, real and financial. It provides a unifying paradigm to explain the propagation of business fluctuations, to clarify why monetary policy is effective and to justify the use of such policy as a stabilization tool. Adding any of these rigidities to our theory only strengthen our conclusions. However, we do not explore such complementarity in this paper.

In this paper we explore the way a central bank can attain stabilization by countering the effect of private expectations. We examine alternative monetary policies in order to study their 
impact on economic volatility. Numerical simulations are used to clarify the qualitative implications of our theory but we do not aim at accurate calibration. Only order of magnitude of the phenomena of interest are explored. The structure of this paper is as follows. In Sections 2-3 we develop our formal model, explain the structure of beliefs and the restrictions which the RB principle imposes on them. In Section 4 we study the volatility of the RBE with money shocks. We compare its volatility with the level of fluctuations of the traditional Real Business Cycles (RBC in short) model and with a hypothetical economy in which money grows at a constant rate. In Section 5 we introduce the monetary rules and study in detail the performance of the economy under simple Taylor (1993) type rules with and without discretion. Section 6 concludes.

\section{The Economic Environment}

The economy has four traded goods: a consumption good, one period nominal bill, labor services and fiat money. Agents trade all goods on competitive markets. There are two types of agents and a large number of identical agents within each type. Each agent is a member of one of two types of infinitely lived dynasties identified by their labor, by their utility (which is defined over consumption, labor services and real money holding) and by their beliefs. A member of a dynasty lives a fixed short life and during his life makes decisions based on his own state of belief without knowing the states of belief of his predecessors. An agent also manages a constant returns to scale firm owned by the dynasty. The firm employs the capital stock the dynasty owns and produces consumer goods while operating in competitive markets for labor services and for short term loans. Since each firm is owned by a dynasty, the intertemporal decisions of the firm are made based on the stochastic discount factors of its owner. The income of agents consists of labor income and the income from four assets owned. First, capital owned by the agent and employed by the dynasty's firm. Second are ownership share in the dynasty's firm. These ownership shares do not trade on the open market. Third is a one period, zero net supply nominal bill which pays a riskless return hence it is risky with respect to the rate of inflation. Fourth is fiat money issued by a central bank.

Under a monetary environment of random money growth each agent receives a proportional share of the money growth but the mean growth rate of money equals the mean growth rate of GNP hence the long term average rate of inflation is zero. Under a nominal interest rate policy rule a change in the money supply results from an endogenous change in the demand for money. In that 
model the target rate of inflation is set equal to $1 \%$ per quarter. We assume government balanced budget so that all changes in money supply are financed by lump sum, per capita taxes or subsidies.

At each date, firms hire labor in competitive markets, make investment decisions and select optimal rates of capacity utilization of the capital they employ. In making investments agents can produce new capital goods by using their own savings or by borrowing on the open market to finance these projects. Investments are irreversible: once produced, capital goods cannot be turned back into consumption goods but they depreciate with use. Firms' decisions maximize discounted present value of future cash flow from producing consumer goods, given the nominal interest rate, the nominal wage rate and the prices of consumer goods. Markets for consumption good, labor and short term bonds (or bills) are competitive and all prices are flexible: no prices are sticky.

Our model is then traditional. There are no informational asymmetries. The main feature of our theory is that agents hold diverse belief, not Rational Expectations. Since an agent owns his firm, we could bypass the firm problem by writing a grand household problem. This is equivalent to separating the household from the firm's problem. Such separate treatment is simple and contributes to the clarity of the exposition hence we decentralize and discuss the two problems separately.

\section{$2.1 \quad$ The Household Problem}

Our model has two infinitely lived dynasties of agents enumerated $\mathrm{j}=1,2$ but for simplicity we shall refer to each one of them as "agents $j$ " and introduce the following notation:

$\mathrm{C}_{\mathrm{t}}^{\mathrm{j}}$ - consumption of $\mathrm{j}$ at $\mathrm{t}$;

$\mathrm{P}_{\mathrm{t}}$ - price level or, the nominal price of a unit of the consumption good at $\mathrm{t}$;

$\ell_{t}^{j}-$ leisure of agent $j$ at $t$;

$\mathrm{L}_{\mathrm{t}}^{\mathrm{j}}$ - labor employed by firm $\mathrm{j}$ at $\mathrm{t}$;

$\tilde{\mathrm{W}}_{\mathrm{t}}$ - nominal wage at $\mathrm{t} t ; \mathrm{W}_{\mathrm{t}}=\frac{\tilde{\mathrm{W}}_{\mathrm{t}}}{\mathrm{P}_{\mathrm{t}}}$ - the real wage at $\mathrm{t}$;

$\xi_{\mathrm{t}}$ - the mean level of technological productivity at $\mathrm{t}$;

$\mathrm{K}_{\mathrm{t}}^{\mathrm{j}}$ - number of units of capital owned by $\mathrm{j}$ and employed by the firm owned by $\mathrm{j}$ at date $\mathrm{t}$;

$Y_{t}^{j}$ - real output by firm $j$ of consumer goods at $t$;

$P_{t} Y_{t}^{j}-\tilde{W}_{t} L_{t}^{j}$ - gross nominal capital income of firm $j$ at $t$;

$I_{t}{ }^{j}-$ new investments of $j$ at date $t$; 
$\mathrm{P}_{\mathrm{t}} \tilde{\mathrm{f}}_{\mathrm{t}}^{\mathrm{j}}=\mathrm{P}_{\mathrm{t}} \mathrm{Y}_{\mathrm{t}}^{\mathrm{j}}-\tilde{\mathrm{W}}_{\mathrm{t}} \mathrm{L}_{\mathrm{t}}^{\mathrm{j}}-\mathrm{P}_{\mathrm{t}} \mathrm{I}_{\mathrm{t}}^{\mathrm{j}}$ - total cash flow paid by the firm to $\mathrm{j}$ at $\mathrm{t}$, perhaps negative;

$\frac{\mathrm{P}_{\mathrm{t}}}{\mathrm{P}_{\mathrm{t}-1}}=\mathrm{e}^{\pi_{\mathrm{t}}}$ where $\pi_{\mathrm{t}}$ is the rate of inflation at $\mathrm{t}$;

$B_{t}^{j}$ - amount of one period nominal bill purchased by agent $j$ at $t$;

$\mathrm{q}_{\mathrm{t}}^{\mathrm{b}}$ - the price of a one period bill at $\mathrm{t}$, which is a discount price;

$\mathrm{M}_{\mathrm{t}}^{\mathrm{j}}$ - amount of money held by agent $\mathrm{j}$ at $\mathrm{t}$;

$\varphi_{t}^{j}-$ rate of capacity utilization of firm $j$;

$\mathrm{H}_{\mathrm{t}}$ - history of all observables up to $\mathrm{t}$.

Each household owns a firm with a production function which takes the form

$$
Y_{t}^{j}=e^{v_{t}}\left(\varphi_{t}^{j} K_{t}^{j}\right)^{\sigma}\left(\xi_{t} L_{t}^{j}\right)^{1-\sigma}
$$

The productivity process $\left\{\xi_{\mathrm{t}}, \mathrm{t}=1,2 \ldots\right\}$ is a deterministic trend process satisfying

$$
\frac{\xi_{\mathrm{t}+1}}{\xi_{\mathrm{t}}}=\mathrm{v}^{*}
$$

The random productivity $\left\{v_{t+1}, t=1,2, \ldots\right\}$ is specified when we study the firm's optimization. A firm carries out the household's investment. It maximizes the present value of cash flow and pays the household an amount $P_{t} \tilde{f}_{t}^{j}=P_{t} Y_{t}^{j}-\tilde{W}_{t} L_{t}^{j}-P_{t} I_{t}^{j}$, which the household considers exogenous. $P_{t} \tilde{f}_{t}^{j}$ is not "dividend" as it incorporates the household's capital account and may be negative.

With exogenous money growth $\frac{M_{t+1}}{M_{t}} \equiv v^{*} e^{\varrho_{t+1}} \cdot \varrho_{t+1}$ is a zero mean stochastic growth rate of money. Hence, in the case of exogenous money growth, the long term mean inflation rate in the model is zero. A similar condition applies to each agent. That is

$$
M_{t}^{j}=M_{t-1}^{j} v^{*} e^{Q_{t}} \text { for } j=1,2 \text {. }
$$

Under an interest rate policy money is endogenous. If $\mathrm{j}$ increases money holdings from $\mathrm{M}_{\mathrm{t}-1}^{\mathrm{j}}$ to $\mathrm{M}_{\mathrm{t}}^{\mathrm{j}}$ he pays the government $\mathrm{M}_{\mathrm{t}}^{\mathrm{j}} / \mathrm{P}_{\mathrm{t}}-\mathrm{M}_{\mathrm{t}-1}^{\mathrm{j}} / \mathrm{P}_{\mathrm{t}}$ units of consumption goods. To maintain balanced budget we introduce lump sum transfers $\mathrm{T}_{t} \xi_{t}$ in units of consumption goods and make the "Ricardian" assumption that $\mathrm{P}_{\mathrm{t}} \mathrm{T}_{\mathrm{t}} \xi_{\mathrm{t}}$ equals the value of the newly issued money. Transfers per agent are equal. 
To ensure the existence of a steady state for the economy we assume the rate of discount and degree of risk aversion are the same for all agents. If $\mathrm{Q}^{\mathrm{j}}$ is a probability belief of $\mathrm{j}$ then he solves

$$
\operatorname{Max} E_{Q^{j}}\left[\sum_{t=1}^{\infty} \beta^{t-1} \frac{1}{1-\gamma}\left(\left(C_{t}^{j}\left(\ell_{t}^{j}\right)^{\zeta}\right)^{1-\gamma}+\left(\frac{M_{t}^{j}}{P_{t}}\right)^{1-\gamma}\right) \mid H_{t}\right], \quad 0<\beta<1
$$

subject to two possible budget constraints. Under an exogenous growth of the money the budgets are

$$
P_{t} C_{t}^{j}=\left(1-\ell_{t}^{j}\right) \tilde{W}_{t}+P_{t} \tilde{f}_{t}^{j}+B_{t-1}^{j}+M_{t-1}^{j} v^{*} e^{Q_{t}}-B_{t}^{j} q_{t}^{b}-M_{t}^{j} \quad j=1,2 .
$$

Under an interest rate rule the budget constraint are

$$
P_{t} C_{t}^{j}=\left(1-\ell_{t}^{j}\right) \tilde{W}_{t}+P_{t} \tilde{f}_{t}^{j}+B_{t-1}^{j}+M_{t-1}^{j}+\frac{1}{2} P_{t}\left(T_{t} \xi_{t}\right)-B_{t}^{j} q_{t}^{b}-M_{t}^{j} \quad j=1,2 .
$$

Normalizing, define $c_{t}^{j}=\frac{C_{t}^{j}}{\xi_{t}}, b_{t}^{j}=\frac{B_{t}^{j}}{P_{t} \xi_{t}}, w_{t}=\frac{\tilde{W}_{t}}{P_{t} \xi_{t}}, i_{t}^{j}=\frac{I_{t}^{j}}{\xi_{t}}, f_{t}^{j}=\frac{\tilde{f}_{t}^{j}}{\xi_{t}}, \frac{M_{t}^{j}}{P_{t} \xi_{t}}=m_{t}^{j}, \frac{M_{t-1}^{j}}{P_{t} \xi_{t}}=\frac{m_{t-1}^{j}}{e^{\pi_{t}} v^{*}}$ hence the inflation rate $\pi_{t}$ is defined by $\frac{P_{t}}{P_{t-1}}=e^{\pi_{t}}$. Using (4a)-(4c) the maximization problem is

$$
\operatorname{Max} E_{Q^{j}} \sum_{t=1}^{\infty} \beta^{t-1} \frac{1}{1-\gamma}\left[\left(c_{t}^{j} \xi_{t}\left(l_{t}^{j}\right)^{\zeta}\right)^{1-\gamma}+\left(m_{t}^{j} \xi_{t}\right)^{1-\gamma} \mid H_{t}\right], \quad 0<\beta<1
$$

subject to two possible budget constraints. Under a money growth regime the budget constraints are

$$
c_{t}^{j}=\left(1-\ell_{t}^{j}\right) w_{t}+f_{t}^{j}+e^{\left(e_{t}-\pi_{t}\right)} m_{t-1}^{j}+\frac{b_{t-1}^{j} e^{-\pi_{t}}}{v^{*}}-b_{t}{ }^{j} q_{t}^{b}-m_{t}^{j}, \quad j=1,2
$$

and under a nominal interest rate rule regime they are

$$
c_{t}^{j}=\left(1-l_{t}^{j}\right) w_{t}+f_{t}^{j}+\frac{m_{t-1}^{j}+b_{t-1}^{j}}{v^{*} e^{\pi_{t}}}-b_{t}^{j} q_{t}^{b}-m_{t}^{j}+\frac{1}{2} T_{t}, \quad j=1,2 .
$$

The first order conditions are entirely standard. For labor supply the conditions are (for $\mathrm{j}=1,2$ )

$$
c_{t}^{j}=\frac{1}{\zeta} l_{t}^{j} w_{t} .
$$


The first order condition with respect to bond purchases $b_{t}^{j}$ is

$$
\mathrm{q}_{\mathrm{t}}^{\mathrm{b}}=\mathrm{E}_{\mathrm{Q}^{\mathrm{j}}}\left[\beta\left(v^{*-\gamma}\right)\left(\frac{\mathrm{c}_{\mathrm{t}+1}^{\mathrm{j}}}{\mathrm{c}_{\mathrm{t}}^{\mathrm{j}}}\right)^{-\gamma}\left(\frac{\mathrm{l}_{\mathrm{t}+1}^{\mathrm{j}}}{\ell_{\mathrm{t}}^{\mathrm{j}}}\right)^{\zeta(1-\gamma)} \mathrm{e}^{-\pi_{\mathrm{t}+1}}\right]
$$

The optimum with respect to money holdings under a regime of monetary growth requires

$$
1-\left(\frac{m_{t}^{j}}{c_{t}^{j}}\right)^{-\gamma} \frac{1}{\left(\ell_{t}^{j}\right)^{\zeta(1-\gamma)}}=E_{Q^{j}}\left[\beta\left(v^{*-\gamma}\right)\left(\frac{c_{t+1}^{j}}{c_{t}^{j}}\right)^{-\gamma}\left(\frac{\ell_{t+1}^{j}}{\ell_{t}^{j}}\right)^{\zeta(1-\gamma)} v^{*} e^{\left(\varrho_{t+1}-\pi_{t+1}\right)}\right]
$$

and under a regime of a monetary rule it requires

$$
1-\left(\frac{m_{t}^{j}}{c_{t}^{j}}\right)^{-\gamma} \frac{1}{\left(\ell_{t}^{j}\right)^{\zeta(1-\gamma)}}=E_{Q^{j}}\left[\beta\left(v^{*-\gamma}\right)\left(\frac{c_{t+1}^{j}}{c_{t}^{j}}\right)^{-\gamma}\left(\frac{\ell_{t+1}^{j}}{\ell_{t}^{j}}\right)^{\zeta(1-\gamma)} e^{-\pi_{t+1}}\right]
$$

Observe that firm $\mathrm{j}$ evaluates future cash flow with the stochastic discount rate of agent $\mathrm{j}$ defined by

$$
\mathrm{s}_{\mathrm{t}+\mathrm{n}, \mathrm{t}}^{\mathrm{j}}=\left[\left(\beta v^{*-\gamma}\right)^{\mathrm{n}}\left(\frac{\mathrm{c}_{\mathrm{t}+\mathrm{n}}^{\mathrm{j}}}{\mathrm{c}_{\mathrm{t}}^{\mathrm{j}}}\right)^{-\gamma}\left(\frac{\ell_{\mathrm{t}+\mathrm{n}}^{\mathrm{j}}}{\ell_{\mathrm{t}}^{\mathrm{j}}}\right)^{\zeta(1-\gamma)}\right] .
$$

In all simulations we set $\beta=0.99$ which is appropriate to a quarterly model; $\gamma=2.00$ is a realistic measure of risk aversion and $\zeta=3.00$ is the leisure elasticity. $\zeta=3.00$ ensures the fraction of time worked in steady states is around 0.225 . It implies an elasticity of labor supply (a so-called " $\lambda$ constant elasticity") of around 1.3 which is close to the empirical estimates of this elasticity.

\subsection{Technology, Production and Investments}

We first discuss key features of the production function as defined in (1). The empirically estimated distribution of the productivity $\left\{v_{t+1}, t=1,2, \ldots\right\}$ shocks is Markov of the form

$$
v_{t+1}=\lambda_{v} v_{t}+\rho_{t+1}^{v}, \quad \rho_{t}^{v} \sim N\left(0, \sigma_{v}^{2}\right) \text { i.i.d. }
$$

Productivity is the same across all firms. Most studies estimate the quarterly mean rate of technical change at $v^{*}=1.0045$ and this is the value we use. The key parameters for the traditional RBC literature are $\left(\sigma, \lambda_{v}, \sigma_{v}\right)$, set at $\sigma=0.40, \lambda_{v}=0.976, \sigma_{v}=0.0072$ for quarterly data. We agree with 
the critique (e.g. Summers (1986) and Eichenbaum (1991)) that technological shocks are only a fraction of the Solow residual. The implication is that $\sigma_{v}$ should be a fraction of 0.0072 and accordingly, we set these parameters in our model at $\sigma=0.40, \lambda_{v}=0.976$ and $\sigma_{v}=0.003$. However, for low values of $\sigma_{v}$ the RBC model cannot explain the observed data (see King and Rebelo [1999], Fig. 8, page 965), and an alternative propagation mechanism is needed. Examples of such models within the RBC tradition include Wen (1998a), (1998b) and King and Rebelo (1999).

Capacity utilization was studied by writers such as Greenwood, Hercowitz and Huffman (1988), Burnside Eichenbaum and Rebelo (1995), Burnside and Eichenbaum (1996), Basu (1996) and others. They show it is an important component of cyclical fluctuations. We agree that underemployed resources are central to economic fluctuations. Indeed, a weak component of our model (which we plan to correct in the future) is its failure to incorporate under- employed labor. In the absence of explicit labor unemployment, capacity utilization in our model should be taken as $a$ general proxy for factors which can be more intensely utilized when needed.

Capital accumulation of $\mathrm{j}$ is described by a linear transition defined by

$$
\mathrm{K}_{\mathrm{t}+1}^{\mathrm{j}}=\left(1-\Delta\left(\varphi_{\mathrm{t}}^{\mathrm{j}}\right)\right) \mathrm{K}_{\mathrm{t}}^{\mathrm{j}}+\mathrm{I}_{\mathrm{t}}^{\mathrm{j}} \quad, \quad \Delta\left(\varphi_{\mathrm{t}}\right)=\bar{\delta}+\frac{\delta_{0}}{\tau} \varphi_{\mathrm{t}}^{\tau}
$$

where $\Delta\left(\varphi_{t}\right)$ is the rate of depreciation. The empirical evidence about the elasticity $\tau$ is mixed. For example, King and Rebelo (1999) use the value $\tau=1.1$ while Burnside and Eichenbaum (1996) estimate $\tau=1.56$. We set $\tau$ a bit smaller $\tau=1.3$ to give some representation to potential underemployed labor which is missing from our model. The availability of under-employed resources which can be mobilized in response to expectations is central to our approach. The other two parameters in (8) are determined by the data. The mean rate of depreciation is 0.025 per quarter and the mean rate of capacity utilization 0.80 . Hence we have the implied parameter restriction

$$
\bar{\delta}+\frac{\delta_{0}}{\tau}(0.8)^{\tau}=0.025 .
$$

We show later that the last parameter is pinned down by our assumption that the economy has a riskless steady state. $I_{t}{ }^{j}$ in (8) is investment of $j$ measuring the number of new units of capital put into production at $\mathrm{t}+1$. We normalize $\mathrm{k}_{\mathrm{t}}^{\mathrm{j}}=\frac{\mathrm{K}_{\mathrm{t}}^{\mathrm{j}}}{\xi_{\mathrm{t}}}, \mathrm{i}_{\mathrm{t}}^{\mathrm{j}}=\frac{\mathrm{I}_{\mathrm{t}}^{\mathrm{j}}}{\xi_{\mathrm{t}}}, \mathrm{w}_{\mathrm{t}}=\frac{\tilde{\mathrm{W}}_{\mathrm{t}}}{\xi_{\mathrm{t}} \mathrm{P}_{\mathrm{t}}}, \mathrm{y}_{\mathrm{t}}^{\mathrm{j}}=\frac{\mathrm{Y}_{\mathrm{t}}^{\mathrm{j}}}{\xi_{\mathrm{t}}}$ and define 


$$
\begin{aligned}
\mathrm{y}_{\mathrm{t}}^{\mathrm{j}} & =\frac{\mathrm{Y}_{\mathrm{t}}^{\mathrm{j}}}{\xi_{\mathrm{t}}}=\mathrm{e}^{\mathrm{v}_{\mathrm{t}}} \mathrm{L}_{\mathrm{t}}^{\mathrm{j}}\left(\frac{\varphi_{\mathrm{t}}^{\mathrm{j}} \mathrm{k}_{\mathrm{t}}}{\mathrm{L}_{\mathrm{t}}^{\mathrm{j}}}\right)^{\sigma} \\
\mathrm{k}_{\mathrm{t}+1}^{\mathrm{j}} & =\frac{\left(1-\Delta\left(\varphi_{\mathrm{t}}^{\mathrm{j}}\right)\right) \mathrm{k}_{\mathrm{t}}^{\mathrm{j}}+\mathrm{i}_{\mathrm{t}}^{\mathrm{j}}}{\mathrm{v}^{*}} .
\end{aligned}
$$

The competitive firms carry out production and investment decisions using the stochastic discount rate $s_{t+n, t}^{j}$ in (7). Gross real capital income of firm $j$ is $Y_{t}^{j}-W_{t} L_{t}^{j}$. It incurs real investment cost of $\mathrm{I}_{\mathrm{t}}^{\mathrm{j}}$ hence at some dates the net cash flow may be negative. It maximizes

$$
\operatorname{Max}_{\left(L_{t+n}^{j}, I_{t+n}^{j}, \varphi_{t+n}^{j}\right)} E_{Q_{t}^{j}}\left(\sum_{n=0}^{\infty} s_{t+n, t}^{j}\left(Y_{t+n}^{j}-W_{t+n} L_{t+n}^{j}-I_{t+n}^{j}\right) \mid H_{t}\right)
$$

subject to (8), (9a)-(9b). Changes to capacity utilization entail reorganization including engineering design, plans for second shifts, etc. Evidence shows such decisions are carried with delay. We model the planning period for capacity utilization changes to be three months. We thus assume decisions on capacity utilization at date $t+1$ are made at date $t$ : a firm must commit to a utilization rate one period ahead. Such changes correspond to the process of investments where a firm commit at date $t$ to an investment plan which results in capital employed at date $t+1$. Hence, a commitment to capital and a commitment to a utilization rate are actually made together as they are naturally joint decisions.

To state the first order conditions define first the normalized marginal productivity of factors

$$
y_{L_{t}^{j}}=e^{v_{t}}(1-\sigma)\left(\frac{\varphi_{t}^{j} k_{t}^{j}}{L_{t}^{j}}\right)^{\sigma} \quad y_{k_{t}^{j}}=e^{v_{t}} \sigma\left(\frac{\varphi_{t}^{j} k_{t}^{j}}{L_{t}^{j}}\right)^{\sigma-1} \varphi_{t}^{j} .
$$

Then the three Euler equations are as follows:

$$
\begin{aligned}
& 0=y_{L_{t}^{j}}-w_{t} \\
& 1=E_{Q_{t}^{j}}\left(s_{t+1, t}^{j}\left(1+y_{k_{t+1}^{j}}-\Delta\left(\varphi_{t+1}^{j}\right)\right)\right. \\
& 0=E_{Q_{t}^{j}}\left(s_{t+1, t}^{j}\left(y_{k_{t+1}^{j}}-\delta_{0}\left[\varphi_{t+1}^{j}\right]^{\tau}\right)\right) .
\end{aligned}
$$

(10c) determines capacity utilization but at steady state we require $\left(\varphi^{\mathrm{j}}\right)=0.80$ hence (10c) imposes the final steady state condition $\beta\left(v^{*}\right)^{-\gamma} \sigma\left(\frac{0.80 \mathrm{k}^{\mathrm{j}}}{\mathrm{L}^{\mathrm{j}}}\right)^{\sigma-1}=\delta_{0}[0.80]^{\tau-1}$ on the parameters $\left(\bar{\delta}, \delta_{0}, \tau\right)$. 


\subsection{Monetary Policy and Money Neutrality}

In the analysis of monetary policy we examine two family of models. We first explore the simple exogenous and stochastic monetary growth described by the familiar process

$$
\begin{aligned}
& M_{t}=M_{t-1} v^{*} e^{\varrho_{t}} \\
& \varrho_{t+1}=\lambda_{\varrho} \varrho_{t}+\rho_{t+1}^{\varrho} .
\end{aligned}
$$

Since $m_{t}=M_{t} /\left(\xi_{t} P_{t}\right)$, we have $m_{t}=m_{t-1} e^{\left(\mathfrak{Q}_{t}-\pi_{t}\right)}$. The model of money injection is a bit unrealistic as it hard to see a central bank distributing money to cash holders when $\varrho_{t}>0$ and extracting it when $\varrho_{\mathrm{t}}<0$. Also, since there is no one "money" it is not clear which of the near moneys a bank should control. In spite of these drawbacks the monetary shocks model is a useful idealization. It provides a reference point to measure the efficacy of monetary policy in economies with a monetary rule.

We next study economies with nominal interest rate rule. A central bank sets $q_{t}^{b}=\frac{1}{1+r_{t}}$, the price of the nominal bill, where $r_{t}$ is the nominal rate. The inflation rate target is assumed $1 \%$ per quarter. In the simulations we consider the performance of a Taylor (1993) type policy rules with and without discretion and inertia which we present and discuss in Section 5. The balanced budget condition under the proposed policy rule requires the lump-sum tax or subsidy rates to satisfy

$$
\mathrm{m}_{\mathrm{t}}-\frac{\mathrm{m}_{\mathrm{t}-1}}{\mathrm{e}^{\pi_{\mathrm{t}}} v^{*}}=\mathrm{T}_{\mathrm{t}}
$$

\section{A Comment On Money Neutrality.}

In a model with monetary shocks the date $t+1$ shock is not known at $t$. However, once a shock is realized, agents observe it and equilibrium prices adjust to it. This means that although unanticipated monetary shocks are included in the model, under REE unanticipated shocks have no real effect. The reason is that under REE agents know the true distribution of the shocks and expect money to be neutral: the price level fully adjusts and agents correctly expect prices to adjust. Hence, our model is strongly biased in favor of money neutrality. However, this mechanism does not work in an RBE where agents expect money shocks to have real effect but disagree about the magnitude of these real effects. An important channel for money non neutrality in the RBE is the belief of an agent that these shocks will affect the belief of other agents about the future course of the economy.

To conclude this discussion we observe that even if we wanted to introduce real effect of unanticipated shock under REE, we would need to introduce some friction or delay in the response of 
prices to realized and observed shocks. We do not address this issue here. We study economies in which monetary policy is conducted with a nominal interest rate rule and in such economies the mechanism described above is not relevant. In fact, in an economy with a monetary rule the money neutrality phenomenon is actually one of a dichotomy between the real and monetary parts of the economy. For monetary policy to have a real effect this dichotomy must be broken.

\subsection{Market Clearing Conditions}

The market clearing conditions are then

(14d) for the money shock model

$$
b_{t}^{1}+b_{t}^{2}=0 \quad \text { for all } t
$$$$
\left(1-l_{t}^{1}\right)+\left(1-l_{t}^{2}\right)=L_{t}^{1}+L_{t}^{2} \text { for all } t \text {; }
$$

(14e) for the interest rule model

$$
\begin{array}{ll}
\mathrm{m}_{\mathrm{t}}^{1}+\mathrm{m}_{\mathrm{t}}^{2}=\mathrm{m}_{\mathrm{t}} & \text { for all } \mathrm{t} . \\
\mathrm{m}_{\mathrm{t}}-\frac{\mathrm{m}_{\mathrm{t}-1}}{\mathrm{e}^{\pi_{\mathrm{t}}} \mathrm{v}^{*}}=\tau \mathrm{f}_{\mathrm{t}} & \text { for all } \mathrm{t} .
\end{array}
$$

We turn now to the central question of the beliefs of the agents.

\section{Constructing a Rational Belief Equilibrium (RBE)}

\subsection{The State of Belief and the Equilibrium Map}

The environment of a typical RBE is non-stationary and agents believe the economic structure vary over time hence a general treatment of such economies is complex. To simplify we study monetary policy by constructing a broad family of equilibria and examine the impact of alternative policies on their volatility. The family is defined by an autoregressive stochastic law of motion of the state variables and by the structure of agents' beliefs. Since this is a theoretical paper, one needs to consider these specifications mainly as vehicles to develop the central ideas.

To define an RBE consider the economy as a data generating mechanism so that from past data agents know the empirical distribution of observables. A Rational Belief is a probability measure on sequences of future states together with a model of the economy. It has the property that if simulated, it generates the same empirical distribution of observables as the known distribution for the economy. Conditional forecasts may be wrong at any date but their time average is correct. The 
probability on sequences implied by the empirical distribution is called The Stationary Measure ${ }^{6}$. To use these concepts we need a tractable way to describe beliefs and this is our main task now.

The tool we use to describe the distribution of beliefs at $t$ is the "market state of belief." In a two agent economy it is a vector $z_{t}=\left(z_{t}^{1}, z_{t}^{2}\right) \in \mathbb{R}^{2}$ which uniquely defines date $t$ conditional probability functions of the agents. In any equilibrium endogenous variables are functions of state variables, lagged endogenous variables. In our case we add $\left(\mathrm{z}_{\mathrm{t}}{ }^{1}, \mathrm{z}_{\mathrm{t}}^{2}\right)$. If we denote exogenous shocks and lagged endogenous variables by $\varpi_{t}$, the process $\left\{\left(q_{t}{ }^{b}, \pi_{t}, T_{t}\right), t=1,2, \ldots\right\}$ of equilibrium prices and tax transfers is defined by a map like

$$
\left[\begin{array}{c}
\mathrm{q}^{\mathrm{b}} \\
\pi_{\mathrm{t}} \\
\mathrm{T}_{\mathrm{t}}
\end{array}\right]=\Xi\left(\varpi_{\mathrm{t}}, \mathrm{z}_{\mathrm{t}}^{1}, \mathrm{z}_{\mathrm{t}}^{2}\right) .
$$

Our equilibrium is a Radner (1972) equilibrium with an expanded state space that includes the state of belief $\left(z_{t}{ }^{1}, z_{t}^{2}\right)$. The map (15) reflects this fact. Since agents use a price map to forecast future prices, they forecast future market state of beliefs, which are the future beliefs of "other" agents. Although both agents use the map $\Xi$ in (15) to forecast $t+1$ prices, their price forecasts are different since each agent forecasts future state variables and future market beliefs given his own private state of belief. We explore this issue in detail later when we discuss the subjective models of the agents.

Our procedure is to construct an RBE, use perturbation methods to compute it and study its volatility via simulations. Since we wish to demonstrate our economy exhibits fluctuations which are qualitatively similar to those observed in the market, our construction proceeds in three steps ${ }^{7}$. (i) Specify a family of empirical distributions of state variables which is then assumed known to agents who learn it from the data. Most parameter selections are based on their estimated values, known from other studies. Some values are based on our best judgement.

\footnotetext{
${ }^{6}$ The empirical distribution of observable variables or their moments induce a probability measure over infinite sequences of observables. A general definition and construction of this probability measure is explained in Kurz (1997a) or Kurz-Motolese (2001) where it is shown that this probability must be stationary. Any statement in the text about "the stationary measure" or "the empirical distribution" is always a reference to this probability measures. Its centrality to the theory arises from the fact that it is derived from public information and hence this probability is known to all agents.

${ }^{7}$ For a detailed account of the theory of Rational Beliefs see Kurz (1997a) and for additional details regarding the constructive approach to RBE, see Kurz and Motolese (2001), Section 2.4.
} 
(ii) Specify the beliefs of agents and formulate conditions which rationalize them relative to the empirical distribution specified in (i). These are the rationality conditions of the RBE.

(iii) Use the equilibrium conditions developed earlier to define prices and endogenous variables.

\subsection{The Empirical Distribution of the State}

In a Markov economy a probability is represented by transition functions. In our constructed RBE the state variables are $\left(v_{t}, \varrho_{t}, z_{t}{ }^{1}, z_{t}^{2}\right)$, hence to define an empirical distribution we specify stationary transition functions for these variables. The true process of the shocks $\left\{\left(v_{t}, \varrho_{t}\right), t=1\right.$, $2, \ldots\}$ is an unspecified, stable ${ }^{8}$ and non-stationary process, incorporating structural changes with a probability law which is not known. Indeed, for equilibrium analysis the true process does not matter: what matters is the empirical distribution of the process and what agents believe about the true process. We assume the joint empirical distribution of the exogenous shocks and the states of belief is an AR process of the form

$$
\begin{aligned}
& v_{t+1}=\lambda_{v} v_{t}+\rho_{t+1}^{v} \\
& \varrho_{\mathrm{t}+1}=\lambda_{\mathrm{Q}} \varrho_{\mathrm{t}}+\rho_{\mathrm{t}+1}^{\varrho}
\end{aligned}
$$

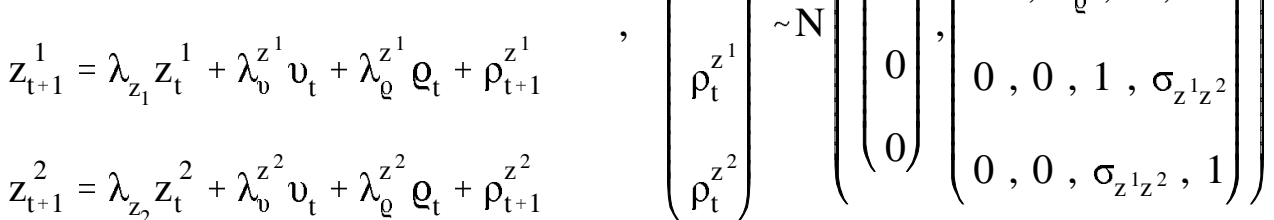

In (16) states of belief may depend upon exogenous shocks. As noted, $\lambda_{v}=0.976, \sigma_{v}=0.003$. Money shock parameters are from Mankiw and Reis's [2002] who estimate $\lambda_{\varrho}=0.5, \sigma_{\varrho}=0.007$. To specify parameters of the $z^{j}$ equations we used forecasts of the Survey of Professional Forecasters and Blue Chip Indicators and"purged” them of observables. By estimating principal components we handle multiple variables forecasted (for details, see Fan (2003)). The extracted belief indexes exhibit autocovariances of $0.5-0.8$. We set $\lambda_{\mathrm{z}}=0.65$ where $\lambda_{\mathrm{z}}=\lambda_{\mathrm{z}^{1}}=\lambda_{\mathrm{z}^{2}}$. The data exhibit high correlations across agents and 0.9 is a reasonable estimate of $\sigma_{\mathrm{z}^{1} \mathrm{z}^{2}}$.

We consider here only the symmetric case $\lambda_{v}^{z^{1}}=\lambda_{v}^{z^{2}}=\lambda_{v}^{z}$ and $\lambda_{\varrho}^{z^{1}}=\lambda_{\varrho}^{z^{2}}=\lambda_{\varrho}^{z}$. Evidence reveals that above normal productivity shocks lead to upward revisions of the mean growth of the economy,

${ }^{8}$ A Stable Process is defined in Kurz (1994). It is a stochastic process which has an empirical distribution defined by the limits of relative frequencies of finite dimensional events. These limits are used to define the empirical distribution and to construct the associated stationary measure on infinite sequences. 
implying $\lambda_{v}^{z}>0$. In the simulations we set $\lambda_{v}^{z}=8$. We have little evidence on the value of $\lambda_{\varrho}^{z}$ which has an important money non-neutrality impact. We set $\lambda_{\varrho}^{\mathrm{z}}=8$ and the empirical reasoning which leads to assuming $\lambda_{\varrho}^{\mathrm{z}}>0$ is simple: for positive money shocks to induce positive response of output and consumption we must have $\lambda_{\varrho}^{z}>0$. This means that positive monetary shocks at $\mathrm{t}$ lead agents to expect above normal $z_{t+1}^{j}$ hence above normal future output. Finally, we denote by $m$ the probability measure on infinite sequences implied by (16) together with the invariant distribution as an initial distribution.

To write (16) in a compact notation let $x_{t}=\left(v_{t}, \varrho_{t}, z_{t}^{1}, z_{t}^{2}\right), \rho_{t}=\left(\rho_{t}^{v}, \rho_{t}^{\varrho}, \rho_{t}^{z^{1}}, \rho_{t}^{z^{2}}\right)$ and denote by A the $4 \times 4$ matrix of parameters in (16). We then write

$$
\mathrm{x}_{\mathrm{t}+1}=\mathrm{Ax}_{\mathrm{t}}+\rho_{\mathrm{t}+1} \quad, \quad \rho_{\mathrm{t}+1} \sim \mathrm{N}(0, \Sigma)
$$

where $\Sigma$ is the covariance matrix in (16). Denote by V the $4 \times 4$ unconditional covariance of $\mathrm{x}$ defined by $\mathrm{V}=\mathrm{E}_{\mathrm{m}}\left(\mathrm{xx}^{\prime}\right)$. We later need the value of $\mathrm{V}$ and compute it as solution of the equation

$$
\mathrm{V}=\mathrm{AVA}^{\prime}+\Sigma
$$

\subsection{Personal States of Belief and the Anonymity Principle}

In a non-stationary environment an agent's conditional probability belief is time dependent, deviating from the stationary forecasts of the empirical probability. His belief may be above the empirical probability (he is "optimistic") or below it (he is "pessimistic"). Since the rationality principle requires the time average of the agent's belief to equal the empirical probability, his periodic probability beliefs fluctuate around the empirical probability. We need a tractable mathematical description of such nonstationary dynamics while not providing reasons why an agent selects any particular belief. We only seek a way to describe market diversity.

Our main tool is the individual state of belief $\mathrm{g}_{\mathrm{t}}^{\mathrm{j}} \in \mathrm{G}^{\mathrm{j}}$ of $\mathrm{j}$. It is an index which fully specifies his conditional probability function at each date. The advantage of this sequence is statistical since the stochastic structure specifies the empirical regularity of $\mathrm{g}_{\mathrm{t}}^{\mathrm{j}}$ in relation to observables. Since rational agents do not deviate systematically from the empirical forecasts, to establish rationality of belief we need a statistical measure of deviations from these forecasts. $\mathrm{g}_{\mathrm{t}}{ }^{\mathrm{j}} \in \mathrm{G}^{\mathrm{j}}$ are the mathematical devices used to 
measure such regularity. Before proceeding we offer an economic interpretation of this key tool.

\section{3a Interpreting the State of Belief: Some Examples}

The RB principle applies to a wide range of models agents employ to form belief. To explain what states of belief $\mathrm{g}_{\mathrm{t}}^{\mathrm{j}}$ or $\mathrm{z}_{\mathrm{t}}^{\mathrm{j}}$ are, we consider three examples which illustrate how to think about them. (i) Measure of Animal Spirit. The idea of "Animal Spirit" captures the intensity at which agents carry out investments. However, investments decisions are deduced from beliefs about rewards. $\mathrm{g}_{\mathrm{t}}^{\mathrm{j}}$ identifies the probability an agent assigns to abnormally high or abnormally low values of rewards to investments. Since rewards motivate "animal spirit," the parameter $\mathrm{g}_{\mathrm{t}}^{\mathrm{j}}$ is interpreted as a measure of "animal spirit." (ii) Posterior parameter value defining regime variables. In a learning context each member of a dynasty starts with a prior on a joint space of observables and unknown parameters defining structural changes. One can then identify $g_{t}{ }^{j}$ with the posterior parameter deduced from the observations made by a dynasty member. When a new member of the dynasty arrives, he starts with the same prior but assumes a change of regime hence past data does not apply to parameters he tries to learn. Persistence of $\mathrm{g}_{\mathrm{t}}{ }^{\mathrm{j}}$ results from the accumulated learning during the life span of a member. No convergence occurs since the life span of each regime is short.

(iii) Subjective and privately generated sunspot which depend upon real economic variables. $\mathrm{g}_{\mathrm{t}}{ }^{\mathrm{j}}$ may play the role of a privately generated sunspot with three properties (a) each agent generates it under a true marginal distribution known only to him, (b) it is not observed by the other agents in the market, and (c) the distribution of this variable may depend upon real economic variables. It is clear these conditions do not satisfy the traditional definition of "sunspot" variables. Moreover, the structure of correlation in the market is an externality, not known to agents. That is, an agent does not know the true correlation between his own $\mathrm{g}_{\mathrm{t}}^{\mathrm{j}}$ and real variables or with subjective sunspots of other agents. Under this interpretation $g_{t}{ }^{j}$ is a substantial extension of the notion of a "sunspot" variable.

We stress that $\mathrm{g}_{\mathrm{t}}^{\mathrm{j}}$ are privately perceived by agent $\mathrm{j}$ only. Since a dynasty consists of a sequence of decision makers, $\mathrm{a}_{\mathrm{t}}{ }_{\mathrm{j}}^{\mathrm{j}}$ used by $\mathrm{j}$ has nothing to do with the beliefs of other dynasty members. $G^{j}$ and $G^{k}$ for $j \neq k$ do not need to be the same spaces: an agent's theory about investing in technology of one era (when $\mathrm{j}$ lives) has little to do with investments in a different era (when $\mathrm{k}$ lives). Unfortunately, diversity of $\mathrm{G}^{\mathrm{j}} \neq \mathrm{G}^{\mathrm{k}}$ for $\mathrm{j} \neq \mathrm{k}$ is not tractable. For tractability we make two 
assumptions. First, we use the same space $G^{j}=\mathbb{R}$ for all $\mathrm{j}$ and assume an agent knows only the short history of his own states $g_{t}{ }^{j}$ but does not know the $g_{\tau}{ }^{j}$ of his predecessors $\tau<t$. Second, we assume individual states are made public and their distribution $\left(z_{t}^{1}, z_{t}^{2}\right)$ is recorded as a "market state of beliefs" subject to anonymity of the individuals behind the data. To maintain competitive markets each agent is assumed to disassociate his own belief from the market state. Due to the finite number of agents in the model (two in our case) this anonymity assumption needs some clarification.

\section{3b Anonymity}

Although the market state of beliefs at $t$ is nothing but a distribution of the $g_{t}{ }_{t}$, anonymity requires that agents do not make any connection between their own $g_{t}{ }^{j}$ and the distribution of beliefs in the market ${ }^{9}$. Anonymity is so central that we use three notational devices to highlight it.

(i) $\mathrm{g}_{\mathrm{t}} \mathrm{j}$ denotes the state of belief of $\mathrm{j}$ as known by the agent only.

(ii) $\left(\mathrm{z}_{\mathrm{t}}^{1}, \mathrm{z}_{\mathrm{t}}^{2}\right)$ denotes the market state of belief, observed by all agents. Being competitive, they do not associate $\mathrm{y}_{\mathrm{t}}^{\mathrm{j}}$ with $\left(\mathrm{z}_{\mathrm{t}}^{1}, \mathrm{z}_{\mathrm{t}}^{2}\right)$ although $\mathrm{g}_{\mathrm{t}}^{\mathrm{j}}=\mathrm{z}_{\mathrm{t}}^{\mathrm{j}}$ is a basic consistency condition.

(iii) $\left(\mathrm{z}_{\mathrm{t}+1}^{\mathrm{j} 1}, \mathrm{z}_{\mathrm{t}+1}^{\mathrm{j} 2}\right)$ describes agent $\mathrm{j}$ 's forecast of the market state of belief at future date $\mathrm{t}+1$. To formulate the rationality of belief conditions we specify a sequence of individual states $\left\{\mathrm{g}_{\mathrm{t}}^{\mathrm{j}}, \mathrm{t}=1,2\right.$, ... f for $\mathrm{j}=1,2$. The consistency condition $\mathrm{g}_{\mathrm{t}}{ }^{\mathrm{j}}=\mathrm{z}_{\mathrm{t}}^{\mathrm{j}}$ (not known by agents) requires the empirical distribution of $g_{t}{ }^{j}$ to be the same as the distribution of $z_{t}^{j}$. Thus, the agent's belief is characterized by a sequence of random variables $\tilde{\rho}_{t}^{\mathrm{g}^{\mathrm{j}}}, \mathrm{t}=1,2, \ldots$ such that $\left\{\mathrm{g}_{\mathrm{t}}^{\mathrm{j}}, \mathrm{t}=1,2, \ldots\right\}$ are the realizations of

$$
\mathrm{g}_{\mathrm{t}+1}^{\mathrm{j}}=\lambda_{\mathrm{z}} \mathrm{g}_{\mathrm{t}}^{\mathrm{j}}+\lambda_{\mathrm{v}}^{\mathrm{z}} v_{\mathrm{t}}+\lambda_{\varrho}^{\mathrm{z}} \varrho_{\mathrm{t}}+\tilde{\rho}_{\mathrm{t}+1}^{\mathrm{g}^{\mathrm{j}}} \quad, \quad \tilde{\rho}_{\mathrm{t}+1}^{\mathrm{g} j} \sim \mathrm{N}\left(0, \tilde{\sigma}_{\mathrm{g}}^{\mathrm{j}}\right) \quad, \quad \mathrm{j}=1,2 .
$$

(19) is compatible with the $z_{t}^{j}$ equation in (16) but by anonymity $\operatorname{Cov}\left(\tilde{\rho}_{t+1}^{g^{j}}, \rho_{t+1}^{z^{1}}\right)=\operatorname{Cov}\left(\tilde{\rho}_{t+1}^{g^{j}}, \rho_{t+1}^{z^{2}}\right)=0$. Since $\left\{g_{t}{ }^{j}, t=1,2, \ldots\right\}$ exhibit serial correlation, the rationality of belief require that we exclude from $g_{t}{ }_{t}$ public information in the market at $t$. To that end we introduce a variable $u_{t}{ }^{j}\left(g_{t}{ }^{j}\right)$, defined as follows. Denote by $r_{j}=\operatorname{Cov}\left(x, g^{j}\right)$ the covariance vector in the agent's model and using (18) define $u_{t}{ }_{t}^{j}\left(g_{t}^{j}\right)$ by

\footnotetext{
${ }^{9}$ This requirement on the agent is analogous to the behavior of producers in a competitive market with a finite number of firms who are required to disregard their impact on prices. By looking at past data a competitive firm in a market with a finite number of firms can demonstrate that it had an effect on prices in violation of this assumption. This type of empirical "test" is what is assumed away here to ensure competitive behavior of agents.
} 


$$
u_{t}^{j}\left(g_{t}^{j}\right)=g_{t}^{j}-r_{j}^{\prime} V^{-1} x_{t}
$$

By construction, the pure belief index $u_{t}{ }^{j}\left(g_{t}^{j}\right)$ is uncorrelated with date $t$ information. In Appendix B we demonstrate that it is also serially uncorrelated. We stress: $u_{t}^{j}\left(g_{t}^{j}\right)$ acquires meaning only after we specify what $j$ does in state $g_{t}^{j}$. The formal structure to do that are the perception models of the agents.

\subsection{Perception Models and the Rationality of Belief Conditions}

\section{4a General Formulation}

A perception model is a set of transition functions of the state variables, reflecting the agent's belief about date $t+1$ transition probability. We first explain the general form of a perception model, using (17), providing details later. Let $\mathrm{x}_{\mathrm{t}+1}^{\mathrm{j}}$ be a vector of stochastic state variables at date $\mathrm{t}+1$ as perceived by agent $j$ and let $\Psi_{\mathrm{t}+1}\left(\mathrm{u}_{\mathrm{t}}^{\mathrm{j}}\right)$ be a 4 dimensional vector of date $\mathrm{t}+1$ random variables conditional upon parameter $u_{t}^{j}$. A perception model has the general form

$$
\mathrm{x}_{\mathrm{t}+1}^{\mathrm{j}}=\mathrm{Ax}_{\mathrm{t}}+\Psi_{\mathrm{t}+1}\left(\mathrm{u}_{\mathrm{t}}^{\mathrm{j}}\right) \text { together with }
$$

Since $E_{m}\left(x_{t+1} \mid H_{t}\right)=A x_{t}$, we write (21a) in the simpler form

$$
\mathrm{x}_{\mathrm{t}+1}^{\mathrm{j}}-\mathrm{E}_{\mathrm{m}}\left(\mathrm{x}_{\mathrm{t}+1} \mid \mathrm{H}_{\mathrm{t}}\right)=\Psi_{\mathrm{t}+1}\left(\mathrm{u}_{\mathrm{t}}^{\mathrm{j}}\right) \text {. }
$$

In general $E\left[\Psi_{t+1} \mid u_{t}^{j}\right] \neq 0$ hence j's forecast function changes with $u_{t}^{j}$. (21b) shows how agent $j$ 's forecasts deviate from $E_{m}\left(x_{t+1} \mid H_{t}\right)$ and how the deviations depends upon $u_{t}{ }^{j}$. If $\Psi_{t+1}\left(u_{t}{ }^{j}\right)=\rho_{t+1}$ as in (17), $\mathrm{j}$ uses the empirical probability $\mathrm{m}$ as his belief. We can now explain the rationality of belief conditions requiring the empirical distributions of (17) and (21a) to be the same. For $\left[\mathrm{x}_{\mathrm{t}+1}-\mathrm{E}_{\mathrm{m}}\left(\mathrm{x}_{\mathrm{t}+1} \mid \mathrm{H}_{\mathrm{t}}\right)\right]$ to have the same empirical distribution as $\left[\mathrm{x}_{\mathrm{t}+1}^{\mathrm{j}}-\mathrm{E}_{\mathrm{m}}\left(\mathrm{x}_{\mathrm{t}+1} \mid \mathrm{H}_{\mathrm{t}}\right)\right]$ means the empirical distribution of $\left.\left\{\Psi_{\mathrm{t}+1}\left(\mathrm{u}_{\mathrm{t}}^{\mathrm{j}}\right), \mathrm{t}=1,2, \ldots\right)\right\}$ in (21a) is the same as the distribution of $\rho_{\mathrm{t}+1}$ in (17), which is $\mathrm{N}(0, \Sigma)$. This implies that the empirical distribution of $\left.\left\{\Psi_{\mathrm{t}+1}\left(\mathrm{u}_{\mathrm{t}}^{\mathrm{j}}\right), \mathrm{t}=1,2, \ldots\right)\right\}$ is $\mathrm{N}(0, \Sigma)^{10}$ and that $\Psi_{\mathrm{t}+1}\left(\mathrm{u}_{\mathrm{t}}^{\mathrm{j}}\right)$ does not

${ }^{10}$ From the perspective of the agent $\mathrm{a} \mathrm{g}_{\mathrm{t}}^{\mathrm{j}}$ sequence is just a sequence of parameters. However, for these rationality conditions we need to study the empirical distribution of sequences $\left.\left\{\Psi_{t+1}\left(u_{t}{ }^{j}\right), t=1,2, \ldots\right)\right\}$ which depend upon the $u_{t}{ }_{t}$. In order to do that we need to know the empirical regularity of the $g_{t}{ }^{j}$ and this is where the specification (19), about the statistical regularity of these assessment variables, come into play. 
exhibit serial correlation. We now explain the details of these requirements.

\section{4b The Perception Models}

In modeling $\Psi_{\mathrm{t}+1}\left(\mathrm{u}_{\mathrm{t}}{ }^{\mathrm{j}}\right)$ we consider several factors. In an RBE agents may be over-confident by being optimistic or pessimistic relative to the empirical forecasts. Evidence from the psychological literature (e.g. Svenson (1981), Camerer and Lovallo (1999) and references there) shows agents exhibit such behavior. Since in an RBE agents do not know true probabilities, such behavior is not " irrational" if it respects the rationality principle. Also, rationality requires $\Psi_{t+1}\left(\mathrm{u}_{\mathrm{t}}{ }^{\mathrm{j}}\right)$ to be serially uncorrelated.

To address these issues we specify the random sequence $\Psi_{t+1}\left(u_{t}{ }^{j}\right)$ to take the simple form

$$
\Psi_{t+1}\left(u_{t}^{j}\right)=\left(\begin{array}{l}
\lambda_{g}^{v} \rho_{t+1}^{j}\left(u_{t}^{j}\right)+\tilde{\rho}_{t+1}^{v^{j}} \\
\lambda_{g y}^{e} \rho_{t+1}^{j}\left(u_{t}^{j}\right)+\tilde{\rho}_{t+1}^{e^{j}} \\
\lambda_{g}^{z} \rho_{t+1}^{j}\left(u_{t}^{j}\right)+\tilde{\rho}_{t+1}^{z^{j 1}} \\
\lambda_{g}^{z} \rho_{t+1}^{j}\left(u_{t}^{j}\right)+\tilde{\rho}_{t+1}^{z^{j 2}}
\end{array}\right)
$$

where $\tilde{\rho}_{(t+1)}^{j}=\left(\tilde{\rho}_{t+1}^{v^{j}}, \tilde{\rho}_{t+1}^{\mathrm{e}^{\mathrm{j}}}, \tilde{\rho}_{t+1}^{z^{j 1}}, \tilde{\rho}_{t+1}^{z^{j 2}}\right)$ are i.i.d. zero mean, normal variables with covariance matrix $\Omega_{\rho \rho}$ to be pinned down by the rationality conditions. $\Omega_{\rho \rho}$ has dimension $4 \times 4$, as does $\Sigma$ in (17). However, a perception model incorporates $\mathrm{y}_{\mathrm{t}}^{\mathrm{j}}$ as a fifth dimension with a covariance matrix denoted by $\Omega$, reflecting the vector $r_{j}^{i}=\operatorname{Cov}\left(x^{i}, g^{j}\right)$ for $i=1,2,3,4$. The parameters $\lambda_{g}=\left(\lambda_{g}^{v}, \lambda_{g}^{\varrho}, \lambda_{g}^{z}\right)$ are the main object of our study and their effect on volatility is examined later. Since we study only the symmetric case, the state of belief is the only difference between agents. We next construct the random variables $\rho_{t+1}^{j}\left(u_{t}^{j}\right)$. The Random Variables $\Psi_{t+1}^{j}$ : Intensity of Fat Tails in the Agent's Beliefs

The variables $\rho_{t+1}^{j}\left(u_{t}^{j}\right)$ are the tools which enable agents to exhibit subjective beliefs with "fat" tails, reflecting over-confidence. We define $\rho_{t+1}^{j}\left(u_{t}{ }^{j}\right)$ by specifying its density, conditional on $u_{t}{ }^{j}$ :

$$
P\left(\rho_{t+1}^{j} \mid u^{j}\right)=\left\{\begin{array}{cl}
\varphi_{1}\left(u^{j}\right) \Phi\left(\rho_{t+1}^{j}\right) & \text { if } \rho_{t+1}^{j} \geq 0 \\
\varphi_{2}(u) \Phi\left(\rho_{t+1}^{j}\right) & \text { if } \rho_{t+1}^{j}<0
\end{array} \quad \text { where } \quad \Phi(s)=\frac{1}{\sqrt{2 \pi}} e^{-\frac{s^{2}}{2}} .\right.
$$

$\rho_{t+1}^{j}$ and $\tilde{\rho}_{t+1}^{g^{j}}$ (in (19)) are independent and we use a logistic approximation to define

$$
\psi\left(\mathrm{u}^{\mathrm{j}}\right)=\frac{1}{1+\mathrm{e}^{\mathrm{bu} \mathrm{j}^{\mathrm{j}}\left(\mathrm{g}^{\mathrm{j}}\right)}} \quad, \quad \mathrm{b}<0, \quad \mathrm{~B}=\mathrm{E}\left[\psi\left(\mathrm{u}^{\mathrm{j}}\right)\right], \quad \varphi_{1}(\mathrm{u})=\frac{\psi(\mathrm{u})}{\mathrm{B}} \quad, \quad \varphi_{2}(\mathrm{u})=2-\varphi_{1}(\mathrm{u}) .
$$


(24) ensures that (23) is a probability density. Technical details are developed in Appendix A but we note here that this construction depends upon one parameter $b$.

Although a key question, we defer the explanation of what $u_{t}{ }^{j}>0$ means. (23)-(24) is a formal description of "over confidence" (relative to the empirical distribution) via $\rho_{t+1}^{j}$. When $u_{t}^{j}>0$ and large, $\psi\left(\mathrm{u}^{\mathrm{j}}\right)$ is also large: an agent is over confident that $\rho_{\mathrm{t}+1}^{\mathrm{j}}$ takes positive values with high probability. He multiplies the positive part of a normal density in (23) by $\varphi_{1}\left(\mathrm{u}_{\mathrm{t}}^{\mathrm{j}}\right)>1$ and the negative part by $\varphi_{2}\left(\mathrm{u}_{\mathrm{t}}^{\mathrm{j}}\right)<1$. When $u_{t}{ }^{j}<0$ the opposite occurs: agent $j$ is over confident that $\rho_{t+1}^{j}$ take negative values with high probability but now $\varphi_{1}\left(u_{t}^{j}\right)<1$ and $\varphi_{2}\left(u_{t}^{j}\right)>1$. The amplifications $\left(\varphi_{1}\left(u^{j}\right), \varphi_{2}\left(u^{j}\right)\right)$ are determined by $u^{j}$ and by the "fat tails" parameter b. Figure 1 exhibits two non normal densities of $\rho^{j}\left(u^{j}\right)$ for $u^{j}>0$ and for $u^{j}<0$. As $u_{t}^{j}$ varies, the densities of $\rho_{t+1}^{j}\left(u_{t}^{j}\right)$ change. But the empirical distribution of $u^{j}$ is normal. Hence, as $u^{j}$ varies over time, averaging the densities $\rho^{\mathrm{j}}\left(\mathrm{u}^{\mathrm{j}}\right)$ over $\mathrm{u}^{\mathrm{j}}$ generates a random variable which is normal and its empirical distribution is drawn in the center of Figure 1.

\section{FIGURE 1 PLACE HERE}

As (22) shows, each component of $\Psi_{t+1}\left(u_{t}{ }^{j}\right)$ is a sum of two random variables. The first is as in Figure 1 and the second is normal. Figure 2 exhibits two densities of the $v$ component of $\Psi_{t+1}\left(u_{t}^{j}\right)$, assuming $\lambda_{g}^{\mathrm{v}}>0$. Each is a convolution of a normal density with a density as in Figure 1: one for $\mathrm{u}^{\mathrm{j}}>0$ and one for $\mathrm{u}^{\mathrm{j}}<0$, showing each has a "fat tail" relative to the empirical distribution which is normal. Since the parameter $\mathrm{b}$ measures the intensity by which the positive and negative portions in Figure 1 are shifted, it measures the degree of fat tails in the distribution of $\Psi_{t+1}\left(u_{t}{ }^{j}\right)$. The fat tail parameter $b$ is central as it regulates the intensity of the agents' over confidence about future distributions of the state variables. Such variations in the bullish or bearish outlook of future economic events relative to the empirical distribution is the driving force of our model.

\section{FIGURE 2 PLACE HERE}

We finally arrive at the key question of what do $u^{j}>0$ or $u^{j}<0$ mean? We have shown that when $u^{j}>0$ agent $j$ is over confident that $\rho_{t+1}^{j}\left(u_{t}^{j}\right)$ take positive values and when $u^{j}<0$ he is over confident that $\rho_{t+1}^{j}\left(u_{t}^{j}\right)$ take negative values. But then what does $\rho_{t+1}^{j}\left(u_{t}^{j}\right)>0$ or $\rho_{t+1}^{j}\left(u_{t}^{j}\right)<0$ mean? Keeping in mind that $u_{t}{ }^{j}$ determines the belief via a single factor $\rho_{t+1}\left(u_{t}{ }^{j}\right)$ in all equations in (22), the answer is clear from (22): it depends upon the component of $\Psi_{\mathrm{t}+1}\left(\mathrm{u}_{\mathrm{t}}{ }^{\mathrm{j}}\right)$ we consider and what is the sign of the corresponding $\lambda_{\mathrm{g}}=\left(\lambda_{\mathrm{g}}^{\mathrm{v}}, \lambda_{\mathrm{g}}^{\varrho}, \lambda_{\mathrm{g}}^{\mathrm{z}}\right)$ parameter. This fact justifies the following definition: 
- If $\lambda_{\mathrm{g}}^{\mathrm{v}}>0$ agent $\mathrm{j}$ is said to be optimistic or over confident that $\mathrm{v}_{\mathrm{t}+1}>\mathrm{E}_{\mathrm{m}}\left[\mathrm{v}_{\mathrm{t}+1} \mid \mathrm{H}_{\mathrm{t}}\right]$

- If $\lambda_{\mathrm{g}}^{\varrho}>0$ agent $\mathrm{j}$ is said to be optimistic or over confident that $\varrho_{t+1}>\mathrm{E}_{\mathrm{m}}\left[\varrho_{\mathrm{t}+1} \mid \mathrm{H}_{\mathrm{t}}\right]$

- If $\lambda_{\mathrm{g}}^{\mathrm{z}}>0$ agent $\mathrm{j}$ is said to be optimistic or over confident that $\mathrm{z}_{\mathrm{t}+1}^{\mathrm{jn}}>\mathrm{E}_{\mathrm{m}}\left[\mathrm{z}_{\mathrm{t}+1}^{\mathrm{jn}} \mid \mathrm{H}_{\mathrm{t}}\right], \mathrm{n}=1,2$.

We now specify that $\lambda_{\mathrm{g}}^{\mathrm{v}}>0, \lambda_{\mathrm{g}}^{\varrho} \geq 0$. This orients the model so that $\mathrm{u}^{\mathrm{j}}>0 \underline{\text { means }}$ agents are optimistic or over confident in expecting abnormally high productivity shocks and abnormally high monetary shocks. We stress that such orientation is a matter of model convention rather than a model assumption.

The questions we ask are then clear: can we find feasible values of the parameters such that the model replicates the empirical record of the U.S. economy? Moreover, if fluctuations in the economy are caused by endogenous forces as in our model, what are the policy implications of such equilibria?

The final form of the subjective perception model is then

$$
\begin{aligned}
& v_{t+1}^{j}=\lambda_{v} v_{t}+\lambda_{y}^{v} \rho_{t+1}^{j}\left(u_{t}^{j}\right)+\tilde{\rho}_{t+1}^{v^{j}} \\
& \varrho_{t+1}^{j}=\lambda_{\varrho} \varrho_{t}+\lambda_{y}^{\varrho} \rho_{t+1}^{j}\left(u_{t}^{j}\right)+\tilde{\rho}_{t+1}^{\varrho^{j}} \\
& z_{t+1}^{j 1}=\lambda_{z} z_{t}^{1}+\lambda_{v}^{z} v_{t}+\lambda_{\varrho}^{z} \varrho_{t}+\lambda_{y}^{z} \rho_{t+1}^{j}\left(u_{t}^{j}\right)+\tilde{\rho}_{t+1}^{z^{j 1}} \\
& z_{t+1}^{j 2}=\lambda_{z} z_{t}^{2}+\lambda_{v}^{z} v_{t}+\lambda_{\varrho}^{z} \varrho_{t}+\lambda_{y}^{z} \rho_{t+1}^{j}\left(u_{t}^{j}\right)+\tilde{\rho}_{t+1}^{z^{j 2}} \\
& g_{t+1}^{j}=\lambda_{z} g_{t}^{j}+\lambda_{v}^{z} v_{t}+\lambda_{\varrho}^{z} \varrho_{t}+\tilde{\rho}_{t+1}^{g} .
\end{aligned}
$$

The vector $\tilde{\rho}_{t}^{j}$ is distributed i.i.d. Normal with mean zero and covariance matrix $\Omega$ to be specified.

The important parameter $\lambda_{\mathrm{g}}^{\mathrm{z}}$ reflects forecasts of the beliefs of others. Assuming $\lambda_{\mathrm{g}}^{\mathrm{v}}>0, \lambda_{\mathrm{g}}^{\varrho} \geq 0$ if $\lambda_{\mathrm{g}}^{\mathrm{z}}>0$ then an optimistic agent (with $\mathrm{u}_{\mathrm{t}}^{\mathrm{j}}>0$ ) expects others to have above normal level of optimism at $\mathrm{t}+1$. But from (19) he also expects to be less optimistic than others. When $\lambda_{\mathrm{g}}^{\mathrm{z}}<0$ an optimistic agent expects others to have a lower than normal level of optimism and for himself to be more optimistic than others. We show later that $\lambda_{\mathrm{g}}^{\mathrm{z}}<0$ is needed to ensure the model generates sufficient positive correlation between consumption and output. Also, heterogeneous forecasts of the belief of others $\left(\mathrm{z}_{\mathrm{t}+1}^{\mathrm{k} 1}, \mathrm{z}_{\mathrm{t}+1}^{\mathrm{k} 2}\right)$ leads to heterogeneous forecasts of price and other endogenous variables. This is so since equilibrium prices depend on $\left(\mathrm{z}_{\mathrm{t}+1}^{1}, \mathrm{z}_{\mathrm{t}+1}^{2}\right)$. This heterogeneity is a key force which generate efficacy of a monetary rule since it is the cause for breaking the dichotomy between the real and monetary parts of the economy.

\section{The Rationality of Belief Conditions}

As noted before, the rationality principle requires that 
(26) $\quad \Psi_{t+1}\left(u_{t}^{j}\right)=\left(\begin{array}{c}\lambda_{g}^{v} \rho_{t+1}^{j}\left(u_{t}^{j}\right)+\tilde{\rho}_{t+1}^{v^{j}} \\ \lambda_{g}^{\varrho} \rho_{t+1}^{j}\left(u_{t}^{j}\right)+\tilde{\rho}_{t+1}^{\varrho^{j}} \\ \lambda_{g}^{z} \rho_{t+1}^{j}\left(u_{t}^{j}\right)+\tilde{\rho}_{t+1}^{z^{j 1}} \\ \lambda_{g}^{z} \rho_{t+1}^{j}\left(u_{t}^{j}\right)+\tilde{\rho}_{t+1}^{z^{j 2}}\end{array}\right)$ has the same joint empirical distribution as $\rho_{t+1}=\left(\begin{array}{c}\rho_{t+1}^{v} \\ \rho_{t+1}^{\varrho} \\ \rho_{t+1}^{z^{1}} \\ \rho_{t+1}^{z^{2}}\end{array}\right)$.

In Appendix B we show: (a) the main restriction the rationality principle imposes on beliefs is that it pins down the covariance matrix $\Omega$ of $\tilde{\rho}_{t}^{j}$, and (b) that $\Psi_{t+1}\left(u_{t}^{j}\right)$ is serially uncorrelated. However, if $\Omega$ is a covariance matrix then it must be positive definite. This is the last point to explore.

\section{4c Positive Definiteness of $\Omega$ as a Restriction of the Rationality conditions}

Although the parameters $\left(\mathrm{b}, \lambda_{\mathrm{g}}\right)$ where $\lambda_{\mathrm{g}}=\left(\lambda_{\mathrm{g}}^{\mathrm{v}}, \lambda_{\mathrm{g}}^{\varrho}, \lambda_{\mathrm{g}}^{\mathrm{z}}\right)$ are free, $\left(\mathrm{b}, \lambda_{\mathrm{g}}\right)$ are drastically restricted by the condition that $\Omega$ is positive definite. To see why, observe some implications of this condition:

- $\quad \sigma_{\mathrm{v}}=0.003$ implies $\left|\lambda_{\mathrm{g}}^{\mathrm{v}}\right|<0.003$. The covariance structure further restricts $\left|\lambda_{\mathrm{g}}^{\mathrm{v}}\right|<0.0027$.

- $\quad \sigma_{\mathrm{e}}=0.007$ implies $\left|\lambda_{\mathrm{g}}^{\varrho}\right|<0.007$. The covariance structure further restricts $\left|\lambda_{\mathrm{g}}^{\varrho}\right|<0.0032$.

- The covariance structure implies that $\left|\lambda_{\mathrm{g}}^{\mathrm{z}}\right|<0.35$.

- $\quad$ The overconfidence parameter $b$ has a feasible range between 0 and -12 .

\section{4d Model Parameters and Their Interpretation}

The model parameters $\left(\mathrm{b}, \lambda_{\mathrm{g}}\right)$ for our reference economy with random money growth can be specified: $\mathrm{b}=-10, \lambda_{\mathrm{g}}^{\mathrm{v}}=0.0025, \lambda_{\mathrm{g}}^{\varrho}=0$ and $\lambda_{\mathrm{g}}^{\mathrm{z}}=-0.30$. Apart from $\lambda_{\mathrm{g}}^{\varrho}=0$ all parameter are taken close to the maximal values feasible under the restriction that $\Omega$ be positive definite. To explain these, note $\lambda_{\mathrm{g}}^{\mathrm{v}}=0.0025>0$ is compatible with our specified convention. We could extend the possibility of optimism to monetary shocks but for simplicity we assume agents know money injection is implemented by a computer and they know that (11a)-(11b) is the truth, hence $\lambda_{\mathrm{g}}^{\varrho}=0$. As for the last two parameters: $\mathrm{b}<0 \quad$ - for $\mathrm{u}^{\mathrm{j}}>0$ to mean "optimism," $\psi$ in (24) must increase with $\mathrm{u}^{\mathrm{j}}$ hence we must have $\mathrm{b}<0$; $\lambda_{\mathrm{g}}^{\mathrm{z}}<0$ - since "optimism” by $\mathrm{j}$ is a belief in higher investment returns, it turns out such reasoning also calls for expecting lower cost of production at $\mathrm{t}+1$. It is realized if tomorrow other agents' level of optimism is below normal since such market state of belief induces lower wages and higher profits tomorrow. In addition, $\lambda_{\mathrm{g}}^{\mathrm{z}}<0$ is needed for the model to fit the empirical evidence. 


\section{The Role of Technology, Expectation and Money Shocks in Economic Fluctuations 4.1 On Computational Procedures}

We turn to examine economic fluctuations. Our computations employ a program developed by Hehui Jin (see Jin and Judd (2002) and Jin (2003) ) for computing equilibria using perturbation methods. A solution is declared an equilibrium if the following holds: (i) a model is approximated by at least second order derivatives, and (ii) errors in market clearing conditions and Euler equations are less than $10^{-3}$. Since steady state consumption is about 0.7 the permitted error is $1 / 500$ of this marginal utility.

\subsection{Business Cycle Fluctuations in the Model with Money Shocks}

We start by comparing, in Table 1, the volatility of the classical RBC model under REE (without capacity utilization) with the volatility of the RBE with money shocks. The table shows that although $\sigma_{v}$ is a fraction of 0.072 , the RBE reproduces well the U.S. empirical record. As anticipated, our model does not perform well in the labor market. Since it does not have sufficient resource under-employment it does not capture the low volatility of the wage rate, the low correlation between the wage rate and GNP and the high volatility of hours. However, these shortcomings of the model do not diminish its value for the study of monetary policy.

Table 1: Comparing the Volatility of the RBE with the Classical RBC ${ }^{11}$ (percent, all data H-P filtered)

\begin{tabular}{|c|c|c|c|c|c|c|}
\hline & Standard & Deviation & of Variable & Correlation & of Variable & with GNP \\
\hline Variable & $\begin{array}{l}\text { RBC with } \\
\sigma_{v}=0.0072\end{array}$ & U.S. data & $\begin{array}{l}\text { RBE with } \\
\sigma_{v}=0.003\end{array}$ & $\begin{array}{l}\text { RBC with } \\
\sigma_{v}=0.0072\end{array}$ & U.S. data & $\begin{array}{l}\text { RBE with } \\
\sigma_{v}=0.003\end{array}$ \\
\hline $\mathrm{Y}$ & 1.39 & 1.81 & 1.82 & 100 & 100 & 100 \\
\hline I & 4.09 & $\begin{array}{l}1.01 \\
5.30\end{array}$ & $\begin{array}{l}1.02 \\
5.24\end{array}$ & 0.99 & 0.80 & 0.94 \\
\hline $\mathrm{C}$ & 0.61 & 1.35 & 0.93 & 0.94 & 0.88 & 0.73 \\
\hline L & 0.67 & 1.79 & $\begin{array}{l}1.02 \\
\end{array}$ & 0.97 & 0.88 & 0.87 \\
\hline W & 0.75 & 0.68 & 1.05 & 0.98 & 0.12 & 0.88 \\
\hline$\pi$ & na & 1.79 & 2.91 & na & 0.24 & 0.33 \\
\hline
\end{tabular}

The correlation between consumption and GNP is a central problem in an RBE and reveals the complexity of dynamics when fluctuations are propagated by expectations. In a standard RBC model a high correlation among aggregate variables results from the large persistent technological shocks which

${ }^{11}$ Results for the standard RBC model with $\sigma_{v}=0.0072$ are from King and Rebelo (1999, Table 3). Data for the U.S. economy are from Stock and Watson (1999) except for inflation which is measured by the GNP deflator and which we computed for the entire period 1947:1 - 2003:2. Stock and Watson (1999) computed the data for the period 1953:1-1996:4. 
increase GNP, investments and consumption together. When expectations of high future returns drive high investment rate, a competitive force emerges between investment and consumption. A date $\mathrm{t}$ increased output which is associated with increased agent's expected return on investments leads to increased investment but tends to reduce date t consumption. This force leads to a negative correlation between consumption and GNP. Kurz, Jin and Motolese (2003) show the potential dominance of this factor. An opposite force operates when increased investments together with increased capacity utilization result in higher date $\mathrm{t}+1$ output, making increased output and consumption possible, causing positive correlation between them. Such positive correlation is driven by persistence in beliefs which generate the higher investments and capacity utilization to begin with. Persistence of beliefs expressed by $\lambda_{\mathrm{z}}=0.65, \lambda_{\mathrm{v}}^{\mathrm{z}}=8.00$ and the condition $\lambda_{\mathrm{g}}^{\mathrm{z}}=-0.30$ are both needed for the positive 0.72 correlation between output and consumption seen in Table 1 .

Economic fluctuations in our RBE are caused by three factors: technology, expectations and monetary shocks. What are the contributions of these factors to the observed fluctuations in the U.S.?

\section{2a Decomposing the Effect of Technology, Expectations and Money Shocks}

In Table 2 we answer the question above. $\sigma_{X}$ is the standard deviation of $X$ and $\rho(X, Y)$ is the correlation of $\mathrm{X}$ with GNP. Column 1 reproduces the data in Table 1. Next, we shut off the random money shock by setting $\sigma_{0}=0$ hence money grows at a constant rate $v^{*}$. Column 3 reports results for the REE with constant money growth and flexible capacity utilization. If we think of REE volatility as measuring the effect of technology, then we arrive at the following rough approximation:

Table 2: Decomposing the Components of Business Cycles (percent, all data H-P filtered)

\begin{tabular}{|l|ll|ll|ll|}
\hline & \multicolumn{2}{|c|}{$\begin{array}{c}\text { RBE with Random } \\
\text { Money Growth }\end{array}$} & \multicolumn{2}{|c|}{$\begin{array}{c}\text { RBE with Constant } \\
\text { Money Growth }\end{array}$} & \multicolumn{2}{c|}{$\begin{array}{c}\text { REE with Constant } \\
\text { Money Growth }\end{array}$} \\
\hline $\mathrm{X}$ & $\sigma_{\mathrm{X}}$ & $\rho(\mathrm{X}, \mathrm{Y})$ & $\sigma_{\mathrm{X}}$ & $\rho(\mathrm{X}, \mathrm{Y})$ & $\sigma_{\mathrm{X}}$ & $\rho(\mathrm{X}, \mathrm{Y})$ \\
\hline $\mathrm{Y}$ & 1.82 & 1.00 & 1.75 & 1.00 & 0.81 & 1.00 \\
$\mathrm{I}$ & 5.24 & 0.94 & 5.02 & 0.95 & 1.97 & 0.99 \\
$\mathrm{C}$ & 0.93 & 0.73 & 0.89 & 0.74 & 0.39 & 0.99 \\
$\mathrm{~L}$ & 1.02 & 0.87 & 0.97 & 0.88 & 0.33 & 0.99 \\
$\mathrm{~W}$ & 1.05 & 0.88 & 1.01 & 0.89 & 0.48 & 0.99 \\
$\pi$ & 2.91 & 0.33 & 1.60 & 0.57 & 0.73 & -0.10 \\
\hline
\end{tabular}

- $40 \%$ of real fluctuations in the model are due to technological shocks and capacity utilization;

- $\quad 4 \%$ of real fluctuations are due to random monetary shocks amplified by agents' expectations;

- $\quad 56 \%$ of real fluctuations in the model are demand driven, due to pure expectations of agents. 
Recall that prices adjust immediately to a change in the money supply hence the REE is strongly neutral: unanticipated effects of money are impossible. Nevertheless, the effect of money in Table 2 is of interest as it measures a hypothetical level of fluctuations attained by suppressing the impact of market expectations via the elimination of random shocks to the money supply. This level is then a basic and plausible yardstick for the success of any monetary policy rule to be discussed later.

\section{2b Money non-Neutrality, Phillips Curve and Sticky prices in the RBE}

The RBE reported in Tables 1 and 2 is the basic reference economy which we study later under alternative monetary rules. Hence, we discuss two monetary properties of this economy.

(i) Phillips Curve Behavior. By simulating 10,000 observations of the reference economy we can estimate the following statistical Phillips Curve which is compatible with many published estimates:

$$
\pi_{\mathrm{t}}-\pi^{*}=0.1754\left[\log \left(\mathrm{y}_{\mathrm{t}}\right)-\log \left(\mathrm{y}^{*}\right)\right]+0.4272\left[\pi_{\mathrm{t}-1}-\pi^{*}\right]+0.0227\left[\pi_{\mathrm{t}-2}-\pi^{*}\right] .
$$

(ii) Money is Non-Neutral in an RBE and Prices Appear Sticky. Money non-neutrality and impulse response behavior in an RBE were discussed by Kurz, Jin and Motolese (2003). We add here that in a heterogenous belief economy agents have diverse belief about the effects of monetary shocks. Hence money shocks may generate an increase or a decrease of output and consumption, depending upon the structure of market beliefs. $\lambda_{\varrho}^{\mathrm{z}}>0$ is then a sufficient condition which ensures that a positive money shock causes a positive impulse of real variables. This condition says a positive money shock leads agents to expect an increased level of market confidence. Since prices and endogenous variables are functions of $\left(\mathrm{z}_{\mathrm{t}}^{1}, \mathrm{z}_{\mathrm{t}}^{2}\right)$, forecasts of $\left(\mathrm{z}_{\mathrm{t}+1}^{1}, \mathrm{z}_{\mathrm{t}+1}^{2}\right)$ are indirectly forecasts of future prices and endogenous variables. In addition, when agents are confident about the future they increase their consumption and demand for money. Hence, a positive monetary shock which leads to increased forecast of $\left(z_{t+1}^{1}, z_{t+1}^{2}\right)$ actually leads to an increase in the demand for money and thus reduces the inflationary impact of the monetary shock. We arrive at this same conclusion by examining the equilibrium inflation function $\pi_{\mathrm{t}}$ which depend upon $\varrho_{t}$. Indeed, $\frac{\partial \pi_{t}}{\partial}$ is the proportion of a money shock translated into inflation. In an REE, $\frac{\partial \pi_{t}}{\partial \varrho_{t}}=1$ but in our reference ${ }^{t} \operatorname{RBE}, \frac{\partial \pi_{t}}{\partial \varrho}=0.82$. An econometrician studying the relationship between money shocks and inflation in this RBE may conclude that prices are sticky since they do not respond fully to money shocks. This conclusion suggests that an empirical evaluation of the sticky price model needs to consider the fact that our heterogenous belief economy with fully competitive markets and flexible prices exhibits a behavior that may be confused with sticky price behavior. 
For the rest of this paper we use the volatility in the first column of Table 2 as a reference to measuring the efficacy of any monetary policy. Under a Friedman rule of constant money growth, volatility can be reduced to a level specified in the second column. If, in addition, all pure effects of beliefs were neutralized by a central bank policy, fluctuations would be reduced to a level determined by technology as in the third column of Table 2. We thus put forward the following two questions:

(A) Is there a policy rule for which the economy attains the same level of volatility that would be attained by a constant growth of money?

(B) Is there a policy rule for which the economy attains the level of volatility that would be attained in an REE and be determined by technology only?

\section{Economic Stabilization with a Monetary Rule}

\subsection{What is the Objective of Central Bank Policy?}

What is the aim of a central bank when fluctuations are caused by the forces outlined in our theory? One may insist market allocation is optimal and no monetary action is needed. Kurz, Jin and Motolese (2003) argue (pages 222 -225) that market expectations act as an externality generating excess fluctuations and hence the aim of monetary policy should be to reduce that component of aggregate volatility generated by the beliefs of economic agents. We briefly review this argument.

A substantial part of volatility in an RBE is caused endogenously by the beliefs of agents. Hence, the level of market risk is greater than the level induced by exogenous shocks. But if social risk is caused by human conduct then society may elect to place limits on individual choice so as to reduce the level of endogenous volatility. The problem is that an RBE with complete hedging opportunities is ex-ante Pareto optimal hence an effective policy makes some agents worse off. It comes down to a choice between ex-ante optimality and the excess volatility caused by diverse and inconsistent beliefs of investors which often leads to poor collective investments and consumption decisions. The ex-post consequences of excess volatility in a market may thus be undesirable.

The problem of reconciling ex-ante and ex-post social outcomes is not new. It was discussed by Diamond (1967), Starr (1973), Mirrlees (1974), Hammond (1981), (1983), Nielsen (2000) (2003), Silvestre (2001) and others. The interest in an ex-post optimality is motivated by two considerations. First, researchers suggest that in an uncertain world agents may hold incorrect probability beliefs and regret their decisions (e.g. Hammond (1981), page 236). In a free society investors may use private 
capital for a project but when their beliefs are wrong, as they may be in an RBE, their decisions may have negative collective impact. One can construct examples where the consequences of such actions are jointly undesirable (see Kurz, Jin and Motolese (2003) page 224). Under such circumstances social preferences are sensitive to ex-post as well as ex-ante "expected" outcomes and society may benefit from a coordination policy. Second, diverse probability beliefs which are inconsistent across agents raise the difficulty of even defining a "representative consumer" who holds a social expected utility. Hammond's [1981],[1983] concept of Ex-Post Welfare Function proposes that society ignores the probability beliefs of individual agents and instead uses society's own probabilities over states.

Applying these ideas to our context, Kurz, Jin and Motolese (2003) argue a central bank recognizes that when agents hold diverse and inconsistent beliefs, some are wrong. Since society has the same information as the agents, the bank cannot determine whose beliefs are right. Consequently, the bank's policy must take a symmetric view of the diversity of beliefs: over time any agent may hold a correct belief and policy must be optimal with respect to a random draw of the agents over time. The rationality of belief conditions in an RBE imply the mean belief of any agent over time is exactly the stationary measure. Hence one symmetric perspective would propose that public policy be optimal relative to the stationary measure of an RBE. Here we study only the set of feasible policies.

In the next section we examine outcomes generated by a Taylor (1993) policy rules of the type

$$
\log \frac{1+r_{t}}{1+r^{*}}=v_{y} \log \left(\frac{y_{t}}{y^{*}}\right)+v_{\pi}\left(\pi_{t}-\pi^{*}\right)
$$

where $\left(\mathrm{r}^{*}, \mathrm{y}^{*}\right)$ are equal to the steady state values and $\pi^{*}=0.01$ hence the economy has a positive long run inflation rate. We then study in Section 5.3 a version of this rule with a random term, interpreted as a discretionary component of the policy, not known to the market in advance.

\subsection{Policy Rules without Discretion}

In all policy experiments the real economy is exactly the same as in the reference economy. To examine the effect of rule (28) we turn off the money shocks (i.e. set $\varrho_{t}=0$ ) in the reference economy and replace it with (28). Hence, to study the impact of policy one must focus only on the difference between numbers reported in the tables below and the volatility in the reference economy for which

$$
\sigma_{\mathrm{Y}}=1.82, \sigma_{\mathrm{I}}=5.24, \sigma_{\mathrm{C}}=0.93, \sigma_{\pi}=2.91 \text {. }
$$


Also, under $\varrho_{t}=0$ the central bank commits to a constant money growth hence we also compare volatility under rule (28) with a hypothetical economy with a constant growth of money.

Table 3: Efficacy of Alternative Monetary Rules: No Discretion (percent, all data H-P filtered)

\begin{tabular}{|c|c|c|c|c|c|c|c|c|c|c|c|}
\hline $\mathrm{v}_{\pi}$ & $\mathrm{v}_{\mathrm{y}} \rightarrow$ & 0 & 0.1 & 0.2 & 0.3 & 0.4 & 0.5 & 0.7 & 0.9 & 1.0 & 5.0 \\
\hline 1.1 & $\begin{array}{c}\mathrm{Y} \\
\mathrm{I} \\
\mathrm{C} \\
\pi \\
\rho(\pi, Y)\end{array}$ & $\begin{array}{l}1.80 \\
5.26 \\
0.98 \\
0.35 \\
0.43\end{array}$ & $\begin{array}{l}1.70 \\
4.79 \\
0.79 \\
4.82 \\
-0.57\end{array}$ & $\begin{array}{c}1.61 \\
4.51 \\
0.62 \\
9.94 \\
-0.63\end{array}$ & $\begin{array}{r}1.54 \\
4.48 \\
0.51 \\
15.00 \\
-0.69\end{array}$ & $\begin{array}{r}1.48 \\
4.68 \\
0.47 \\
20.02 \\
-0.76\end{array}$ & $\begin{array}{r}1.44 \\
5.08 \\
0.53 \\
24.99 \\
-0.82\end{array}$ & $\begin{array}{r}1.43 \\
6.28 \\
0.83 \\
34.79 \\
-0.92\end{array}$ & $\begin{array}{r}1.48 \\
7.77 \\
1.21 \\
44.44 \\
-0.97\end{array}$ & unstable & unstable \\
\hline 1.2 & $\begin{array}{c}\mathrm{Y} \\
\mathrm{I} \\
\mathrm{C} \\
\pi \\
\rho(\pi, \mathrm{Y})\end{array}$ & $\begin{array}{l}1.80 \\
5.26 \\
0.98 \\
0.26 \\
0.42\end{array}$ & $\begin{array}{l}1.74 \\
4.97 \\
0.87 \\
2.66 \\
-0.6\end{array}$ & $\begin{array}{c}1.68 \\
4.73 \\
0.76 \\
5.55 \\
-0.63\end{array}$ & $\begin{array}{c}1.63 \\
4.57 \\
0.67 \\
8.41 \\
-0.66\end{array}$ & $\begin{array}{r}1.59 \\
4.48 \\
0.59 \\
11.24 \\
-0.69\end{array}$ & $\begin{array}{r}1.55 \\
4.47 \\
0.52 \\
14.05 \\
-0.72\end{array}$ & $\begin{array}{r}1.49 \\
4.65 \\
0.47 \\
19.59 \\
-0.78\end{array}$ & $\begin{array}{r}1.44 \\
5.06 \\
0.52 \\
25.04 \\
-0.84\end{array}$ & $\begin{array}{r}1.43 \\
5.34 \\
0.58 \\
27.74 \\
-0.87\end{array}$ & unstable \\
\hline 1.3 & $\begin{array}{c}\mathrm{Y} \\
\mathrm{I} \\
\mathrm{C} \\
\pi \\
\rho(\pi, \mathrm{Y})\end{array}$ & $\begin{array}{l}1.79 \\
5.26 \\
0.98 \\
0.20 \\
0.41\end{array}$ & $\begin{array}{l}1.75 \\
5.04 \\
0.90 \\
1.84 \\
-0.64\end{array}$ & $\begin{array}{r}1.71 \\
4.85 \\
0.82 \\
3.86 \\
-0.65\end{array}$ & $\begin{array}{c}1.67 \\
4.70 \\
0.75 \\
5.87 \\
-0.67\end{array}$ & $\begin{array}{c}1.64 \\
4.59 \\
0.68 \\
7.85 \\
-0.69\end{array}$ & $\begin{array}{c}1.61 \\
4.51 \\
0.62 \\
9.81 \\
-0.71\end{array}$ & $\begin{array}{r}1.55 \\
4.47 \\
0.53 \\
13.69 \\
-0.75\end{array}$ & $\begin{array}{r}1.50 \\
4.56 \\
0.47 \\
17.52 \\
-0.79\end{array}$ & $\begin{array}{r}1.49 \\
4.65 \\
0.47 \\
19.41 \\
-0.80\end{array}$ & unstable \\
\hline 1.4 & $\begin{array}{c}\mathrm{Y} \\
\mathrm{I} \\
\mathrm{C} \\
\pi \\
\rho(\pi, \mathrm{Y})\end{array}$ & $\begin{array}{c}1.79 \\
5.26 \\
0.98 \\
0.17 \\
0.4\end{array}$ & $\begin{array}{l}1.76 \\
5.08 \\
0.91 \\
1.41 \\
-0.68\end{array}$ & $\begin{array}{c}1.73 \\
4.92 \\
0.85 \\
2.97 \\
-0.68\end{array}$ & $\begin{array}{c}1.70 \\
4.79 \\
0.79 \\
4.51 \\
-0.69\end{array}$ & $\begin{array}{l}1.67 \\
4.67 \\
0.73 \\
6.04 \\
-0.71\end{array}$ & $\begin{array}{r}1.64 \\
4.59 \\
0.68 \\
7.56 \\
-0.72\end{array}$ & $\begin{array}{r}1.59 \\
4.48 \\
0.59 \\
10.55 \\
-0.75\end{array}$ & $\begin{array}{r}1.55 \\
4.47 \\
0.52 \\
13.50 \\
-0.77\end{array}$ & $\begin{array}{r}1.53 \\
4.49 \\
0.50 \\
14.96 \\
-0.79\end{array}$ & unstable \\
\hline 1.5 & $\begin{array}{c}\mathrm{Y} \\
\mathrm{I} \\
\mathrm{C} \\
\pi \\
\rho(\pi, \mathrm{Y})\end{array}$ & $\begin{array}{l}1.79 \\
5.26 \\
0.98 \\
0.14 \\
0.39\end{array}$ & $\begin{array}{l}1.76 \\
5.10 \\
0.92 \\
1.15 \\
-0.71\end{array}$ & $\begin{array}{c}1.74 \\
4.96 \\
0.87 \\
2.42 \\
-0.71\end{array}$ & $\begin{array}{c}1.71 \\
4.84 \\
0.81 \\
3.67 \\
-0.72\end{array}$ & $\begin{array}{l}1.68 \\
4.74 \\
0.77 \\
4.92 \\
-0.73\end{array}$ & $\begin{array}{l}1.66 \\
4.65 \\
0.72 \\
6.16 \\
-0.74\end{array}$ & $\begin{array}{l}1.62 \\
4.53 \\
0.64 \\
8.60 \\
-0.76\end{array}$ & $\begin{array}{r}1.58 \\
4.47 \\
0.57 \\
11.00 \\
-0.78\end{array}$ & $\begin{array}{r}1.56 \\
4.46 \\
0.54 \\
12.19 \\
-0.79\end{array}$ & unstable \\
\hline 10 & $\begin{array}{c}\mathrm{Y} \\
\mathrm{I} \\
\mathrm{C} \\
\pi \\
\rho(\pi, \mathrm{Y})\end{array}$ & $\begin{array}{l}1.80 \\
5.27 \\
0.98 \\
0.02 \\
0.32\end{array}$ & $\begin{array}{l}1.79 \\
5.24 \\
0.97 \\
0.07 \\
-.099\end{array}$ & $\begin{array}{c}1.79 \\
5.21 \\
0.96 \\
0.15 \\
-0.99\end{array}$ & $\begin{array}{c}1.78 \\
5.18 \\
0.95 \\
0.23 \\
-0.99\end{array}$ & $\begin{array}{c}1.77 \\
5.15 \\
0.94 \\
0.30 \\
-0.99\end{array}$ & $\begin{array}{l}1.77 \\
5.12 \\
0.93 \\
0.38 \\
-0.99\end{array}$ & $\begin{array}{l}1.76 \\
5.06 \\
0.90 \\
0.53 \\
-0.99\end{array}$ & $\begin{array}{l}1.75 \\
5.01 \\
0.88 \\
0.68 \\
-0.99\end{array}$ & $\begin{array}{c}1.74 \\
4.98 \\
0.87 \\
0.75 \\
-0.99\end{array}$ & $\begin{array}{r}1.60 \\
4.49 \\
0.60 \\
3.54 \\
-0.99\end{array}$ \\
\hline$\infty$ & $\begin{array}{c}\mathrm{Y} \\
\mathrm{I} \\
\mathrm{C} \\
\pi \\
\rho(\pi, \mathrm{Y})\end{array}$ & $\begin{array}{c}1.80 \\
5.28 \\
0.98 \\
0.00 \\
\text { na }\end{array}$ & $\begin{array}{c}1.80 \\
5.28 \\
0.98 \\
0.00 \\
\text { na }\end{array}$ & $\begin{array}{c}1.80 \\
5.28 \\
0.98 \\
0.00 \\
\text { na }\end{array}$ & $\begin{array}{c}1.80 \\
5.28 \\
0.98 \\
0.00 \\
\text { na }\end{array}$ & $\begin{array}{c}1.80 \\
5.28 \\
0.98 \\
0.00 \\
\text { na }\end{array}$ & $\begin{array}{c}1.80 \\
5.28 \\
0.98 \\
0.00 \\
\text { na }\end{array}$ & $\begin{array}{c}1.80 \\
5.28 \\
0.98 \\
0.00 \\
\text { na }\end{array}$ & $\begin{array}{c}1.80 \\
5.28 \\
0.98 \\
0.00 \\
\text { na }\end{array}$ & $\begin{array}{c}1.80 \\
5.28 \\
0.98 \\
0.00 \\
\text { na }\end{array}$ & $\begin{array}{c}1.80 \\
5.28 \\
0.98 \\
0.00 \\
\text { na }\end{array}$ \\
\hline
\end{tabular}

Table 3 reports the variability of output, investment, consumption and inflation under the rule (28). It also reports the unconditional correlation between inflation and output. It demonstrates that monetary policy can have a major stabilization effect: there are many policies which lead to reduced real volatility, relative to the reference economy, by a wide margin. The table demonstrates the subtle tradeoff between real volatility and inflation volatility which can be attained using different policy instruments. Some specific points to note are as follows:

(i) Most efficient stabilization policies require joint policy instruments. Efficient policy rules must consider the joint instruments $\mathrm{v}_{\mathrm{y}}$ and $\mathrm{v}_{\pi}$ in order to avoid increased volatility of both inflation and output. Bold borders indicate policy rules which attain, for each $\mathrm{v}_{\pi}$, minimal consumption volatility. 
(ii) Apart from inflation, outcomes of policy instruments are not monotonic. The effects of each policy instrument $v_{y}$ and $v_{\pi}$ (holding the other fixed) on real variables are not monotonic. However, the effects of both instruments on inflation volatility is monotonic: increasing $\mathrm{v}_{\pi}$ decreases inflation volatility while increasing $\mathrm{v}_{\mathrm{y}}$ increases it.

(iii) $\mathrm{v}_{\pi}=\infty$ is an efficient policy. It attains a zero inflation volatility independently of $\mathrm{v}_{\mathrm{y}}$.

(iv) Is there a rule attaining the outcome of a constant money growth for which $\sigma_{\mathrm{Y}}=1.75, \sigma_{\mathrm{I}}=5.02$

$\sigma_{\mathrm{C}}=0.89, \sigma_{\pi}=1.60$ ? The answer to this question $(\mathrm{A})$ is yes $!$ A rule such as $\left(\mathrm{v}_{\pi}=1.3, \mathrm{v}_{\mathrm{y}}=0.1\right)$ attains results which are very close to those attained by a constant money growth policy.

(v) The strongest tradeoff is between consumption and inflation volatility. Consumption volatility may be reduced by as much as $52 \%$ relative to the reference economy.

(vi) There are rules that are socially preferred to a constant money growth rule. Consumption stabilization requires either the cost of high inflation volatility or a very aggressive anti inflationary policy. Also, for some social preferences the policy $\left(\mathrm{v}_{\pi}=1.5, \mathrm{v}_{\mathrm{y}}=0.5\right)$ is superior to the reference economy or to the constant money growth economy. However, the stabilization outcome of this policy is far from the observed U.S. record both with respect to inflation as well as real volatility.

(vii) A stabilization activist policy (i.e. $\mathrm{v}_{\mathrm{y}}>0$ ) which is too aggressive can destabilize the economy. (viii) There is no policy rule under (28) that attains the level determined by technology only, which is $\sigma_{Y}=0.81, \sigma_{I}=1.97, \sigma_{C}=0.39, \sigma_{\pi}=0.73$. However there are policy rules that attain each of the consumption and inflation volatility goals, by itself. The answer to question (B) in Section 4 is $\underline{n o}$, the simple rule (28) cannot jointly stabilize to the level determined by technology only.

\section{2a Activist monetary policy "destroys" the statistical Phillips Curve.}

Policy choices are expressed in our model with the two instruments $\left(\mathrm{v}_{\pi}, \mathrm{v}_{\mathrm{y}}\right)$. It is thus not clear what are the policy choices that would be suggested by a Phillips Curve which is estimated from the equilibrium data of an economy with given policy instruments. In Table 3 we report unconditional correlations between inflation and $\log (\mathrm{GNP})$ and it is clear that as the policy becomes more activist (i.e. $v_{y}>0$ ), this correlation tends to -1 . Focusing on conditional correlations, we report in Table 4 estimates of the same statistical Phillips Curve as in (27). We study two specifications of the model: one is OLS and the second (INST) uses instrumental variables where all exogenous and lagged exogenous variables are used as instruments, given a policy instrument $\mathrm{v}_{\pi}=1.4$ and for rising values of 
$\mathrm{v}_{\mathrm{y}}$. Each estimate is derived from an equilibrium with the specified policy rule. There are three clear conclusions which emerge from Table 4:

Table 4: Estimated Phillips Curves for Monetary Rules with $\mathbf{v}_{\pi}=1.4$; No Discretion

\begin{tabular}{|c|c|c|c|c|c|c|c|c|c|c|c|}
\hline Model & Variable & $\mathrm{v}_{\mathrm{y}}=0$ & $\mathrm{v}_{\mathrm{y}}=0.1$ & $\mathrm{v}_{\mathrm{y}}=0.2$ & $\mathrm{v}_{\mathrm{y}}=0.3$ & $\mathrm{v}_{\mathrm{y}}=0.4$ & $\mathrm{v}_{\mathrm{y}}=0.5$ & $\mathrm{v}_{\mathrm{y}}=0.7$ & $\mathrm{v}_{\mathrm{y}}=0.9$ & $\mathrm{v}_{\mathrm{y}}=1.0$ & $\mathrm{v}_{\mathrm{y}}=5.0$ \\
\hline OLS & $\begin{array}{l}\text { const. } \\
\log (y) \\
\pi_{t-1} \\
\pi_{t-2}^{-}\end{array}$ & $\begin{array}{r}0.009 \\
-0.015 \\
0.907 \\
0.044\end{array}$ & $\begin{array}{r}-0.129 \\
0.258 \\
1.583 \\
-0.396\end{array}$ & $\begin{array}{r}-0.245 \\
0.504 \\
1.525 \\
-0.351\end{array}$ & $\begin{array}{r}-0.232 \\
0.485 \\
1.380 \\
-0.300\end{array}$ & $\begin{array}{r}-0.053 \\
0.116 \\
1.189 \\
-0.244\end{array}$ & $\begin{array}{r}-0.350 \\
-0.720 \\
0.951 \\
-0.181\end{array}$ & $\begin{array}{c}2.041 \\
-4.260 \\
0.338 \\
-0.035\end{array}$ & $\begin{array}{r}5.026 \\
-10.531 \\
-0.378 \\
0.116\end{array}$ & $\begin{array}{r}6.894 \\
-14.459 \\
-0.721 \\
0.181\end{array}$ & $\begin{array}{r}20.269 \\
-42.819 \\
0.029 \\
0.037\end{array}$ \\
\hline INST & $\begin{array}{l}\text { const. } \\
\log (y) \\
\pi_{t-1} \\
\pi_{t-2}\end{array}$ & $\begin{array}{r}0.009 \\
-0.015 \\
0.907 \\
0.044\end{array}$ & $\begin{array}{r}-0.110 \\
0.221 \\
1.528 \\
-0.379\end{array}$ & $\begin{array}{r}-0.279 \\
0.574 \\
1.573 \\
-0.364\end{array}$ & $\begin{array}{r}-0.321 \\
0.667 \\
1.462 \\
-0.321\end{array}$ & $\begin{array}{r}-0.174 \\
0.368 \\
1.273 \\
-0.264\end{array}$ & $\begin{array}{r}-0.220 \\
-0.451 \\
1.022 \\
-0.198\end{array}$ & $\begin{array}{c}2.005 \\
-4.185 \\
0.351 \\
-0.038\end{array}$ & $\begin{array}{r}5.230 \\
-10.959 \\
-0.439 \\
0.128\end{array}$ & $\begin{array}{r}7.233 \\
-15.172 \\
-0.811 \\
0.199\end{array}$ & $\begin{array}{r}20.265 \\
-42.811 \\
0.029 \\
0.037\end{array}$ \\
\hline
\end{tabular}

(i) The statistical Phillips Curve is a relationship between two endogenous variables which is extremely sensitive to the policy regime which prevails in that equilibrium.

(ii) For moderately activist policy rules with $v_{y} \leq 0.4$ the statistical Phillips Curve estimated for each equilibrium is similar to the estimates which are obtained from U.S. data.

(iii) As policy becomes more activist the statistical Phillips Curve becomes essentially vertical. Since this statistical curve changes dramatically with the policy, there is no sense in which it reflects policy choices along the curve; there are no policy instruments to accomplish such choices.

Our results regarding the Phillips Curve raise doubts about a common practice in the policy debate. The practice is to estimate from data a Phillips Curve, treat it as a fixed structural equation and perform policy experiments, assuming the economy moves along that fixed curve. Our General Equilibrium approach suggests this procedure is flawed and would lead to erroneous conclusions.

\subsection{Outcomes Under Policy Rules with Discretion}

We now introduce a discretionary component to the monetary rule. It is formulated as a modified rule containing a random component $d_{t}$ so that the rule takes the form

with an empirical distribution

$$
\log \frac{1+r_{t}}{1+r^{*}}=v_{y} \log \left(\frac{y_{t}}{y^{*}}\right)+v_{\pi}\left(\pi_{t}-\pi^{*}\right)+d_{t}
$$

$$
d_{t+1}=\lambda_{d} d_{t}+\rho_{t+1}^{d} \text { where } \rho_{t+1}^{d} \sim N\left(0, \sigma_{d}\right) .
$$

(29b) does not mean the central bank uses a randomized strategy. Rather, $d_{t}$ is ex-ante unknown to 
the markets and reflects the public's uncertainty about the future rule. "Discretion" $d_{t}$ also includes the bank's unknown reaction to unexpected shocks such as an oil shock, an international crisis etc. Agents know (29a)-(29b) but disagree at each $t$ about the distribution of $d_{t+1}$ and this opens the door for market's beliefs about $d_{t+1}$ to impact the efficacy of the policy. That is, when the policy contains a discretionary "surprise," diverse beliefs about future surprises are rationalizable. We show that policy outcomes are altered by such effects, offering risks and opportunities to bank's policy.

The introduction of $d_{t}$ generates a new policy model but it is mathematically the same as the model in (16) and (25). Formally $d_{t}$ replaces $\varrho_{t}$, but with fundamentally different model implications. Without rewriting (16) and (25) note that the applicable parameters $\left(\lambda_{\varrho}, \sigma_{\varrho}, \lambda_{\mathrm{g}}^{\varrho}, \lambda_{\varrho}^{\mathrm{z}}\right)$ are replaced by $\left(\lambda_{\mathrm{d}}, \sigma_{\mathrm{d}}, \lambda_{\mathrm{g}}^{\mathrm{d}}, \lambda_{\mathrm{d}}^{\mathrm{z}}\right)$. Consider first $\left(\lambda_{\mathrm{d}}, \sigma_{\mathrm{d}}\right)$. McCallum and Nelson (1999) study a rule with a random term and estimate $\sigma_{\mathrm{d}}=0.0017$ but allow lagged variables and inertia in the rule. We assume $\pi^{*}=1 \%$ per quarter hence we postulate $\sigma_{\mathrm{d}}=0.0025$ in order to study a discretion with standard deviation of 25 basis points. Rudebusch (2002) argues policy inertia is inconsistent with lack of predictability of changes in short rate and suggests that measured inertia arises from persistence in discretion. This is expressed by $\lambda_{d}>0$ and we study the hypothetical case of $\lambda_{d}=0.50$. Variations in these parameters have small effects and do not alter our qualitative conclusions. The parameters $\left(\lambda_{\mathrm{g}}^{\mathrm{d}}, \lambda_{\mathrm{d}}^{\mathrm{z}}\right)$ describe beliefs about discretion and before discussing the issues they raise, we first interpret them: $\lambda_{\mathrm{g}}^{\mathrm{d}}$ - effect of an agent belief state on his forecasted central bank discretionary decisions. $\lambda_{d}^{z}$ - the effect of a bank's discretionary surprise on revision of agent's forecasted market state of belief.

It is obvious discretion introduces a random shock into the market and this, by itself, increases volatility. The main issue is how the added volatility interacts with market beliefs since the presence of a random discretionary component triggers diverse beliefs, at any date $\mathrm{t}$, about abnormal future rates. The range of values which $\left(\lambda_{\mathrm{g}}^{\mathrm{d}}, \lambda_{\mathrm{d}}^{\mathrm{z}}\right)$ can feasibly take describes those rationalizable beliefs which may exist in the market when a discretionary element is present in the policy rule.

Now, the parameter $\lambda_{\mathrm{g}}^{\mathrm{d}}$ reflects how an agent's belief about future high productivity and return on investments translates into expectations about the bank's discretionary decisions. If $\lambda_{\mathrm{g}}^{\mathrm{d}}>0$ an agent who believes in abnormally high future productivity growth also believes the central bank is likely to induce a positive discretionary increase of rates above the mean in (29a). If $\lambda_{\mathrm{g}}^{\mathrm{d}}<0$ the opposite is true: an agent who is bullish about high future return on investments also believes the central bank is likely to induce an abnormal discretionary decrease of rates to accommodate liquidity needs of a high investment 
economy. It turns out that both cases are rationalizable with the RBE rationality principle, but within a very narrow feasible range of $-0.0008<\lambda_{\mathrm{g}}^{\mathrm{d}}<0.0008$. In the policy experiments below we study the impact of such market beliefs on the volatility of the economy. We also discuss the desirability of abandoning discretion altogether in favor of fully transparent policy rules.

What about the second parameter $\lambda_{d}^{\mathrm{z}}$ ? Since $\mathrm{d}_{\mathrm{t}}$ is an unexpected shock, it turns out that the parameter $\lambda_{d}^{z}$ has a small effect on volatility which is also not systematic. Hence we ignore it by setting $\lambda_{d}^{z}=0$. We thus study below two hypothetical economies with very modest parameter values of

$$
\begin{aligned}
& \text { Economy I : } \lambda_{\mathrm{d}}^{\mathrm{z}}=0.00, \lambda_{\mathrm{g}}^{\mathrm{d}}=-0.0006 \\
& \text { Economy II : } \lambda_{\mathrm{d}}^{\mathrm{z}}=0.00, \lambda_{\mathrm{g}}^{\mathrm{d}}=0.0006 .
\end{aligned}
$$

Why could the discussed effects of market expectations be useful and what is the empirical evidence in favor of Economy type I vs. type II? To explain these issues we start with a simple general principle which can be stated as follows:

Policy Principle: The efficacy of a monetary policy increases if public expectations are compatible and supportive of the policy goals. With such additional wind in the policy's sails, the same policy goals can be attained with less aggressive instruments relative to an economy in which market expectations go against the policy and render it less effective.

To illustrate how this principle works consider a state when, due to their optimism, agents increase planned consumption and investments conditional on the policy in place. Agents can forecast the bank's normal interest rate using (29a) but what about the bank's discretion? If they expect bank's discretion to accommodate the liquidity needs of an expected abnormal burst of productivity and investments, they would expect the bank to lower the nominal rate (i.e. $d_{t+1}<0$ ). This means $\lambda_{g}^{d}<0$ : when optimistic, agents expect the central bank to accommodate the implied liquidity needs of an abnormally high growth and high investment boom. Now consider the opposite. If agents expect bank's discretion to resist abnormal bursts of productivity and investments, they would expect the bank to raise the nominal rate (i.e. $d_{t+1}>0$ ). This means $\lambda_{g}^{d}>0$ : when optimistic, agents expect the central bank to resist the abnormal growth and investments by raising rates.

We observe that both patterns of behavior are rationalizable. Also, any structure of rationalized beliefs reflects social norms which are established over time under dynamics which is outside the scope of our analysis. However, we show below that for all policy instruments Economy $I$ with $\lambda_{\mathrm{g}}^{\mathrm{d}}<0$ is more volatile than Economy II with $\lambda_{\mathrm{g}}^{\mathrm{d}}>0$. In terms of the above policy principle, this means that when $\lambda_{\mathrm{g}}^{\mathrm{d}}<0$ 
private expectations in Economy I operate against the policy goals resulting in reduced efficacy of policy in Economy I relative to Economy II. Similarly, in Economy II private expectations are aligned with the

policy goals hence they bolster and support them. Since behavior under $\lambda_{g}^{d}>0$ bolsters policy, the central bank prefers private expectations to have the structure in Economy II. However, the bank does not choose the pattern of market beliefs; the bank's only choice is whether to use discretion and this choice should be influenced by the empirical evidence regarding the structure of private expectations. We discuss this choice later, after examining the simulation results.

\section{3a Policy Rules with Discretion: Economy I}

In Table 5 we report results of policy experiments for Economy I. The results show that a central bank's decision whether to use discretion or employ full transparency in the policy rule has effects on market volatility. There are three very clear conclusions which emerge from the table:

(i) For non activist policies with $\mathrm{v}_{\mathrm{y}}=0$ central bank's discretion causes a dramatic rise in the volatility of inflation due to the random discretionary element which is not present in Table 3. This rise in volatility is not generated by the structure of market beliefs.

(ii) For all policy instruments the volatility of real variables is higher in Table 5 under central bank's discretion than in Table 3 without discretion. This rise in volatility is not dramatic but could add as much as $5 \%$ to the long term volatility of consumption. It follows that the belief structure in Economy I works against the policy goals: for any configuration of instruments, central bank discretion increases the volatility of real variables.

(iii) The effect of bank's discretion on volatility falls sharply as stabilization policy becomes more aggressive.

We make two additional observations:

(i) The pattern of non monotonic effects of policy instruments and the effect of policy instruments on the estimated Phillips Curves are the same as in Table 3 and are not be repeated here.

(ii) The very strong policy $\mathrm{v}_{\pi}=\infty$ results in exactly the same volatility in all three cases of Table 3 , Table 5 and Table 6 showing that aggressive anti inflationary policy can neutralize all effects of discretion. We also note that under $\mathrm{v}_{\pi}=\infty$ the level of volatility is virtually the same as in the reference RBE economy except that the volatility of inflation is reduced to 0 . 
Table 5: Volatility Increasing Discretion

(percent, all data H-P filtered)

\begin{tabular}{|c|c|c|c|c|c|c|c|c|c|c|c|}
\hline $\mathrm{v}_{\pi}$ & $\mathrm{v}_{\mathrm{y}} \rightarrow$ & 0 & 0.1 & 0.2 & 0.3 & 0.4 & 0.5 & 0.7 & 0.9 & 1.0 & 5.0 \\
\hline 1.1 & $\begin{array}{c}\mathrm{Y} \\
\mathrm{I} \\
\mathrm{C} \\
\pi \\
\rho(\pi, \mathrm{Y})\end{array}$ & $\begin{array}{l}1.83 \\
5.44 \\
1.04 \\
2.13 \\
0.19\end{array}$ & $\begin{array}{r}1.72 \\
4.91 \\
0.84 \\
4.36 \\
-0.54\end{array}$ & $\begin{array}{r}1.63 \\
4.57 \\
0.67 \\
9.28 \\
-0.61\end{array}$ & $\begin{array}{r}1.56 \\
4.46 \\
0.54 \\
14.29 \\
-0.68\end{array}$ & $\begin{array}{r}1.50 \\
4.59 \\
0.47 \\
19.29 \\
-0.74\end{array}$ & $\begin{array}{r}1.45 \\
4.94 \\
0.50 \\
24.25 \\
-0.80\end{array}$ & $\begin{array}{r}1.42 \\
6.07 \\
0.77 \\
34.05 \\
-0.90\end{array}$ & $\begin{array}{r}1.47 \\
7.53 \\
1.15 \\
43.70 \\
-0.96\end{array}$ & $\begin{array}{r}1.52 \\
8.31 \\
1.35 \\
48.48 \\
-0.98\end{array}$ & unstable \\
\hline 1.2 & $\begin{array}{c}\mathrm{Y} \\
\mathrm{I} \\
\mathrm{C} \\
\pi \\
\rho(\pi, \mathrm{Y})\end{array}$ & $\begin{array}{l}1.83 \\
5.44 \\
1.04 \\
1.78 \\
0.18\end{array}$ & $\begin{array}{l}1.77 \\
5.11 \\
0.92 \\
2.49 \\
-0.53\end{array}$ & $\begin{array}{r}1.71 \\
4.85 \\
0.82 \\
5.10 \\
-0.61\end{array}$ & $\begin{array}{r}1.66 \\
4.65 \\
0.72 \\
7.88 \\
-0.65\end{array}$ & $\begin{array}{r}1.61 \\
4.52 \\
0.63 \\
10.68 \\
-0.68\end{array}$ & $\begin{array}{r}1.57 \\
4.47 \\
0.56 \\
13.47 \\
-0.71\end{array}$ & $\begin{array}{r}1.50 \\
4.57 \\
0.47 \\
19.00 \\
-0.77\end{array}$ & $\begin{array}{r}1.45 \\
4.93 \\
0.50 \\
24.46 \\
-0.82\end{array}$ & $\begin{array}{r}1.44 \\
5.18 \\
0.55 \\
27.15 \\
-0.85\end{array}$ & unstable \\
\hline 1.3 & $\begin{array}{c}\mathrm{Y} \\
\mathrm{I} \\
\mathrm{C} \\
\pi \\
\rho(\pi, \mathrm{Y})\end{array}$ & $\begin{array}{l}1.83 \\
5.43 \\
1.04 \\
1.53 \\
0.17\end{array}$ & $\begin{array}{l}1.78 \\
5.19 \\
0.95 \\
1.83 \\
-0.53\end{array}$ & $\begin{array}{r}1.74 \\
4.98 \\
0.87 \\
3.55 \\
-0.64\end{array}$ & $\begin{array}{c}1.70 \\
4.81 \\
0.80 \\
5.47 \\
-0.66\end{array}$ & $\begin{array}{r}1.67 \\
4.67 \\
0.73 \\
7.41 \\
-0.68\end{array}$ & $\begin{array}{r}1.63 \\
4.56 \\
0.66 \\
9.36 \\
-0.70\end{array}$ & $\begin{array}{r}1.57 \\
4.47 \\
0.56 \\
13.22 \\
-0.74\end{array}$ & $\begin{array}{r}1.52 \\
4.51 \\
0.49 \\
17.04 \\
-0.77\end{array}$ & $\begin{array}{r}1.50 \\
4.58 \\
0.47 \\
18.93 \\
-0.79\end{array}$ & unstable \\
\hline 1.4 & $\begin{array}{c}\mathrm{Y} \\
\mathrm{I} \\
\mathrm{C} \\
\pi \\
\rho(\pi, \mathrm{Y})\end{array}$ & $\begin{array}{l}1.83 \\
5.43 \\
1.03 \\
1.34 \\
0.16\end{array}$ & $\begin{array}{l}1.79 \\
5.23 \\
0.97 \\
1.49 \\
-0.53\end{array}$ & $\begin{array}{c}1.76 \\
5.06 \\
0.90 \\
2.75 \\
-0.66\end{array}$ & $\begin{array}{l}1.72 \\
4.90 \\
0.84 \\
4.21 \\
-0.69\end{array}$ & $\begin{array}{l}1.69 \\
4.77 \\
0.78 \\
5.70 \\
-0.7\end{array}$ & $\begin{array}{r}1.66 \\
4.66 \\
0.73 \\
7.19 \\
-0.71\end{array}$ & $\begin{array}{r}1.61 \\
4.52 \\
0.63 \\
10.17 \\
-0.74\end{array}$ & $\begin{array}{r}1.57 \\
4.47 \\
0.55 \\
13.11 \\
-0.77\end{array}$ & $\begin{array}{r}1.55 \\
4.47 \\
0.52 \\
14.57 \\
-0.78\end{array}$ & unstable \\
\hline 1.5 & $\begin{array}{c}\mathrm{Y} \\
\mathrm{I} \\
\mathrm{C} \\
\pi \\
\rho(\pi, \mathrm{Y})\end{array}$ & $\begin{array}{l}1.83 \\
5.43 \\
1.03 \\
1.19 \\
0.16\end{array}$ & $\begin{array}{r}1.79 \\
5.25 \\
0.97 \\
1.28 \\
-0.52\end{array}$ & $\begin{array}{r}1.76 \\
5.10 \\
0.92 \\
2.26 \\
-0.68\end{array}$ & $\begin{array}{r}1.74 \\
4.96 \\
0.87 \\
3.43 \\
-0.71\end{array}$ & $\begin{array}{r}1.71 \\
4.84 \\
0.82 \\
4.64 \\
-0.72\end{array}$ & $\begin{array}{r}1.68 \\
4.74 \\
0.77 \\
5.85 \\
-0.73\end{array}$ & $\begin{array}{r}1.64 \\
4.58 \\
0.68 \\
8.28 \\
-0.75\end{array}$ & $\begin{array}{r}1.60 \\
4.49 \\
0.60 \\
10.68 \\
-0.77\end{array}$ & $\begin{array}{r}1.58 \\
4.47 \\
0.57 \\
11.87 \\
-0.78\end{array}$ & unstable \\
\hline 10 & $\begin{array}{c}\mathrm{Y} \\
\mathrm{I} \\
\mathrm{C} \\
\pi \\
\rho(\pi, \mathrm{Y})\end{array}$ & $\begin{array}{l}1.80 \\
5.31 \\
1.00 \\
0.11 \\
0.11\end{array}$ & $\begin{array}{r}1.80 \\
5.28 \\
0.98 \\
0.12 \\
-0.52\end{array}$ & $\begin{array}{r}1.79 \\
5.25 \\
0.97 \\
0.18 \\
-0.80\end{array}$ & $\begin{array}{r}1.79 \\
5.22 \\
0.96 \\
0.24 \\
-0.90\end{array}$ & $\begin{array}{r}1.78 \\
5.19 \\
0.95 \\
0.31 \\
-0.94\end{array}$ & $\begin{array}{r}1.77 \\
5.15 \\
0.94 \\
0.39 \\
-0.96\end{array}$ & $\begin{array}{r}1.76 \\
5.10 \\
0.92 \\
0.53 \\
-0.97\end{array}$ & $\begin{array}{r}1.75 \\
5.04 \\
0.90 \\
0.68 \\
-0.98\end{array}$ & $\begin{array}{r}1.75 \\
5.02 \\
0.89 \\
0.75 \\
-0.98\end{array}$ & $\begin{array}{r}1.60 \\
4.50 \\
0.61 \\
3.54 \\
-0.99\end{array}$ \\
\hline$\infty$ & $\begin{array}{c}\mathrm{Y} \\
\mathrm{I} \\
\mathrm{C} \\
\pi \\
\rho(\pi, \mathrm{Y})\end{array}$ & $\begin{array}{c}1.80 \\
5.28 \\
0.98 \\
0.00 \\
\text { na }\end{array}$ & $\begin{array}{c}1.80 \\
5.28 \\
0.98 \\
0.00 \\
\text { na }\end{array}$ & $\begin{array}{c}1.80 \\
5.28 \\
0.98 \\
0.00 \\
\text { na }\end{array}$ & $\begin{array}{c}1.80 \\
5.28 \\
0.98 \\
0.00 \\
\text { na }\end{array}$ & $\begin{array}{c}1.80 \\
5.28 \\
0.98 \\
0.00 \\
\text { na }\end{array}$ & $\begin{array}{c}1.80 \\
5.28 \\
0.98 \\
0.00 \\
\text { na }\end{array}$ & $\begin{array}{c}1.80 \\
5.28 \\
0.98 \\
0.00 \\
\text { na }\end{array}$ & $\begin{array}{c}1.80 \\
5.28 \\
0.98 \\
0.00 \\
\text { na }\end{array}$ & $\begin{array}{c}1.80 \\
5.28 \\
0.98 \\
0.00 \\
\text { na }\end{array}$ & $\begin{array}{c}1.80 \\
5.28 \\
0.98 \\
0.00 \\
\text { na }\end{array}$ \\
\hline
\end{tabular}

\section{3b Policy Rules with Discretion: Economy II}

Table 6 reports results of policy experiments with a specifications of Economy II. Clearly, all volatility measures in Table 6 are lower than in Table 5, hence the structure of beliefs in Economy II works in support of the policy goals. We conclude that if the central bank must use discretion, then the belief structure of Economy II bolsters the policy while the belief structure in Economy I diminishes the efficacy of policy. Table 6 reveals results which are analogous to those reported for Table 5: (i) big rise in inflation volatility for non activist policies with $\mathrm{v}_{\mathrm{y}}=0$; (ii) discretion, as such, increases volatility while the belief structure $\left(\lambda_{g}^{d}>0\right)$ reduces it, implying lower real volatility for most efficient policies relative to the non discretionary case in Table 3; (iii) aggressive stabilization instruments can suppress the negative impact of bank's discretion. Also, the non monotonic effect of policy instruments and the 
effect of policy instruments on the estimated Phillips Curves in Table 6 are the same as in Table 3.

Table 6: Volatility Decreasing Discretion

(percent, all data H-P filtered)

\begin{tabular}{|c|c|c|c|c|c|c|c|c|c|c|c|}
\hline $\mathrm{v}_{\pi}$ & $\mathrm{v}_{\mathrm{y}} \rightarrow$ & 0 & 0.1 & 0.2 & 0.3 & 0.4 & 0.5 & 0.7 & 0.9 & 1.0 & 5.0 \\
\hline 1.1 & $\begin{array}{c}\mathrm{Y} \\
\mathrm{I} \\
\mathrm{C} \\
\pi \\
\rho(\pi, Y)\end{array}$ & $\begin{array}{c}1.76 \\
5.10 \\
0.92 \\
1.75 \\
-0.00\end{array}$ & $\begin{array}{c}1.67 \\
4.68 \\
0.74 \\
5.80 \\
-0.53\end{array}$ & $\begin{array}{c}1.59 \\
4.48 \\
0.58 \\
10.79 \\
-0.62\end{array}$ & $\begin{array}{c}1.52 \\
4.51 \\
0.48 \\
15.80 \\
-0.70\end{array}$ & $\begin{array}{c}1.47 \\
4.78 \\
0.48 \\
20.78 \\
-0.77\end{array}$ & $\begin{array}{c}1.44 \\
5.23 \\
0.56 \\
25.73 \\
-0.83\end{array}$ & $\begin{array}{c}1.43 \\
6.50 \\
0.88 \\
35.51 \\
-0.93\end{array}$ & $\begin{array}{c}1.50 \\
8.01 \\
1.27 \\
45.14 \\
-0.97\end{array}$ & $\begin{array}{r}1.56 \\
8.81 \\
1.47 \\
49.90 \\
-0.98\end{array}$ & unstable \\
\hline 1.2 & $\begin{array}{c}\mathrm{Y} \\
\mathrm{I} \\
\mathrm{C} \\
\pi \\
\rho(\pi, \mathrm{Y})\end{array}$ & $\begin{array}{l}1.76 \\
5.10 \\
0.92 \\
1.50 \\
-0.01\end{array}$ & $\begin{array}{r}1.71 \\
4.83 \\
0.81 \\
3.55 \\
-0.51\end{array}$ & $\begin{array}{c}1.66 \\
4.64 \\
0.71 \\
6.29 \\
-0.60\end{array}$ & $\begin{array}{c}1.61 \\
4.51 \\
0.62 \\
9.09 \\
-0.64\end{array}$ & $\begin{array}{c}1.57 \\
4.47 \\
0.55 \\
11.89 \\
-0.69\end{array}$ & $\begin{array}{c}1.53 \\
4.49 \\
0.50 \\
14.67 \\
-0.72\end{array}$ & $\begin{array}{c}1.47 \\
4.74 \\
0.47 \\
20.18 \\
-0.79\end{array}$ & $\begin{array}{r}1.44 \\
5.21 \\
0.56 \\
25.61 \\
-0.85\end{array}$ & $\begin{array}{c}1.43 \\
5.50 \\
0.62 \\
28.30 \\
-0.87\end{array}$ & unstable \\
\hline 1.3 & $\begin{array}{c}\mathrm{Y} \\
\mathrm{I} \\
\mathrm{C} \\
\pi \\
\rho(\pi, \mathrm{Y})\end{array}$ & $\begin{array}{c}1.76 \\
5.10 \\
0.92 \\
1.31 \\
-0.015\end{array}$ & $\begin{array}{l}1.72 \\
4.90 \\
0.84 \\
2.64 \\
-0.5\end{array}$ & $\begin{array}{c}1.68 \\
4.74 \\
0.77 \\
4.51 \\
-0.60\end{array}$ & $\begin{array}{c}1.65 \\
4.62 \\
0.70 \\
6.45 \\
-0.64\end{array}$ & $\begin{array}{c}1.62 \\
4.53 \\
0.64 \\
8.40 \\
-0.68\end{array}$ & $\begin{array}{c}1.59 \\
4.48 \\
0.58 \\
10.34 \\
-0.70\end{array}$ & $\begin{array}{c}1.53 \\
4.49 \\
0.50 \\
14.19 \\
-0.75\end{array}$ & $\begin{array}{c}1.49 \\
4.63 \\
0.47 \\
17.99 \\
-0.79\end{array}$ & $\begin{array}{c}1.47 \\
4.74 \\
0.47 \\
19.87 \\
-0.81\end{array}$ & unstable \\
\hline 1.4 & $\begin{array}{c}\mathrm{Y} \\
\mathrm{I} \\
\mathrm{C} \\
\pi \\
\rho(\pi, \mathrm{Y})\end{array}$ & $\begin{array}{r}1.76 \\
5.10 \\
0.92 \\
1.16 \\
-0.02\end{array}$ & $\begin{array}{l}1.73 \\
4.94 \\
0.86 \\
2.13 \\
-0.5\end{array}$ & $\begin{array}{c}1.70 \\
4.80 \\
0.80 \\
3.54 \\
-0.61\end{array}$ & $\begin{array}{c}1.67 \\
4.68 \\
0.74 \\
5.02 \\
-0.66\end{array}$ & $\begin{array}{c}1.64 \\
4.60 \\
0.69 \\
6.52 \\
-0.68\end{array}$ & $\begin{array}{l}1.62 \\
4.53 \\
0.64 \\
8.01 \\
-0.71\end{array}$ & $\begin{array}{c}1.57 \\
4.47 \\
0.56 \\
10.98 \\
-0.74\end{array}$ & $\begin{array}{c}1.53 \\
4.49 \\
0.50 \\
13.91 \\
-0.78\end{array}$ & $\begin{array}{c}1.51 \\
4.53 \\
0.48 \\
15.36 \\
-0.79\end{array}$ & unstable \\
\hline 1.5 & $\begin{array}{c}\mathrm{Y} \\
\mathrm{I} \\
\mathrm{C} \\
\pi \\
\rho(\pi, Y)\end{array}$ & $\begin{array}{l}1.77 \\
5.10 \\
0.92 \\
1.04 \\
-0.02\end{array}$ & $\begin{array}{c}1.74 \\
4.96 \\
0.86 \\
1.79 \\
-0.51\end{array}$ & $\begin{array}{l}1.71 \\
4.84 \\
0.81 \\
2.92 \\
-0.62\end{array}$ & $\begin{array}{l}1.68 \\
4.73 \\
0.76 \\
4.12 \\
-0.67\end{array}$ & $\begin{array}{l}1.66 \\
4.65 \\
0.72 \\
5.33 \\
-0.7\end{array}$ & $\begin{array}{c}1.64 \\
4.58 \\
0.68 \\
6.55 \\
-0.72\end{array}$ & $\begin{array}{r}1.59 \\
4.49 \\
0.60 \\
8.96 \\
-0.75\end{array}$ & $\begin{array}{c}1.56 \\
4.46 \\
0.54 \\
11.35 \\
-0.78\end{array}$ & $\begin{array}{c}1.54 \\
4.47 \\
0.51 \\
12.53 \\
-0.79\end{array}$ & unstable \\
\hline 10 & $\begin{array}{c}\mathrm{Y} \\
\mathrm{I} \\
\mathrm{C} \\
\pi \\
\rho(\pi, Y)\end{array}$ & $\begin{array}{l}1.79 \\
5.23 \\
0.97 \\
0.11 \\
0.06\end{array}$ & $\begin{array}{r}1.78 \\
5.20 \\
0.95 \\
0.13 \\
-0.55\end{array}$ & $\begin{array}{c}1.78 \\
5.17 \\
0.94 \\
0.18 \\
-0.81\end{array}$ & $\begin{array}{c}1.77 \\
5.14 \\
0.93 \\
0.25 \\
-0.89\end{array}$ & $\begin{array}{c}1.77 \\
5.10 \\
0.92 \\
0.32 \\
-0.93\end{array}$ & $\begin{array}{l}1.76 \\
5.08 \\
0.91 \\
0.39 \\
-0.95\end{array}$ & $\begin{array}{c}1.75 \\
5.02 \\
0.89 \\
0.54 \\
-0.97\end{array}$ & $\begin{array}{l}1.74 \\
4.97 \\
0.87 \\
0.69 \\
-0.97\end{array}$ & $\begin{array}{c}1.73 \\
4.95 \\
0.86 \\
0.76 \\
-0.98\end{array}$ & $\begin{array}{r}1.59 \\
4.48 \\
0.59 \\
3.54 \\
-0.99\end{array}$ \\
\hline$\infty$ & $\begin{array}{c}\mathrm{Y} \\
\mathrm{I} \\
\mathrm{C} \\
\pi \\
\rho(\pi, \mathrm{Y})\end{array}$ & $\begin{array}{c}1.80 \\
5.28 \\
0.98 \\
0.00 \\
\text { na }\end{array}$ & $\begin{array}{c}1.80 \\
5.28 \\
0.98 \\
0.00 \\
\text { na }\end{array}$ & $\begin{array}{c}1.80 \\
5.28 \\
0.98 \\
0.00 \\
\text { na }\end{array}$ & $\begin{array}{c}1.80 \\
5.28 \\
0.98 \\
0.00 \\
\text { na }\end{array}$ & $\begin{array}{c}1.80 \\
5.28 \\
0.98 \\
0.00 \\
\text { na }\end{array}$ & $\begin{array}{c}1.80 \\
5.28 \\
0.98 \\
0.00 \\
\text { na }\end{array}$ & $\begin{array}{c}1.80 \\
5.28 \\
0.98 \\
0.01 \\
\text { na }\end{array}$ & $\begin{array}{c}1.80 \\
5.28 \\
0.98 \\
0.01 \\
\text { na }\end{array}$ & $\begin{array}{c}1.80 \\
5.28 \\
0.98 \\
0.01 \\
\text { na }\end{array}$ & $\begin{array}{c}1.80 \\
5.28 \\
0.98 \\
0.00 \\
\text { na }\end{array}$ \\
\hline
\end{tabular}

The beliefs patterns in Economies I and II are both rationalizable, but which of the two better

reflects the empirical record? We do not have conclusive evidence but the recent experience of the period 1996 - 2001 provides a hint. During that time, the economy experienced very high growth rate above normal and most private sector observers demanded and predicted the central bank will follow a low discretionary interest rate policy, accommodating the liquidity needs of an abnormally high growth economy. This implies an expectations parameter $\lambda_{\mathrm{g}}^{\mathrm{d}}<0$ of Economy I, proposing it to be the norm hence the qualitative results of Table 5 may be more likely to be the correct ones relative to Table 6.

We add that during the 1996-2003 episode the Fed actually executed a discretionary component of low interest policy which contributed to the intense investment boom of 1996-1999. Claiming to detect a structural break into a regime of high and persistent productivity growth, the Fed maintained 
low interest rates up to very late in June of 1999 when it began to raise rates. Late in 2000 it became evident the over-heated investment boom was weakening and in January 2001 the Fed drastically reversed course starting a historical reduction of the fund's rate during 2001. Evidence in support of the Fed's claim of a structural break into high productivity regime is limited. Our theory proposes that had the Fed followed a non discretionary policy it would have raised rates earlier, slowing early the economy's excess. The resulting level of real and financial volatility in 1996-2003 would have been lower. The Fed's discretionary "judgment" contributed to the actual volatility during this time.

Should discretion be practices by a central bank? There are unique circumstances like a war, an imminent collapse of a major financial institution when discretion has obvious social benefits not in our model. However, recognizing that discretion is costly, our theory leads to several conclusions:

(i) If a bank follows a mild, non activist anti inflation policy such as $\left(\mathrm{v}_{\pi} \leq 1.5, \mathrm{v}_{\mathrm{y}}=0\right)$ then the effects of discretion on inflation volatility are large and in this case a central bank should abandon discretion altogether.

(ii) If a bank follows a strong stabilization policy such as $\left(\mathrm{v}_{\pi}>1.5, \mathrm{v}_{\mathrm{y}}>0.3\right)$ then the effects of discretion are small and in practice may be disregarded. Discretion has very low cost.

(iii) In most intermediate cases discretion has significant cost which depend upon the structure of market expectations. Discretion may be a desirable feature of the policy rule if the belief structure of agents is in accord with Economy II. The limited evidence does not support this case and suggests that in that case discretion should be avoided.

Notwithstanding the above, we note that a central bank does not have better information or superior ability to make economic judgments than the private sector. Hence, the real social gain from discretion can arise only in those unequivocal catastrophic circumstances when there is no objection to a central bank's discretion. As a result, the weight of the argument supports the conclusion that central bank policy should be transparent and should abandon discretion except for most unusual circumstances.

\section{$5.4 \quad$ On Inertia and Inflation Volatility}

All policy rules studied up to now implied extremely high equilibrium volatility of inflation. While recorded inflation volatility is around $2 \%$ our models predict much higher, counterfactual, levels of inflation volatility induced by any activist policy rule. This problem is resolved by the introduction of 
inertia into the policy rule. We thus consider the rule

$$
\log \frac{1+r_{t}}{1+r^{*}}=v_{y} \log \left(\frac{y_{t}}{y^{*}}\right)+v_{\pi}\left(\pi_{t}-\pi^{*}\right)+\alpha\left[\log \frac{1+r_{t-1}}{1+r^{*}}\right]
$$

The available econometric estimates for $\alpha$ are around 0.8 and this is the value we us. We have then computed the RBE under the general policy rule (30) with inertia but without discretion.

Table 7: Monetary Rules with Inertia: $\alpha=0.80$, No Discretion

\begin{tabular}{|c|c|c|c|c|c|c|c|c|c|c|c|}
\hline $\mathrm{v}_{\pi}$ & $\mathrm{v}_{\mathrm{y}} \rightarrow$ & 0 & 0.1 & 0.2 & 0.3 & 0.4 & 0.5 & 0.7 & 0.9 & 1.0 & 5.0 \\
\hline 1.1 & $\begin{array}{c}\mathrm{Y} \\
\mathrm{I} \\
\mathrm{C} \\
\pi \\
\rho(\pi, \mathrm{Y})\end{array}$ & $\begin{array}{r}1.79 \\
5.26 \\
0.98 \\
0.08 \\
-0.44\end{array}$ & $\begin{array}{r}1.76 \\
5.07 \\
0.91 \\
0.71 \\
-0.49\end{array}$ & $\begin{array}{r}1.72 \\
4.91 \\
0.84 \\
1.47 \\
-0.46\end{array}$ & $\begin{array}{r}1.69 \\
4.77 \\
0.78 \\
2.23 \\
-0.47\end{array}$ & $\begin{array}{r}1.66 \\
4.67 \\
0.73 \\
3.00 \\
-0.47\end{array}$ & $\begin{array}{r}1.64 \\
4.59 \\
0.68 \\
3.77 \\
-0.49\end{array}$ & $\begin{array}{r}1.59 \\
4.49 \\
0.60 \\
5.33 \\
-0.51\end{array}$ & $\begin{array}{r}1.56 \\
4.46 \\
0.53 \\
6.91 \\
-0.54\end{array}$ & $\begin{array}{r}1.54 \\
4.47 \\
0.51 \\
7.70 \\
-0.55\end{array}$ & unstable \\
\hline 1.2 & $\begin{array}{c}\mathrm{Y} \\
\mathrm{I} \\
\mathrm{C} \\
\pi \\
\rho(\pi, \mathrm{Y})\end{array}$ & $\begin{array}{c}1.79 \\
5.26 \\
0.98 \\
0.08 \\
-0.44\end{array}$ & $\begin{array}{c}1.76 \\
5.08 \\
0.91 \\
0.62 \\
-0.55\end{array}$ & $\begin{array}{l}1.73 \\
4.93 \\
0.85 \\
1.28 \\
-0.52\end{array}$ & $\begin{array}{c}1.70 \\
4.80 \\
0.80 \\
1.94 \\
-0.52\end{array}$ & $\begin{array}{l}1.67 \\
4.70 \\
0.75 \\
2.61 \\
-0.52\end{array}$ & $\begin{array}{c}1.65 \\
4.62 \\
0.70 \\
3.28 \\
-0.53\end{array}$ & $\begin{array}{c}1.61 \\
4.51 \\
0.62 \\
4.64 \\
-0.55\end{array}$ & $\begin{array}{c}1.57 \\
4.47 \\
0.56 \\
6.01 \\
-0.57\end{array}$ & $\begin{array}{c}1.56 \\
4.46 \\
0.53 \\
6.70 \\
-0.58\end{array}$ & unstable \\
\hline 1.3 & $\begin{array}{c}\mathrm{Y} \\
\mathrm{I} \\
\mathrm{C} \\
\pi \\
\rho(\pi, \mathrm{Y})\end{array}$ & $\begin{array}{c}1.79 \\
5.26 \\
0.98 \\
0.07 \\
-0.45\end{array}$ & $\begin{array}{l}1.76 \\
5.09 \\
0.92 \\
0.55 \\
-0.6\end{array}$ & $\begin{array}{l}1.73 \\
4.95 \\
0.86 \\
1.13 \\
-0.57\end{array}$ & $\begin{array}{c}1.71 \\
4.83 \\
0.81 \\
1.72 \\
-0.56\end{array}$ & $\begin{array}{l}1.68 \\
4.73 \\
0.76 \\
2.31 \\
-0.56\end{array}$ & $\begin{array}{l}1.66 \\
4.65 \\
0.72 \\
2.91 \\
-0.57\end{array}$ & $\begin{array}{c}1.62 \\
4.53 \\
0.64 \\
4.10 \\
-0.58\end{array}$ & $\begin{array}{l}1.58 \\
4.48 \\
0.58 \\
5.31 \\
-0.6\end{array}$ & $\begin{array}{c}1.57 \\
4.47 \\
0.55 \\
5.91 \\
-0.61\end{array}$ & unstable \\
\hline 1.4 & $\begin{array}{c}\mathrm{Y} \\
\mathrm{I} \\
\mathrm{C} \\
\pi \\
\rho(\pi, \mathrm{Y})\end{array}$ & $\begin{array}{c}1.79 \\
5.26 \\
0.98 \\
0.07 \\
-0.45\end{array}$ & $\begin{array}{c}1.77 \\
5.10 \\
0.92 \\
0.49 \\
-0.65\end{array}$ & $\begin{array}{l}1.74 \\
4.97 \\
0.87 \\
1.02 \\
-0.61\end{array}$ & $\begin{array}{l}1.71 \\
4.86 \\
0.82 \\
1.54 \\
-0.6\end{array}$ & $\begin{array}{l}1.69 \\
4.76 \\
0.78 \\
2.07 \\
-0.6\end{array}$ & $\begin{array}{l}1.67 \\
4.68 \\
0.73 \\
2.61 \\
-0.61\end{array}$ & $\begin{array}{c}1.63 \\
4.55 \\
0.66 \\
3.68 \\
-0.62\end{array}$ & $\begin{array}{l}1.59 \\
4.49 \\
0.60 \\
4.75 \\
-0.63\end{array}$ & $\begin{array}{c}1.58 \\
4.47 \\
0.57 \\
5.30 \\
-0.64\end{array}$ & unstable \\
\hline 1.5 & $\begin{array}{c}\mathrm{Y} \\
\mathrm{I} \\
\mathrm{C} \\
\pi \\
\rho(\pi, \mathrm{Y})\end{array}$ & $\begin{array}{c}1.80 \\
5.26 \\
0.98 \\
0.06 \\
-0.45\end{array}$ & $\begin{array}{c}1.77 \\
5.11 \\
0.92 \\
0.45 \\
-0.69\end{array}$ & $\begin{array}{c}1.74 \\
4.99 \\
0.88 \\
0.93 \\
-0.65\end{array}$ & $\begin{array}{c}1.72 \\
4.88 \\
0.83 \\
1.40 \\
-0.64\end{array}$ & $\begin{array}{c}1.69 \\
4.78 \\
0.79 \\
1.88 \\
-0.64\end{array}$ & $\begin{array}{l}1.67 \\
4.70 \\
0.75 \\
2.36 \\
-0.64\end{array}$ & $\begin{array}{c}1.64 \\
4.58 \\
0.68 \\
3.33 \\
-0.65\end{array}$ & $\begin{array}{l}1.60 \\
4.51 \\
0.62 \\
4.31 \\
-0.66\end{array}$ & $\begin{array}{l}1.59 \\
4.48 \\
0.59 \\
4.80 \\
-0.67\end{array}$ & unstable \\
\hline 10 & $\begin{array}{c}\mathrm{Y} \\
\mathrm{I} \\
\mathrm{C} \\
\pi \\
\rho(\pi, \mathrm{Y})\end{array}$ & $\begin{array}{r}1.80 \\
5.27 \\
0.98 \\
0.01 \\
-0.47\end{array}$ & $\begin{array}{r}1.79 \\
5.24 \\
0.97 \\
0.07 \\
-0.99\end{array}$ & $\begin{array}{r}1.79 \\
5.21 \\
0.96 \\
0.14 \\
-0.99\end{array}$ & $\begin{array}{r}1.78 \\
5.17 \\
0.95 \\
0.20 \\
-0.99\end{array}$ & $\begin{array}{r}1.77 \\
5.15 \\
0.94 \\
0.27 \\
-0.99\end{array}$ & $\begin{array}{r}1.77 \\
5.11 \\
0.93 \\
0.33 \\
-0.99\end{array}$ & $\begin{array}{r}1.76 \\
5.06 \\
0.90 \\
0.46 \\
-0.99\end{array}$ & $\begin{array}{r}1.75 \\
5.01 \\
0.88 \\
0.59 \\
-0.99\end{array}$ & $\begin{array}{r}1.74 \\
4.98 \\
0.87 \\
0.66 \\
-0.99\end{array}$ & $\begin{array}{r}1.64 \\
4.58 \\
0.68 \\
3.33 \\
-0.65\end{array}$ \\
\hline$\infty$ & $\begin{array}{c}\mathrm{Y} \\
\mathrm{I} \\
\mathrm{C} \\
\pi \\
\rho(\pi, \mathrm{Y})\end{array}$ & $\begin{array}{c}1.80 \\
5.28 \\
0.98 \\
0.00 \\
\text { na }\end{array}$ & $\begin{array}{c}1.80 \\
5.28 \\
0.98 \\
0.00 \\
\text { na }\end{array}$ & $\begin{array}{c}1.80 \\
5.28 \\
0.98 \\
0.00 \\
\text { na }\end{array}$ & $\begin{array}{c}1.80 \\
5.28 \\
0.98 \\
0.00 \\
\text { na }\end{array}$ & $\begin{array}{c}1.80 \\
5.28 \\
0.98 \\
0.00 \\
\text { na }\end{array}$ & $\begin{array}{c}1.80 \\
5.28 \\
0.98 \\
0.00 \\
\text { na }\end{array}$ & $\begin{array}{c}1.80 \\
5.28 \\
0.98 \\
0.01 \\
\text { na }\end{array}$ & $\begin{array}{c}1.80 \\
5.28 \\
0.98 \\
0.00 \\
\text { na }\end{array}$ & $\begin{array}{c}1.80 \\
5.28 \\
0.93 \\
0.00 \\
\text { na }\end{array}$ & $\begin{array}{c}1.80 \\
5.28 \\
0.98 \\
0.00 \\
\text { na }\end{array}$ \\
\hline
\end{tabular}

In Table 7 we report simulation results for the same policy instruments $v_{\pi}$ and $v_{y}$ as in Table 3 . It is clear from the table that with inertia the volatility level of inflation is drastically reduced and for most efficient policy rules it is less than $2.5 \%$ per quarter, which is compatible with the empirical record. But Table 7, compared with Table 3, reveals some additional and very interesting results.

(i) Feasible stabilization of real variables is reduced under inertia. For activist rules with $\mathrm{v}_{\mathrm{y}} \leq 1$ the 
lowest consumption volatility is around $0.51 \%$ compared to $0.47 \%$ without inertia. For output this minimal volatility is $1.43 \%$ without inertia and $1.54 \%$ with inertia. Under the drastic rule $\mathrm{v}_{\pi}=\infty$ all volatility measures are the same with or without inertia.

(ii) The rule $\mathrm{v}_{\pi}=1.5$ and $\mathrm{v}_{\mathrm{y}}=0.5$ attains more real stability than the constant money rule. With inertia, $\left(\mathrm{v}_{\pi}=1.5, \mathrm{v}_{\mathrm{y}}=0.5\right)$ implies a lower real volatility than volatility under constant money growth but with higher inflation volatility. With $\left(\mathrm{v}_{\pi}=1.5, \mathrm{v}_{\mathrm{y}}=0.5\right)$ we have $\sigma_{\mathrm{Y}}=1.67, \sigma_{\mathrm{I}}=4.70, \sigma_{\mathrm{C}}=0.75$, $\sigma_{\pi}=2.36$ while with Friedman's rule $\sigma_{\mathrm{Y}}=1.75, \sigma_{\mathrm{I}}=5.02, \sigma_{\mathrm{C}}=0.89, \sigma_{\pi}=1.60$.

(iii) Policy rules with inertia generate negative unconditional correlation between inflation and output. In addition, for activist policy rules in Table 7 our analysis shows that statistical Phillips Curves are not present in the data. For activist policies with $v_{y}>0.3$ they are essentially vertical.

\subsection{How Activist is the Current U.S. Policy?}

To answer this question we review two key results which bear on the question at hand.

(i) The reference economy with money shocks replicates well the empirical record, including a statistical Phillips Curve which matches those estimated with U.S. data.

(ii) All economies under a monetary rule can replicate the real empirical record. However, such economies generate data with negative correlation between output and inflation and in which the statistical Phillips Curves are inverted for all activist policy rules with $\mathrm{v}_{\mathrm{y}} \geq 0.4$. But then all activist monetary rules offer more real stabilization than observed in the real data.

Since real data exhibit a statistical Phillips Curve, the policy rules which are compatible with this fact require $\mathrm{v}_{\mathrm{y}} \leq 0.4$. But this seems to contradict the econometric estimates which propose that the policy rule used in the U.S. is around $\mathrm{v}_{\pi}=1.5$ and $\mathrm{v}_{\mathrm{y}}=0.5$ with an inertia parameter around 0.8 . To explore this issue note that such a policy rule, with or without inertia, implies real stabilization which is much stronger (i.e. $\sigma_{\mathrm{Y}}=1.67, \sigma_{\mathrm{I}}=4.70, \sigma_{\mathrm{C}}=0.75$ ) than the volatility of the reference economy or the volatility observed in the U.S. data. In addition, such a rule requires the data to exhibit negative correlation between inflation and output. In all models we examined here $\left(\mathrm{v}_{\pi}=1.5, \mathrm{v}_{\mathrm{y}}=0.5\right)$ is not compatible with the estimated statistical Phillips Curves, implying incorrect slopes. The only conclusion which is not contradicted by the data is that the policy perceived by the markets is less activist. For example, to generate an inflation volatility of about $2 \%$ the policy $\mathrm{v}_{\pi}=1.3$ and $\mathrm{v}_{\mathrm{y}}=0.1$ without 
discretion or inertia generate data which approximate the empirical record, including statistical Phillips Curve. With discretion the policy $\mathrm{v}_{\pi}=1.3$ and $\mathrm{v}_{\mathrm{y}}=0.1$ also approximates the empirical record. With inertia the policy $\mathrm{v}_{\pi}=1.3$ and $\mathrm{v}_{\mathrm{y}}=0.3$ is a reasonable approximation. Since the Fed has not committed to any particular policy rule, the empirical record may also be affected by other factors such as the uncertainty perceived by agents about the rule itself. These issues are not explored here.

\section{Concluding Comments}

The literature on policy rules is so extensive that it is difficult to compare our results with others. The effects of any policy rule depends upon the structural theory explaining why the policy has real effects. Our model is traditional: it assumes perfect competition, flexible prices and symmetric information. The novelty of our theory is that it offers a unified paradigm of economic fluctuations in which heterogeneity of beliefs is the key propagation mechanism. We show most volatility (real and financial) is driven by demand where fluctuations in demand are induced by market states of belief. We show that market beliefs amplify exogenous shocks and propagate business cycles; they generates money non-neutrality; they are responsible for the efficacy of monetary policy and provide the reason why monetary policy should aim at economic stabilization. Our main results are as follows:

- $\quad$ Assuming small technological shocks, our RBE economy replicates well the empirical business cycle record in the U.S. This includes the estimated Phillips Curve from the simulated data of an economy with exogenous money injection shocks.

- $\quad$ Relative to a hypothetical economy in which money supply grows at a random rate, the level of fluctuations would decline by about $4 \%$ - 5\% if money grew at a constant rate.

- $\quad$ Although prices are fully flexible, money shocks result in less than a proportional changes in inflation hence the aggregate price level appears "sticky" with respect to money shocks.

- A monetary rule without discretion and without inertia offers strong stabilization choices between inflation and real volatility. Aggressive anti-inflationary rule can reduce inflation volatility to zero. Significant real stabilization is attainable by either accepting high inflation volatility or by an aggressive inflation stabilization, jointly employed with output stabilization.

- $\quad$ Activist monetary rules generate market data which exhibit no statistical Phillips Curve.

- Discretion in monetary policy has significant impact on volatility. For the two extremes cases we show that if a non activist policy is followed, the effects of discretion on inflation volatility are large and if an aggressive stabilization policy is followed the effects of discretion are small.

- In intermediate cases the effect of discretion depends upon the structure of market beliefs.

- Since real social gain from discretion arise only in extraordinary cases when the gain is obvious, the weight of the argument leads to the conclusion that bank's policy should be transparent and abandon discretion except for most unusual circumstances.

- The main effect of inertia is to reduce dramatically inflation volatility to the observed levels. 


\section{References}

Basu, S. (1996): "Procyclical Productivity: Increasing Returns or Cyclical Utilization?" The Quarterly Journal of Economics, 111 , 719 -751.

Bernanke, B.S., Gertler, M. Gilchrist, S. (1999): "The Financial Accelerator in a Quantitative Business Cycle Framework." In J. Taylor and M. Woodford (eds.) The Handbook of Macroeconomics, Volume 1C. Amsterdam: North-Holland, Chapter 21, 1342 -1385.

Burnside, C., Eichenbaum, M., Rebelo S.T. (1995): "Capital Utilization and Returns to Scale." In: J.J. Rotemberg and B.S. Bernanke, eds. NBER Macroeconomics Annual, Cambridge, MA: MIT Press.

Burnside, C., Eichenbaum, M. (1996): "Factor-Hoarding and the Propagation of Business-Cycle Shocks."American Economic Review 86, 1154- 1174.

Calvo, G. A. (1983): "Staggered Prices in a Utility-Maximizing Framework." Journal of Monetary Economics, 12, 383 - 398.

Camerer, C., Lovallo, D., (1999): "Overconfidence and Excess Entry: An Experimental Approach." American Economic Review, 89, 306 - 318.

Clarida, R., Galí, J., Gertler, M. (1999): "The Science of Monetary Policy: A New Keynesian Perspective." Journal of Economic Literature, 37, 1661 - 1707.

Diamond, P. A. (1967): "Cardinal Welfare, Individualistic Ethics and Interpersonal Comparisons of Utility: A Comment." Journal of Political Economy, 75, 765-766.

Eichenbaum, M. (1991): "Real Business-Cycle Theory, Wisdom or Whimsy?" Journal of Economic Dynamics and Control, 15, 607 - 626.

Fan, M. (2003): "Evolving Term Structure with Heterogenous Beliefs." Manuscript, Department of Economics, Stanford University, August.

Goodfriend, M., King, R.G. (1997) "The New Neoclassical Synthesis and the Role of Monetary Policy." NBER Macroeconomics Annual 12, 231 - 283.

Greenwood, J., Hercowitz, Z., Huffman, G.W. (1988): "Investment, Capacity Utilization, and the Real Business Cycle." American Economic Review 78, 402 - 417.

Hammond, P.J. (1981): "Ex-ante and Ex-post Welfare Optimality Under Uncertainty." Economica 48, $235-250$.

Hammond, P.J. (1983): "Ex-post Optimality as a Dynamically Consistent Objective for Collective Choice Under Uncertainty." In Pattanaik, P.K., Salle, M. (ed.).: Social Choice and Welfare, Chapter 10, 175 - 205, Amsterdam: North Holland.

Jin, H., Judd, K. (2002): " Perturbation Method for General Dynamic Stochastic Models." Stanford University, $\quad$ http://www.stanford.edu/group/site/judd.03.2.pdf

Jin, H. (2003): "PSD - A Perturbation Solver for Dynamic Systems." Stanford University, Department of Economics, http://www.stanford.edu/ jinhehui/psdman.pdf

King, R.G., Rebelo, S.T. (1999): "Resuscitating Real Business Cycles." In J. Taylor and M. Woodford (eds.), Handbook of Macroeconomics, Volume 1B. Amsterdam: North-Holland, Chapter 14, $927-1007$.

Kurz, M. (1994): "On the Structure and Diversity of Rational Beliefs." Economic Theory 4, pp. 877 900 . (An edited version appears as Chapter 2 of Kurz, M. (ed.).: 1997)

Kurz, M. (ed.) (1996): "Symposium: Rational Beliefs and Endogenous Uncertainty." Economic Theory, 8, 383 - 553 . 
Kurz, M. (ed) (1997a): Endogenous Economic Fluctuations: Studies in the Theory of Rational Belief. Studies in Economic Theory, No. 6, Berlin and New York: Springer-Verlag.

Kurz, M. (1997b): "On the Volatility of Foreign Exchange Rates." In Kurz, M. (ed.). (1997), Chapter 12, 317 - 352.

Kurz, M., Beltratti, A. (1997) : "The Equity Premium is No Puzzle." In Kurz, M. (ed.).: 1997, Chapter 11, 283 - 316.

Kurz, M., Jin, H., Motolese, M. (2003): "Endogenous Fluctuations and the Role of Monetary Policy." In Aghion, P., Frydman, R., Stiglitz, J., Woodford, M. (ed.) Knowledge, Information, and Expectations in Modern Macroeconomics, in Honor of Edmund S. Phelps, Chapter 10, 188 227. Princeton: Princeton University Press.

Kurz, M., Schneider, M. (1996): "Coordination and Correlation in Markov Rational Belief Equilibria." Economic Theory 8, pp. 489.

Kurz, M., Motolese, M. (2001): "Endogenous Uncertainty and Market Volatility." Economic Theory, 17, 497 - 544.

Levin, A., Wieland, V., Williams, J. C., (1999): "Robustness of Simple Monetary Policy Rules Under Model Uncertainty." In Taylor, J. (ed.): Monetary Policy Rules. NBER Business Cycles Series Volume 31, Chicago: Chicago University Press , Chapter 6, 263 - 318.

Lucas, R. E. Jr. (1972): "Expectations and the Neutrality of Money." Journal of Economic Theory, 4, 103-1024.

Mankiw, N. G., Reis, R. (2002): "Sticky Information versus Sticky Prices: A Proposal to Replace the New Keynesian Phillips Curve." Quarterly Journal of Economics, 471, 1295 - 1328.

McCallum, B.T., Nelson, E. (1999): "Performance of Operational Policy Rules in An Estimated Semiclassical Structural Model." In Taylor, J. (ed.): Monetary Policy Rules. NBER Business Cycles Series Volume 31, Chicago: Chicago University Press , Chapter 1, 15 - 45.

Mirrlees, J. A. (1974): "Notes On Welfare Economics, Information and Uncertainty." In Balch, M.S., McFadden, D.L., Wu, S.Y. (ed.): Essays on Eeonomic Behavior Under Uncertainty, 243 -258, Amsterdam: North Holland.

Mishkin, F. (1982): "Does Unanticipated Money Matter? An Econometric Investigation." Journal of Political Economy, 91, 22-51.

Motolese, M. (2001): "Money Non-Neutrality in a Rational Belief Equilibrium with Financial Assets." Economic Theory, 18, 97 - 16.

Motolese, M. (2003): "Endogenous Uncertainty and the Non-Neutrality of Money." Economic Theory, 21, 317 - 345.

Nielsen, K. C. (1996): "Rational Belief Structures and Rational Belief Equilibria." Economic Theory, 8, $531-554$.

Nielsen, K. C. (2000): "Stabilizing, Pareto Improving Policies in an OLG Model with Incomplete Markets: The Rational Expectations and Rational Beliefs Case." Banco de España, May 19.

Nielsen, K. C. (2003): " Floating Exchange Rates Versus Monetary Union Under Rational Beliefs: the Role of Endogenous Uncertainty." Economic Theory, 21, 293 - 316.

Radner, R. (1972): "Existence of equilibrium of plans, prices and price expectations in a sequence of Markets." Econometrica 40, 289-303.

Rotemberg, J. J., Woodford, M. (1999): "Interest Rate Rules in an Estimated Sticky Price Model." In Taylor, J. (ed.): Monetary Policy Rules. NBER Business Cycles Series Volume 31, Chicago: Chicago University Press, Chapter 2, 57 - 126. 
Rudebusch, G.D., (2002): "Term Structure Evidence On Interest Rate Smoothing and Monetary Policy Inertia." Journal of Monetary Economics, 49, 1161 -1187.

Sargent, T.J., Wallace, N. (1975): "Rational Expectations, the Optimal Monetary Instrument, and the Optimal Money Supply Rule." Journal of Political Economy 83, 241 - 254.

Silvestre, J. (2002): "Discrepancies Between Ex-Ante and Ex-Post Efficiency Under Subjective Probabilities." Economic Theory, 18, 413 - 425

Starr, R.(1976): "Optimal Production and Allocation Under Uncertainty." Quarterly Journal of Economics, 87, 81-95.

Stock, H. J., Watson, W. M. (1999): "Business Cycle Fluctuations in US Macroeconomic Time Series." In J. Taylor and M. Woodford (eds.), Handbook of Macroeconomics, Volume $1 B$. Amsterdam: North-Holland, Chapter 1 , 3 - 64.

Summers, L. H. (1986): "Some Skeptical Observations on Real Business Cycle Theory." Federal Reserve Bank of Minneapolis Quarterly Review 10, 23 - 27.

Svenson, O., (1981): “Are We All Less Risky and More Skillful Than Our Fellow Drivers?” Acta Psychologica, 47, 143 - 148.

Taylor, J. B. (1980): "Staggered Contracts." Carnegie - Rochester Conference Series On Public Policy 39, $195-214$.

Taylor, J. B. (1993): "Discretion Versus Policy Rules in Practice." Carnegie - Rochester Conference Series On Public Policy 39, 195-214.

Taylor, J.B. (ed.) (1999): Monetary Policy Rules. NBER Business Cycles Series Volume 31, Chicago: Chicago University Press.

Wen, Y. (1998a): "Investment Cycles." Journal of Economic Dynamic and Control 22, 1139 - 1165.

Wen, Y. (1998b): "Can a Real Business Cycle Model Pass the Watson Test?" Journal of Monetary Economics 42, 185 - 203.

Woodford, M. (2001a): "Inflation Stabilization and Welfare." Working Paper 8071, National Bureau of Economic Research, Cambridge, Massachusetts, January.

Woodford, M. (2001b): "Interest and Prices, Chapter 3: Optimizing Models with Nominal Rigidities." Princeton University, December.

Woodford, M. (2002): "Interest and Prices, Chapter 2: Price-Level Determination Under Interest-Rate Rules." Princeton University, January.

Wu, H. W., W.C. Guo (2003): "Speculative Trading with Rational Belief and Endogenous Uncertainty." Economic Theory, 21, 263 - 292

Yun, T. (1996): "Nominal Price Rigidity, Money Supply Endogeneity, and Business Cycles." Journal of Monetary Economics 37, 345 - 370. 


\section{Appendix A: Construction of the Random Variables $\rho_{t+1}^{j}\left(u_{t}^{j}\right)$}

The variables $\rho_{t+1}^{j}\left(u_{t}^{j}\right)$ are our tools to enable agents to exhibit subjective beliefs with "fat" tails reflecting over confidence. We define $\rho_{t+1}^{j}\left(u_{t}{ }^{j}\right)$ by specifying its density, conditional on $u_{t}{ }^{j}$ :

$$
P\left(\rho_{t+1}^{j} \mid u^{j}\right)= \begin{cases}\varphi_{1}\left(u^{j}\right) \Phi\left(\rho_{t+1}^{j}\right) & \text { if } \rho_{t+1}^{j} \geq 0 \\ \varphi_{2}(u) \Phi\left(\rho_{t+1}^{j}\right) & \text { if } \rho_{t+1}^{j}<0\end{cases}
$$

where $\rho_{\mathrm{t}+1}^{\mathrm{j}}$ and $\tilde{\rho}_{\mathrm{t}+1}^{\mathrm{g}}($ in $(19))$ are independent and where ${ }_{\mathrm{s}^{2}}$

$$
\Phi(\mathrm{s})=\frac{1}{\sqrt{2 \pi}} \mathrm{e}^{-\frac{\mathrm{s}^{2}}{2}} \text {. }
$$

To show the agent can hold such a belief and be rational, we use the Conditional Stability Theorem (see Kurz Schneider (1996)). A sufficient condition which it suggests requires that if $G\left(u^{j}\right)$ is the empirical density of $u^{j}$ then we need to ensure that

$$
\int_{-\infty}^{\infty} P\left(\rho^{j} \mid u^{j}\right) G\left(u^{j}\right) d u^{j}=\Phi\left(\rho^{j}\right), \text { a Normal density of } \rho^{j} \text {. }
$$

From (A1) it follows that this condition is implied by

$$
\int_{-\infty}^{\infty} \varphi_{1}\left(\mathrm{u}^{\mathrm{j}}\right) \mathrm{G}\left(\mathrm{u}^{\mathrm{j}}\right) \mathrm{du} \mathrm{u}^{\mathrm{j}}=1 \quad \text { and } \quad \int_{-\infty}^{\infty} \varphi_{2}\left(\mathrm{u}^{\mathrm{j}}\right) \mathrm{G}\left(\mathrm{u}^{\mathrm{j}}\right) \mathrm{du} \mathrm{u}^{\mathrm{j}}=1 \text {. }
$$

To explain, since the empirical distribution of $\mathrm{u}^{\mathrm{j}}$ is normal, average over $\mathrm{u}^{\mathrm{j}}$ generates a random variable $\bar{\rho}_{\mathrm{t}+1}^{\mathrm{j}}$ such that $\bar{\rho}_{\mathrm{t}+1}^{\mathrm{j}} \sim \mathrm{N}(0,1)$. Averaged components of $\Psi_{\mathrm{t}+1}\left(\mathrm{u}_{\mathrm{t}}^{\mathrm{j}}\right)$ (i.e. $\left.\lambda_{\mathrm{v}}(\cdot) \bar{\rho}_{\mathrm{t}+1}^{\mathrm{j}}+\tilde{\rho}_{\mathrm{t}+1}^{\mathrm{v}}\right)$ are then normally distributed with mean 0 and variance determined by the rationality conditions.

As for interpreting $\rho_{t+1}^{j}\left(u_{t}^{j}\right)$, the functions $\varphi_{i}\left(u^{j}\right)$ allow agents to be optimistic or pessimistic about $\rho_{\mathrm{t}+1}^{\mathrm{j}}$ being positive or negative. $\varphi_{\mathrm{j}}\left(\mathrm{u}^{\mathrm{j}}\right)$ are monotone: $\varphi_{1}\left(\mathrm{u}^{\mathrm{j}}\right)$ is rising with $\mathrm{y}^{\mathrm{j}}$ and $\varphi_{2}\left(\mathrm{u}^{\mathrm{j}}\right)$ declining with $\mathrm{u}^{\mathrm{j}}$. When they converge rapidly to their asymptotic values the densities take the form (i) For large positive $u^{j}\left(\right.$ or $\left.g^{j}\right)$ the mean value of the density becomes positive since

$$
\begin{aligned}
P\left(\rho_{t+1}^{j} \mid u^{j} \text { large }\right)=\left\{\begin{array}{l}
\varphi_{1}(\infty) \Phi\left(\rho_{t+1}^{j}\right) \\
\varphi_{2}(\infty) \Phi\left(\rho_{t+1}^{j}\right)
\end{array} \text { for } \rho_{t+1}^{j}<0\right. \\
\text { Appendix }-1
\end{aligned}
$$


(ii) For large negative $u^{j}$ (or $\left.g^{j}\right)$ the mean value of the density becomes positive since

$$
P\left(\rho_{t+1}^{j} \mid u^{j} \text { small }\right)= \begin{cases}\varphi_{1}(-\infty) \Phi\left(\rho_{t+1}^{j}\right) & \text { for } \rho_{t+1}^{j} \geq 0 \\ \varphi_{2}(-\infty) \Phi\left(\rho_{t+1}^{j}\right) & \text { for } \rho_{t+1}^{j}<0 .\end{cases}
$$

As a practical approximation we have selected the function

$$
\psi\left(u^{j}\right)=\frac{1}{1+e^{b u^{j}\left(g^{j}\right)}}, \quad B=\int_{-\infty}^{\infty} \psi\left(u^{j}\right) \hat{G}\left(u^{j}\right) d u^{j}, \quad \varphi_{1}(u)=\frac{\psi(u)}{B} .
$$

Direct calculations reveal the three empirical moments of the random variable $\rho^{j}$ under discussion

$$
E\left[\rho^{j}\right]=0 \quad, \quad E\left[\left(\rho^{j}\right)^{2}\right]=1 \quad, \quad E\left[\rho^{j} u^{j}\right]=\frac{2}{\sqrt{2 \pi}} \frac{E\left[\psi\left(u^{j}\right) u^{j}\right]}{B} .
$$

The parameter $\mathrm{b}$ is the over confidence parameter as it specifies the degree of fat tails in the conditional distribution of $\rho_{t+1}^{\mathrm{j}}\left(\mathrm{u}_{\mathrm{t}}^{\mathrm{j}}\right)$. In the discussion of the symmetric case below we shall use the notation $\sigma_{\mathrm{u}}^{2}=\operatorname{Var}(\mathrm{u})$ and $\mathrm{r}_{\rho \mathrm{u}}=\mathrm{E}\left[\frac{\rho_{\mathrm{t}+1}(\mathrm{u}) \mathrm{u}}{\sigma_{\mathrm{u}}}\right]$.

\section{Appendix B: Statement of the Rationality Conditions}

The rationality of belief principle requires that

(B1) $\Psi_{t+1}\left(u_{t}^{j}\right)=\left(\begin{array}{c}\lambda_{g}^{v} \rho_{t+1}^{j}\left(u_{t}^{j}\right)+\tilde{\rho}_{t+1}^{v^{j}} \\ \lambda_{g}^{\varrho} \rho_{t+1}^{j}\left(u_{t}^{j}\right)+\tilde{\rho}_{t+1}^{e^{j}} \\ \lambda_{g}^{z^{1}} \rho_{t+1}^{j}\left(u_{t}^{j}\right)+\tilde{\rho}_{t+1}^{z^{j 1}} \\ \lambda_{g}^{z^{2}} \rho_{t+1}^{j}\left(u_{t}^{j}\right)+\tilde{\rho}_{t+1}^{z^{j 2}}\end{array}\right)$ has the same joint empirical distribution as $\rho_{t+1}=\left(\begin{array}{c}\rho_{t+1}^{v} \\ \rho_{t+1}^{\varrho} \\ \rho_{t+1}^{z^{1}} \\ \rho_{t+1}^{z^{2}}\end{array}\right)$.

To clarify the mathematical development below keep in mind the consistency conditions between $\mathrm{g}^{\mathrm{j}}$ and $\mathrm{z}^{\mathrm{j}}$. These conditions require that the realizations of the two are the same and hence they have the same marginal empirical distribution. This fact is not known to the agent and hence this equality does not hold in the agent's perception model. More generally, in the agent's perception model there is nothing to require that the covariance between $\mathrm{g}^{\mathrm{j}}$ and any state variable be the same as the covariance implied by the system (16) between $z^{j}$ and that variable. Indeed, the presence of $\rho_{t+1}^{j}\left(u_{t}^{j}\right)$ in all 
equations of the perception model (25) generates covariance between $\mathrm{g}^{\mathrm{j}}$ and other state variables which is perceived by agent $\mathrm{j}$ but is not present in (16). The idea is that any covariance between an agent's own state of belief and other variables in the economy are strictly in the mind of the agent and no rationality conditions are imposed on them. An important way to understand this is to note that under the condition of anonymity an agent sees no relationship between his own state of belief and the market vector of belief. Below we give a precise mathematical definition of anonymity.

We show first that (B1) fully specify the covariance matrix $\Omega_{\rho \rho}^{\mathrm{j}}$ of the four dimensional vector $\tilde{\rho}_{t+1}^{j}$ in the perception models (25)-(26). To see this rewrite (21a) in the form

$$
\mathrm{x}_{\mathrm{t}+1}^{\mathrm{j}}=A x_{\mathrm{t}}+\lambda_{\mathrm{g}} \rho_{\mathrm{t}+1}^{\mathrm{j}}\left(\mathrm{u}_{\mathrm{t}}^{\mathrm{j}}\right)+\tilde{\rho}_{\mathrm{t}+1}^{\mathrm{j}} \text {. }
$$

Now define $\sigma_{\rho}^{2}=E\left[\left(\rho_{t+1}^{j}\left(u_{t}^{j}\right)\right)^{2}\right]$ and denote by $V$ be the covariance matrix of the random vector $x_{t}$ according to the empirical distribution (18). Computing the covariance matrix in (B2) and equating the computed value to $\mathrm{V}$ leads to the equality $\mathrm{V}=\mathrm{AVA}^{\prime}+\lambda_{\mathrm{g}} \mathrm{j}\left(\lambda_{\mathrm{g} j}\right)^{\prime} \sigma_{\rho}^{2}+\Omega_{\rho \rho}^{\mathrm{j}}$ which means that

$$
\Omega_{\rho \rho}^{\mathrm{j}}=\mathrm{V}-\mathrm{AVA}^{\prime}-\lambda_{\mathrm{g}}\left(\lambda_{\mathrm{g}}\right)^{\prime} \sigma_{\rho}^{2} \text {. }
$$

Given vector of parameters $\left(b, \lambda_{g}\right)$ all magnitudes on the right of (B3) are known and this pins down the covariance matrix $\Omega_{\rho \rho}^{\mathrm{j}}$. In the symmetric case used in this paper the parameters are the same for both agents hence in the computations we have

$$
\Omega_{\rho \rho}=\mathrm{V}-\mathrm{AVA}^{\prime}-\lambda_{\mathrm{g}}\left(\lambda_{\mathrm{g}}\right)^{\prime} \sigma_{\rho}^{2} .
$$

Since a perception model includes (19), it follows that in the model of the agent we need to specify the full joint distribution of five variables: the four basic observables $x_{t}$ together with the agent state of belief $g_{t}{ }^{j}$. Hence the agent's perception model is specified by a $5 \times 5$ covariance matrix $\Omega$ of the innovations. Focusing on the symmetric case we write the matrix $\Omega$ in the block form

$$
\Omega=\left(\begin{array}{cc}
\Omega_{\rho \rho}, & \Omega_{\mathrm{xg}} \\
\Omega_{\mathrm{xg}}^{\prime} & , \sigma_{\mathrm{g}}^{2}
\end{array}\right)
$$

where $\Omega_{x g}=\left[\operatorname{Cov}\left(\tilde{\rho}_{t+1}^{v}, \tilde{\rho}_{t+1}^{g}\right), \operatorname{Cov}\left(\tilde{\rho}_{t+1}^{\varrho}, \tilde{\rho}_{t+1}^{g}\right), \operatorname{Cov}\left(\tilde{\rho}_{t+1}^{z^{1}}, \tilde{\rho}_{t+1}^{g}\right), \operatorname{Cov}\left(\tilde{\rho}_{t+1}^{z^{j}}, \tilde{\rho}_{t+1}^{g}\right)\right]$ is a $4 \times 1$ covariance vector of the innovations of the agent's belief and the innovations of the observables in the agent's perception model (see 25). Now define the following

$r_{j} \equiv \operatorname{Cov}\left(x, g^{j}\right)$ is the unconditional covariance between $g^{j}$ and the four observables $x$;

$a_{j}=\left(\lambda_{v}^{z^{j}}, \lambda_{\varrho}^{z^{j}}, 0,0\right)$ the vector of $x$ parameters in the $g^{j}$ equation (19);

A simple direct computation reveals that we have at hand two systems of 4 equations each: 


$$
\begin{aligned}
& \mathrm{r}_{\mathrm{j}}=\lambda_{\mathrm{z}^{\mathrm{j}}} \mathrm{Ar}_{\mathrm{j}}+\mathrm{AVa}_{\mathrm{j}}+\lambda_{\mathrm{z}} \lambda_{\mathrm{g}} \mathrm{r}_{\mathrm{pu}} \sigma_{\mathrm{u}}+\Omega_{\mathrm{xg}} \\
& \Omega_{\mathrm{xg}}=\mathrm{r}_{\mathrm{j}}-\lambda_{\mathrm{z}^{\mathrm{j}}} \mathrm{A} \mathrm{r}_{\mathrm{j}}-\mathrm{AVa_{ \textrm {j } }}+\lambda_{\mathrm{z}} \lambda_{\mathrm{g}} \mathrm{r}_{\mathrm{pu}} \sigma_{\mathrm{u}}
\end{aligned}
$$

where $\mathrm{r}_{\mathrm{pu}}=\mathrm{E}\left[\frac{\rho_{\mathrm{t}+1}(\mathrm{u}) \mathrm{u}}{\sigma_{\mathrm{u}}}\right]$. We need conditions which will pin down $\Omega_{\mathrm{xg}}$. Note that this matrix would be fully specified if ${ }^{u}$ e specify the $4 \times 1$ vector $r_{j} \equiv \operatorname{Cov}\left(x, g^{j}\right)$ since we can use this information to compute $\Omega_{\mathrm{xg}}$ in (B4.2). We proceed here in two steps. First we utilize the definition of anonymity to specify the last two components of $\Omega_{\mathrm{xg}}$, which are $\operatorname{Cov}\left(\tilde{\rho}_{\mathrm{t}+1}^{z^{1}}, \tilde{\rho}_{\mathrm{t}+1}^{\mathrm{g}^{\mathrm{j}}}\right), \operatorname{Cov}\left(\tilde{\rho}_{\mathrm{t}+1}^{\mathrm{Z}^{2}}, \tilde{\rho}_{\mathrm{t}+1}^{\mathrm{g}^{j}}\right)$. We thus introduce Definition: A belief is said to satisfy the condition of anonymity if

$$
\left(\begin{array}{c}
\Omega_{\mathrm{z}^{1} \mathrm{~g}^{j}} \\
\Omega_{\mathrm{z}^{2} \mathrm{~g}^{\mathrm{j}}}
\end{array}\right)=\left(\begin{array}{c}
\operatorname{Cov}\left(\tilde{\rho}_{\mathrm{t}+1}^{\mathrm{z}^{1}}, \tilde{\rho}_{\mathrm{t}^{\mathrm{j}}}^{\mathrm{g}^{\mathrm{j}}}\right) \\
\operatorname{Cov}\left(\tilde{\rho}_{\mathrm{t}+1}^{\mathrm{z}^{2}}, \tilde{\rho}_{\mathrm{t}+1}^{\mathrm{g}^{\mathrm{j}}}\right)
\end{array}\right)=\left(\begin{array}{l}
0 \\
0
\end{array}\right) .
$$

It is then clear that anonymity pins down the last two elements of $\Omega_{\mathrm{xg}}$. We need two more restriction on (4B.1)-(4B.2) to pin down the first two elements. With this objective in mind we show that these two restrictions are deduced from the final rationality condition of no serial correlation of $\Psi_{t+1}\left(u_{t}^{j}\right)$.

For $\Psi_{\mathrm{t}+1}\left(\mathrm{u}_{\mathrm{t}}^{\mathrm{j}}\right)$ to exhibit no serial correlation it is sufficient that it is uncorrelated with date $\mathrm{t}$ public information. To see why this is true recall that $\Psi_{t+1}\left(u_{t}^{j}\right)=x_{t+1}-A x_{t}$ hence

$$
\mathrm{E}\left[\Psi_{\mathrm{t}+1}\left(\mathrm{u}_{\mathrm{t}}^{\mathrm{j}}\right) \Psi_{\mathrm{t}}\left(\mathrm{u}_{\mathrm{t}-1}^{\mathrm{j}}\right)\right]=\mathrm{E}\left[\Psi_{\mathrm{t}+1}\left(\mathrm{u}_{\mathrm{t}}^{\mathrm{j}}\right)\left(\mathrm{x}_{\mathrm{t}}-\mathrm{Ax}_{\mathrm{t}-1}\right)\right]=\mathrm{E}\left[\Psi_{\mathrm{t}+1}\left(\mathrm{u}_{\mathrm{t}}^{\mathrm{j}}\right)\left(\mathrm{x}_{\mathrm{t}}\right)\right]-\mathrm{E}\left[\Psi_{\mathrm{t}+1}\left(\mathrm{u}_{\mathrm{t}}^{\mathrm{j}}\right) \mathrm{Ax}_{\mathrm{t}-1}\right]=0 .
$$

But now, to ensure that these conclusions hold we need to put restrictions on $r_{j}$ to imply that $u_{t}{ }^{j}$ are not correlated with any $\mathrm{x}_{\mathrm{t}-\mathrm{i}}^{\mathrm{j}}$ for all $\mathrm{i}$. To that end note that by definition

$$
u\left(g_{t+1}^{j}\right)=g_{t+1}^{j}-r_{j}^{\prime} V^{-1} x_{t+1} \text {. }
$$

Hence, direct computations reveal that

$$
\mathrm{u}\left(\mathrm{g}_{\mathrm{t}+1}^{\mathrm{j}}\right)=\mathrm{g}_{\mathrm{t}+1}^{\mathrm{j}}-\mathrm{r}_{\mathrm{j}} \mathrm{V}^{-1} \mathrm{x}_{\mathrm{t}+1}=\lambda_{\mathrm{z}} \mathrm{g}_{\mathrm{t}}^{\mathrm{j}}+\mathrm{a}_{\mathrm{j}} \mathrm{x}_{\mathrm{t}}+\tilde{\rho}_{\mathrm{t}+1}^{\mathrm{g}^{\mathrm{j}}}-\mathrm{r}_{\mathrm{j}}{ }^{\prime} \mathrm{V}^{-1}\left(A x_{\mathrm{t}}+\lambda_{\mathrm{g}} \mathrm{\rho}_{\mathrm{t}+1}^{\mathrm{j}}\left(\mathrm{u}_{\mathrm{t}}\right)+\tilde{\rho}_{\mathrm{t}+1}^{\mathrm{j}}\right) .
$$

Hence, the condition $\operatorname{Cov}\left(\mathrm{u}_{\mathrm{t}+1}^{\mathrm{j}}, \mathrm{x}_{\mathrm{t}}\right) \equiv \mathrm{E}\left[\mathrm{u}_{\mathrm{t}+1}^{\mathrm{j}} \mathrm{x}_{\mathrm{t}}{ }^{\prime}\right]=0$ requires

$$
\lambda_{\mathrm{z}} \mathrm{r}_{\mathrm{j}}{ }^{\prime}+\mathrm{a}_{\mathrm{j}}{ }^{\prime} \mathrm{V}-\mathrm{r}_{\mathrm{j}}{ }^{\prime} \mathrm{V}^{-1} \mathrm{AV}=0 .
$$

Although equation (B5) is a system of 4 equations, we now show that (B5) are the last two restrictions implied by the rationality of belief conditions. To see this fact note that since $\mathrm{V}$ is an invertible matrix, equation (B5) can be solved for the covariance vector $r_{j}$, implying the following restrictions

$$
\left[\mathrm{A}^{\prime}-\lambda_{\mathrm{z}^{\mathrm{j}}} \mathrm{I}\right] \mathrm{V}^{-1} \mathrm{r}_{\mathrm{j}}{ }^{\prime}=\mathrm{a}_{\mathrm{j}} \text {. }
$$

We study here only the symmetric case $\lambda_{z^{1}}=\lambda_{z^{2}}=\lambda_{z}$. In this case we have that the matrix A takes the following form 


$$
\mathrm{A}^{\prime}=\left(\begin{array}{c}
\lambda_{v}, 0, \lambda_{\mathrm{v}}^{\mathrm{z}_{1}}, \lambda_{\mathrm{v}}^{\mathrm{z}_{2}} \\
0, \lambda_{\varrho}, \lambda_{\varrho}^{\mathrm{z}_{1}}, \lambda_{\varrho}^{\mathrm{z}_{2}} \\
0,0, \lambda_{\mathrm{z}}, 0 \\
0,0,0, \lambda_{\mathrm{z}}
\end{array}\right)
$$

hence $\left[\mathrm{A}^{\prime}-\lambda_{\mathrm{z}} \mathrm{I}\right]$ is singular with the last two rows being zero. This is compatible with the fact that $a_{j}=\left(\lambda_{v}^{z^{j}}, \lambda_{\varrho}^{z^{j}}, 0,0\right)$ hence, (B5) consists of only two restrictions. Now (B5) together with the earlier conditions $\Omega_{z^{1} g^{j}}=\Omega_{z^{2} g^{j}}=0$ determines $r_{j}$. When $r_{j}$ is known, $\tilde{\sigma}_{g j}^{2}$ is pinned down as follows. Since we know that $\sigma_{u}^{2}{ }_{j}=\operatorname{var}\left(g^{j}\right)-r_{j}{ }^{\prime} V^{-1} r_{j}$, we use the condition $\operatorname{var}\left(g^{j}\right)=\operatorname{var}\left(z^{j}\right)$ to compute $\tilde{\sigma}_{g}^{2}=\left(1-\lambda_{z}^{2}\right) \operatorname{var}\left(g^{j}\right)-a_{j}{ }^{\prime} V a_{j}-2 \lambda_{z^{j}} a_{j}{ }^{\prime} r_{j}$. 

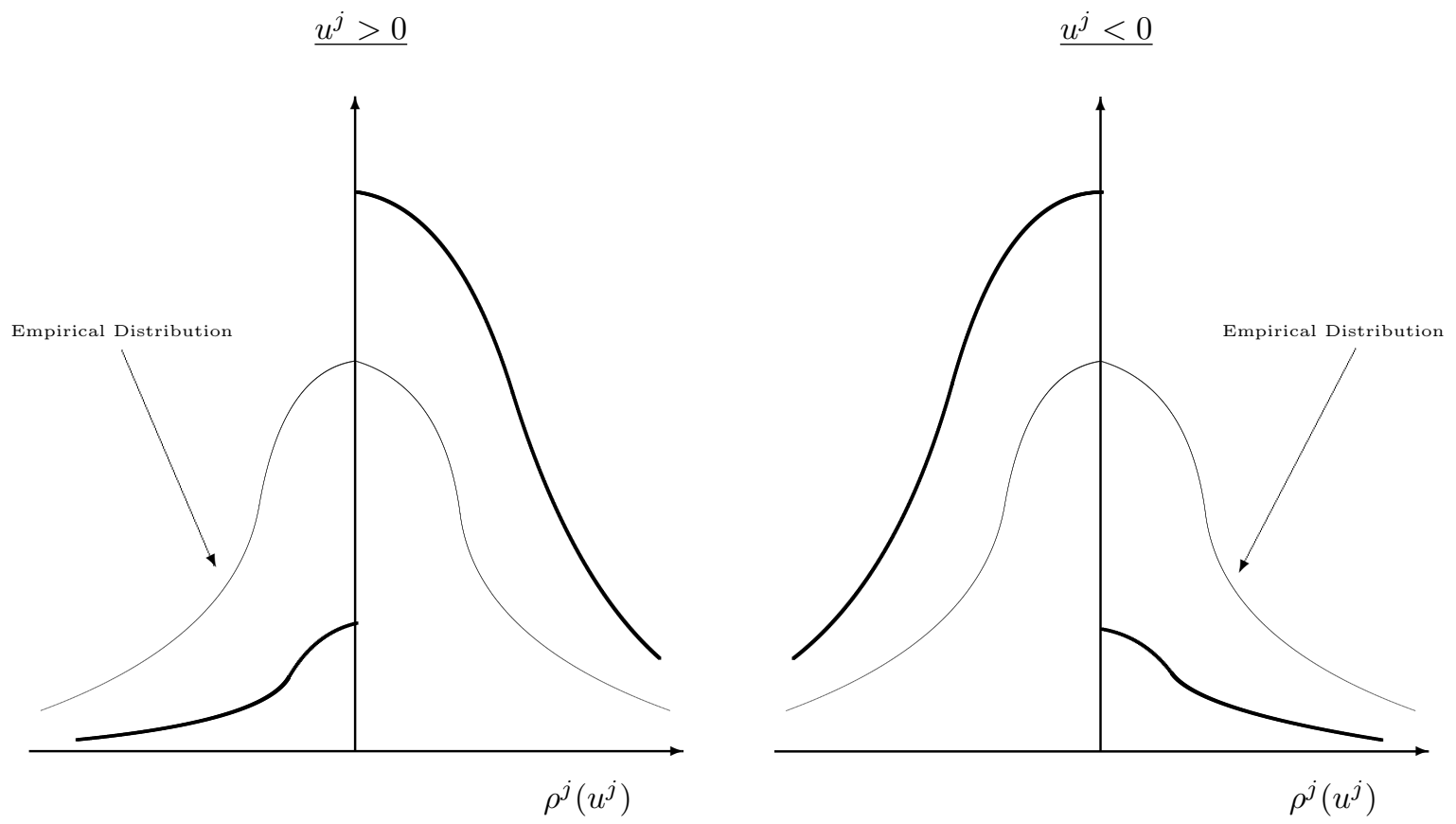

Figure 1: Non-Normal Belief Densities. 


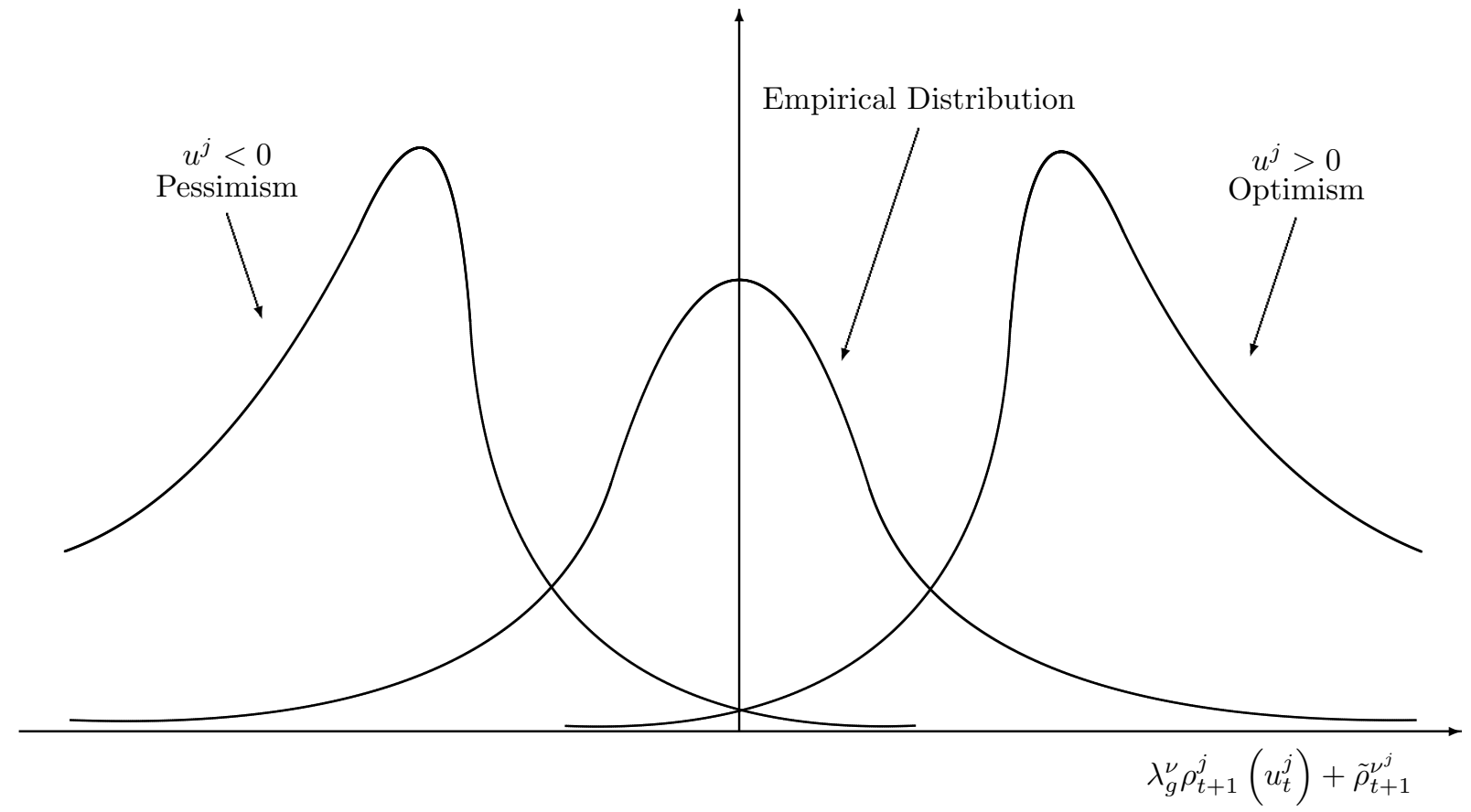

Figure 2: Density of $\Psi\left(u_{t}^{j}\right)$ with Fat Tails. 


\section{CFS Working Paper Series:}

\begin{tabular}{|c|c|c|}
\hline No. & Author(s) & Title \\
\hline $2003 / 34$ & Issam Hallak & $\begin{array}{l}\text { Courts and Sovereign Eurobonds: Credibility of } \\
\text { the Judicial Enforcement of Repayment }\end{array}$ \\
\hline $2003 / 35$ & $\begin{array}{l}\text { Torben G. Andersen } \\
\text { Tim Bollerslev } \\
\text { Francis X. Diebold }\end{array}$ & $\begin{array}{l}\text { Some Like it Smooth, and Some Like it Rough: } \\
\text { Untangling Continuous and Jump Components in } \\
\text { Measuring, Modeling, and Forecasting Asset } \\
\text { Return Volatility }\end{array}$ \\
\hline $2003 / 36$ & Reinhard H. Schmidt & $\begin{array}{l}\text { Corporate Governance in Germany: } \\
\text { An Economic Perspective }\end{array}$ \\
\hline $2003 / 37$ & $\begin{array}{l}\text { George W. Evans } \\
\text { Bruce McGough }\end{array}$ & $\begin{array}{l}\text { Monetary Policy, Indeterminacy } \\
\text { and Learning }\end{array}$ \\
\hline $2003 / 38$ & $\begin{array}{l}\text { James Bullard } \\
\text { In-Koo Cho }\end{array}$ & Escapist Policy Rules \\
\hline $2003 / 39$ & $\begin{array}{l}\text { Seppo Honkapohja } \\
\text { Kaushik Mitra }\end{array}$ & $\begin{array}{l}\text { Performance of Inflation Targeting Based On } \\
\text { Constant Interest Rate Projections }\end{array}$ \\
\hline $2003 / 40$ & $\begin{array}{l}\text { Athanasios Orphanides } \\
\text { John C. Williams }\end{array}$ & $\begin{array}{l}\text { Imperfect Knowledge, Inflation Expectations, } \\
\text { and Monetary Policy }\end{array}$ \\
\hline $2003 / 41$ & $\begin{array}{l}\text { Sharon Kozicki } \\
\text { P.A. Tinsley }\end{array}$ & $\begin{array}{l}\text { Permanent and Transitory Policy Shocks in an } \\
\text { Empirical Macro Model with Asymmetric } \\
\text { Information }\end{array}$ \\
\hline $2003 / 42$ & $\begin{array}{l}\text { Mordecai Kurz } \\
\text { Hehui Jin } \\
\text { Maurizio Motolese }\end{array}$ & $\begin{array}{l}\text { The Role of Expectations in Economic } \\
\text { Fluctuations and the Efficacy of Monetary Policy }\end{array}$ \\
\hline $2003 / 43$ & $\begin{array}{l}\text { William A. Brock } \\
\text { Steven N. Durlauf } \\
\text { Kenneth D. West }\end{array}$ & $\begin{array}{l}\text { Policy Evaluation in Uncertain Economic } \\
\text { Environments }\end{array}$ \\
\hline $2003 / 44$ & $\begin{array}{l}\text { Timothy Cogley } \\
\text { Sergei Morozov } \\
\text { Tomas J. Sargent }\end{array}$ & $\begin{array}{l}\text { Bayesian Fan Charts for U.K. Inflation: } \\
\text { Forecasting and Sources of Uncertainty in an } \\
\text { Evolving Monetary System }\end{array}$ \\
\hline
\end{tabular}

Copies of working papers can be downloaded at http://www.ifk-cfs.de/ 